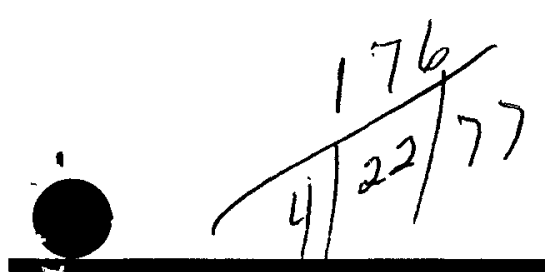

GA-A14126

UC-77

\title{
INTERIM DESIGN STATUS AND OPERATIONAL REPORT FOR SEMIREMOTE HANDLING FIXTURES: SIZE REDUCTION SYSTEM
}

\author{
by \\ A. S. BALLARD
}

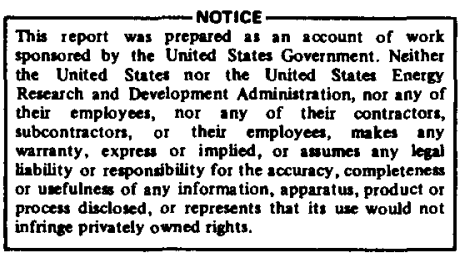

Prepared under

Contract EY-76-C-03-0167

Project Agreement No. 53

for the San Francisco Operations Office

U.S. Energy Research and Development Administration 


\section{DISCLAIMER}

This report was prepared as an account of work sponsored by an agency of the United States Government. Neither the United States Government nor any agency Thereof, nor any of their employees, makes any warranty, express or implied, or assumes any legal liability or responsibility for the accuracy, completeness, or usefulness of any information, apparatus, product, or process disclosed, or represents that its use would not infringe privately owned rights. Reference herein to any specific commercial product, process, or service by trade name, trademark, manufacturer, or otherwise does not necessarily constitute or imply its endorsement, recommendation, or favoring by the United States Government or any agency thereof. The views and opinions of authors expressed herein do not necessarily state or reflect those of the United States Government or any agency thereof. 


\section{DISCLAIMER}

Portions of this document may be illegible in electronic image products. Images are produced from the best available original document. 
$\bullet$

,

i 


\begin{abstract}
Crushing of HTGR fuel elements is accomplished by a three-stage crushing system consisting of two overhead eccentric jaw crushers, a double-roll crusher, and an oversize reduction system to ensure complete reduction to the desired size.
\end{abstract}

The crushing system is mounted in a special framework which enables gravity flow, eliminates material transport, and minimizes material holdup. The system has been designated UNIFRAME because of the integrated nature of the equipment. This report addresses the demonstration of semiremote maintenance of the crusher in a nonradioactive environment.

Although the crusher maintenance system has some remote handling capability inherent in its design, the scope of this initial program is limited to the handling of selected components and allows for manual assistance in certain circumstances. This mode of operation is designated semiremote maintenance and is intended as an effort to gather experience. 


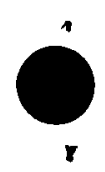




\section{CONTENTS}

ABSTRACT . . . . . . . . . . . . . . . . . . . . . $i i i$

1. INTRODUCTION . . . . . . . . . . . . . . . . . . . . . . . 1

2. SEMIREMOTE HANDLING FIXTURES - SIZE REDUCTION SYSTEM . . . . . . 4

2.1. Lift Fixture - Primary Crusher Pitman Assembly . . . . . 5

2.1.1. Design Requirements............. 5

2.1.2. Design Principles . . . . . . . . . . . . 8

2.1.3. Functional Description. . . . . . . . . . . 8

2.1.4. Control System. . . . . . . . . . . . 10

2.1.5. Reliability . . . . . . . . . . . . 12

2.1.6. Maintenance ............... 13

2.1.7. Availability. . . . . . . . . . . . 15

2.1.8. Safety. . ............... 15

2.1.9. Testing .. . . . . . . . . . . . 16

2.1.10. Performance Evaluation. . . . . . . . . . 16

2.1.11. Recommendations . . . . . . . . . . . 18

2.2 Lift Fixture - Primary Crusher Stationary Jaw. . . . . . 19

2.2.1. Design Requirements . . . . . . . . . . 19

2.2.2. Design Principles . . . . . . . . . . . . 21

2.2.3. Functional Description. . . . . . . . . . . 21

2.2.4. Control System. . . . . . . . . . . . 23

2.2.5. Reliability ............... 23

2.2.6. Maintenance ............... 23

2.2.7. Availability. . . . . . . . . . . 23

2.2.8. Safety. . . . . . . . . . . . . . 24

2.2.9. Testing . . . . . . . . . . . . . 24

2.2.10. Performance Evaluation. . . . . . . . . . 25

2.2.11. Recommendations . . . . . . . . . . . 27

2.3. Lift Fixture - Secondary Crusher Pitman Assembly . . . . 27

2.3.1. Design Requirements . . . . . . . . . . . 27

2.3.2. Design Principles .............. . 27 
2.3.3. Functional Description . . . . . . . . . 29

2.3.4. Control System . . . . . . . . . . . . . 32

2.3.5. Reliability . . . . . . . . . . . . 32

2.3.6. Maintenance ............... 34

2.3.7. Availability. . . . . . . . . . . 34

2.3.8. Safety . . . . . . . . . . . . . . 34

2.3.9. Testing . . . . . . . . . . . . . 34

2.3.10. Performance Evaluation. . . . . . . . . . 35

2.3.11. Recommendations . . . . . . . . . . . 37

2.4. Horizonta1 Removal Fixture - Secondary Crusher Fixed

Jaw . . . . . . . . . . . . . . . 38

2.4.1. Design Requirements . . . . . . . . . . . 38

2.4.2. Design Principles . . . . . . . . . . . 38

2.4.3. Functional Description. . . . . . . . . . 42

2.4.4. Control System. . . . . . . . . . . . . 47

2.4.5. Reliability . . . . . . . . . . . . 49

2.4.6. Maintenance ............... . 49

2.4.7. Availability ............... 49

2.4.8. Safety. . . . . . . . . . . . . 50

2.4.9. Testing . . . . . . . . . . . . . 50

2.4.10. Future Work ................. 52

2.5 Crusher Shroud Shutoff Valve............. 52

2.5.1. Design Requirements . . . . . . . . . . 52

2.5.2. Design Principles . . . . . . . . . . 55

2.5.3. Functional Description. . . . . . . . . 55

2.5.4. Reliability . . . . . . . . . . . 58

2.5.5. Maintenance . . . . . . . . . . . 58

2.5.6. Availability .............. . 58

2.5.7. Safety. . . . . . . . . . . . . 58

2.5.8. Testing . . . . . . . . . . . . . 59

2.6. Dual Valve Concept for Crusher Shroud and Screener . . . 59

2.6.1. Design Requirements . . . . . . . . . . 59

2.6.2. Design Principles .. . . . . . . . . . 59

2.6.3. Functional Description. . . . . . . . . 60

2.6.4. Recommendations . . . . . . . . . . . 62 
3. SUMMARY . . . . . . . . . . . . . . . . . . .

APPENDIX A - DESIGN DOCUMENT INDEX

APPENDIX B - DESIGN CRITERIA

APPENDIX C - MANUFACTURING DRAWINGS

APPENDIX D - OPERATING PROCEDURE FOR HORIZONTAL REMOVAL FIXTURE FOR SECONDARY CRUSHER FIXED JAW

APPENDIX E - ELECTRICAL SEQUENCE FOR REMOVAL AND REPLACEMENT OF SECONDARY CRUSHER STATIONARY JAW

\section{FIGURES}

1. Diagramatic section through prototype size reduction crusher . . . . . . . . . . . . . . . . . . . . . . . . 2

2. Removal path for primary pitman assembly . . . . . . . . . . . 7

3. Diagramatic representation of the mechanism for lifting the primary pitman assembly . . . . . . . . . . . . . • . . . . 9 9

4. Lift fixture for primary pitman assembly . • • • . . • . . . . 11

5. Primary pitman assembly during removal from UNIFRAME. • . . . . 17

6. Primary pitman assembly showing toggles . . . . . . . . . . . 17

7. Removal path for primary stationary jaw . . . . . . . . . . . 20

8. Lift fixture for primary crusher stationary jaw . • . . . . . 22

9. Primary crusher stationary jaw with semiremote lift fixture . . 26

10. Removal path for secondary pitman assembly. . . . . . . . . 28

11. Diagramatic representation of the mechanism for lifting the secondary pitman assembly . . . . . . . . . . . . . . . 30

12. Lift fixture for secondary pitman . . . . . . . . . . . . 31

13. Secondary pitman assembly showing toggles in the extended position. . . . • . . . . . . . . . . . . . . . . 36

14. Toggles fully retracted by the lift fixture hook mechanism secondary pitman assembly . . . . . . . . . . . . . . . 36

15. Removal path for secondary stationary jaw . . • . • • . . . . . 39

16. Horizontal removal fixture for secondary stationary jaw, first version. . . . . . . . . . . . . . . . . . . . . 41

17. Horizontal removal fixture for secondary crusher stationary jaw with detail of carriage assembly shown at left. . . . . . . . . 43 
18. Horizontal removal fixture: semiremote installation onto UNIFRAME stage one .................. . . 45 45

19. Horizontal removal fixture: semiremote installation onto UNIFRAME stage two . . . . . . . . . . . . . . . 4 46

20. Control pendant for crusher remote maintenance fixture . . . 48

21. Test anchor. . . . . . . . . . . . . . . . 51

22. Pull-down test for carriage jack . . . . . . . . . . . 53

23. Location of shroud shutoff valve... . . . . . . . . . 54

24. Crusher shroud shutoff valve . . . . . . . . . . . 56

25. Latch mechanism for crusher shroud and screener shutoff valves . . . . . . . . . . . . . . . . . 61

F-1. Horizontal removal fixture: semiremote installation onto UNIFRAME stage one . . . . . . . . . . . . . . F-2

F-2. Horizontal removal fixture: semiremote installation onto UNIFRAME stage two . . . . . . . . . . . . . . . F-3

F-3. Installation of fixture onto UNIFRAME complete . . . . . . F-5

F-4. Engagement of the clevis with the jaw. . . . . . . . . F-6

F-5. Jaw lowered into cradle and secured for withdrawal . . . . . F-7

F-6. Removal of stationary jaw from fixture . . . . . . . . F-8

\section{TABLES}

1. Summary of preliminary failure analysis for primary crusher pitman assembly. . . . . . . . . ...... 14

2. Summary of preliminary failure analysis for crusher pitman assembly . . . . . . . . . . . . . . . . . 


\section{INTRODUCTION}

This report covers a portion of the work performed by General Atomic Company (GA) under U.S. Energy Research and Development Administration Contract EY-76-C-03-0167, Profect Agreement No. 53. This project agreement is part of the program for development of recycle technology for HighTemperature Gas-Cooled Reactor (HTGR) fuels described in the "National HTGR Fuel Recycle Development Program" (ORNL-4702).

The prototype size reduction system (Fig. 1) employs a three-stage crushing machine specially designed by GA to reduce spent HTGR fuel blocks in stages to less than $4.8 \mathrm{~mm}\left(3 / 16-1 n_{\text {. }}\right)$ particle size. The design, which was developed from experimental work on single-stage crushers, utilizes two jaw-crusher stages and one roll-crusher stage stacked vertically in a single frame.

As shown in Fig. 1, each jaw-crusher stage is comprised of a stationary jaw (1) and a movable jaw, or pitman assembly (2). The movable jaw hangs from an eccentric shaft (3), which is driven to impart an oscillatory motion to the jaw. The lower end of the movable faw is coupled to the machine frame by a linkage called a toggle (4). Vertical stacking of the crushing stages enables gravity feed of material into the primary crusher $(1,2)$ at the top, through the secondary crusher $(6,7)$, and into the tertiary crusher (8), which is comprised of two closely spaced power-driven rollers.

A space is provided beneath the assembly to accommodate the screening system (9), which recelves the crushed product. The whole system is enclosed within a shroud (10) designed to limit the release of dust from the operation. The shroud shutoff valve (11) is located between the bottom 


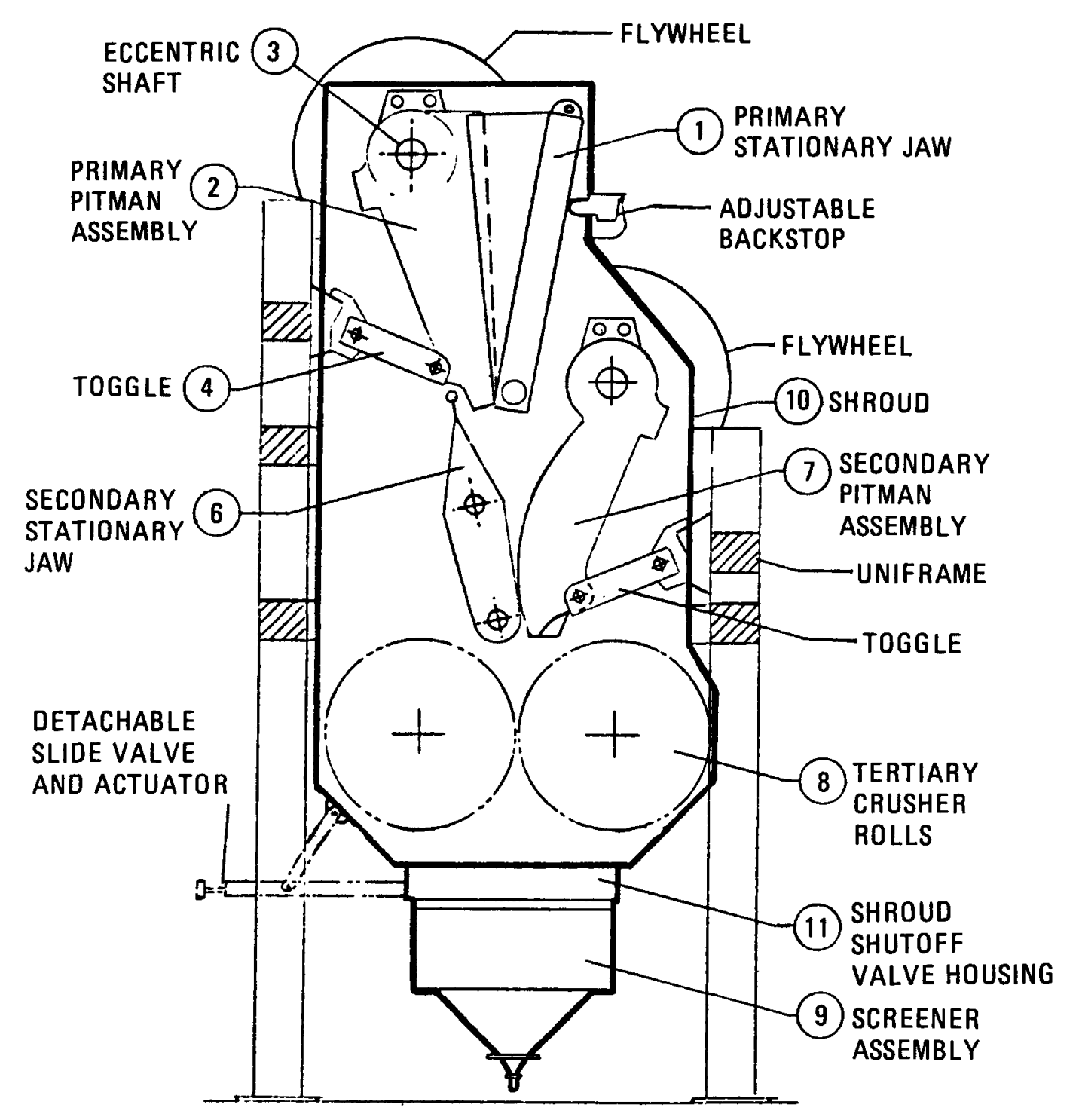

Fig. 1. Diagramatic section through prototype-size reduction crusher 
end of the shroud and the screener assembly. This valve is designed to close the shroud bottom to facilitate removal of the screener without releasing dust. Removable panels in the shroud provide access for maintenance.

This report documents the status of the design and operation of selected handling fixtures for the engineering-scale size reduction system. The fixtures and mechanisms described in this report are used to demonstrate "semiremote" assembly, disassembly, and manipulation of specified parts and assemblies of the size reduction system. The term "semiremote" refers to operations that require some manual manipulation. Appendix A contains a design document list which includes documents, specifications, and drawings for all semiremote size reduction handling equipment. 


\section{SEMIREMOTE HANDLING FIXTURES - SIZE REDUCTION SYSTEM}

In an operational hot cell, the initial stages of any maintenance operation must be performed by remote control. The removal of a component from an assembly for replacement, or decontamination and subsequent repair, may require the use of special fixtures or tools. The tools must be retrieved from the hot cell tool crib, brought to the operating area, and connected to the remote control equipment by using specially designed automatic mechanisms or operator controlled manipulators.

All functions performed by the tool must be either automatic or remotely controllable by an operator outside the cell. The operator views the operations through a window in the cell, via closed circuit television, or by process status indicators.

The engineering-scale pilot plant is intended as a facility to develop hot cell maintenance equipment. To facilitate the development of this equipment in planned stages, a combination of remote and manual operations, termed "semiremote" operation, has been implemented. The manual operations fall into three groups:

1. Interfacing operations with existing pilot plant equipment not designed specifically for remote maintenance.

2. Functions which may easily be performed by manipulators normally available in a hot cell.

3. Functions which are more appropriate for future engineering programs because of their dependence on current equipment development status. 
This report includes the semiremote handling fixtures designed to handle the following components of the size reduction system:
1. Primary pitman assembly
2. Primary stationary jaw
3. Secondary pitman assembly
4. Secondary stationary jaw

Also included is the crusher shroud shutoff valve, which forms a permanent part of the shroud assembly, and its detachable operating mechanism.

\subsection{LIFT FIXTURE - PRIMARY CRUSHER PITMAN ASSEMBLY}

\subsubsection{Design Requirements}

The design criteria (Appendix B) specifies the following requirements:

1. The lifting fixture shall be designed to demonstrate, when used with the pilot plant bridge crane, the semiremote removal and reinstallation of the pitman assembly.

2. The entire pitman assembly consisting of the shaft, faw, toggle, sleeves, bushings, outboard bearing assemblies, oil reservoirs, and flywheels shall be handled as a unit by the lifting fixture.

The weight of this assembly is approximately 4.27 metric tons ( 4.7 tons). The fixture must be designed to ensure compatibility with the space available in the pilot plant and with existing utilities and services.

Stress calculations must be based on a safety factor of two times the actual load, which must include the weight of the fixture where applicable. 
Selection of the optimum exit path for the crusher component is vital to satisfy the following requirements:

1. To minimize the dismantling of any equipment not directly concerned with the component being removed

2. To simplify the equipment and the operation procedure

3. To increase the reliability of the hardware

To take advantage of the relatively clear vertical exit path [Fig. 2(1)] for the primary pitman assembly [Fig. 2(2)], the designer must be cognizant of the effects of the changing distribution of loads during the operation. During the approach and interfacing of the fixture with the Jaw, the fixture carries only its own weight and balances about its own center of gravity. A transition occurs with the mating of the fixture with the jaw and again as the weight of the jaw is felt upon initial lifting.

As shown in Fig. 2, the jaw is provided with a toggle assembly (3) to control the movement of its lower end, which has a limited degree of freedom to swing from its pivot. As the jaw is lifted by the fixture, part of the weight of the toggle is still carried by the UNIFRAME (4); however, at a certain point the toggle will lift clear and its moment arm will change the location of the center of gravity of the assembly. The fixture design must accommodate the shift in center of gravity and preserve the balance and attitude of the assembly.

Space is limited in the crusher assembly, and maintenance of the correct attitude of the jaw during extraction is vital. The lift fixture must therefore provide for correct positioning of the jaw by remote control.

Stress calculations for the fixture must be based on a working load of $10,700 \mathrm{lb}$, with an allowance of $100 \%$ for impact loading, and must be within 


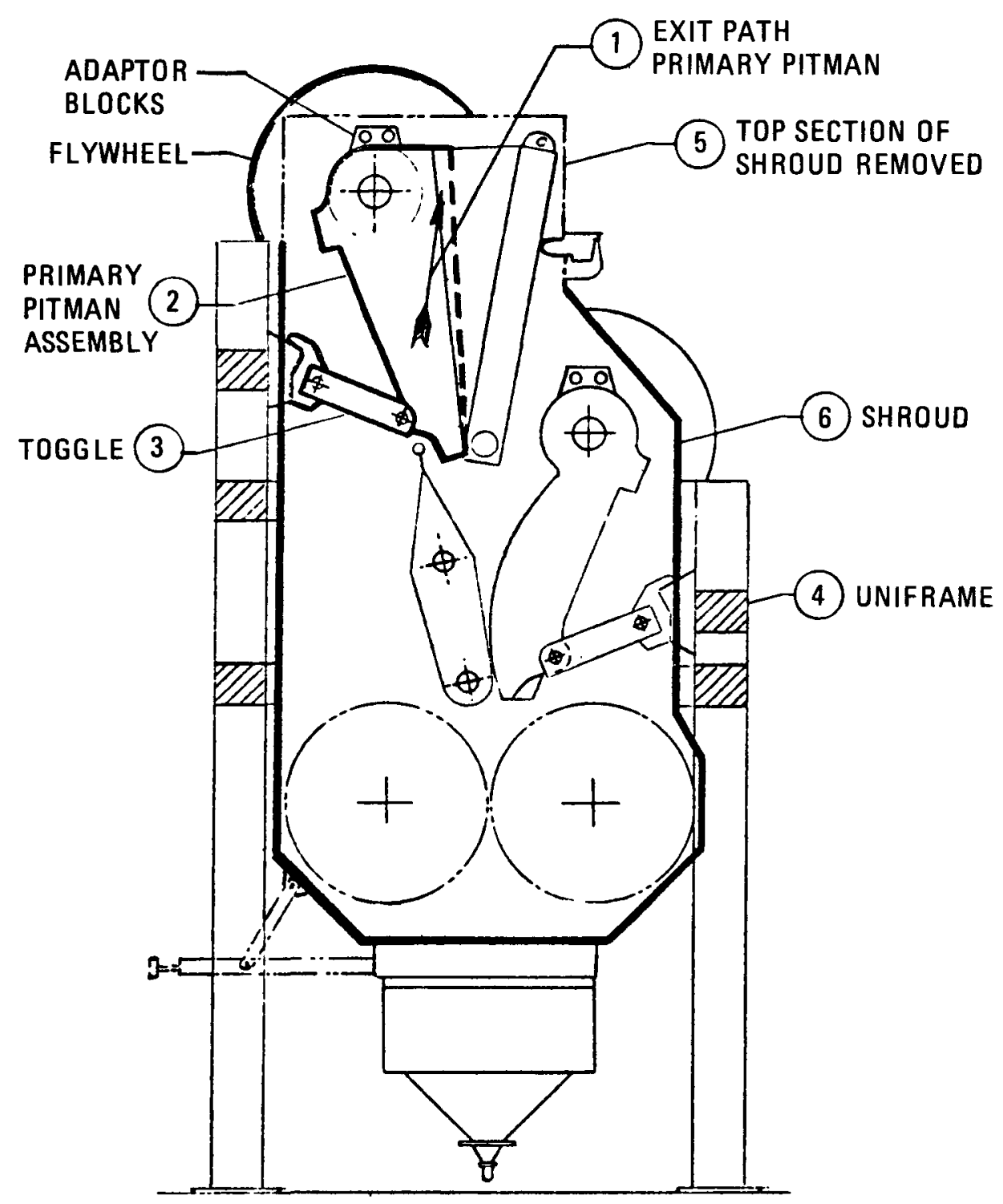

Fig. 2. Removal path for primary pitman assemb1y 
the stress allowable in the AISC specifications for structural steel for buildings. Safe stress for the steel is specified as $60 \%$ of the yield stress.

\subsubsection{Design Principles}

Figure 2 shows the working position occupied by the primary pitman assembly. In order to remove this assembly for maintenance, a section (5) of the shroud must be removed. A relatively clear exit path exists in a vertical direction (1) above the faw and no simple alternative path is available.

The traveling crane in the pilot plant facility has a capacity of 10 tons on each of its two independent hooks and covers the entire area of operation. The remote fixture must bridge the gap between the crane and the jaw in such a manner that the center of gravity of the assembly can be shifted by the operator by remote control. This will allow the corrections in attitude necessary for extraction or replacement of the pitman assembly.

The chosen approach (Fig. 3) utilizes a beam (1) which is connected by dowel pins (2) to the primary pitman (3) and carries a lifting eye (4) fitted with bearings to enable it to move along the beam. The lifting eye can be driven to any desired position by an electrically powered lead screw (5). By moving the lifting eye relative to the jaw (and its center of gravity), the attitude of the assembly in the plane of the slider can be altered to a limited degree.

\subsubsection{Functional Description}

The assembly drawing (Dwg. 5820044, Appendix C) shows the construction of the fixture. The beam is constructed from two steel plates bolted to end plates to form a rectangular box. The lifting eye is provided with recirculating ball-type sliders running on hardened tracks mounted on the Inside of each of the beam plates. A lead screw passes through a bronze 


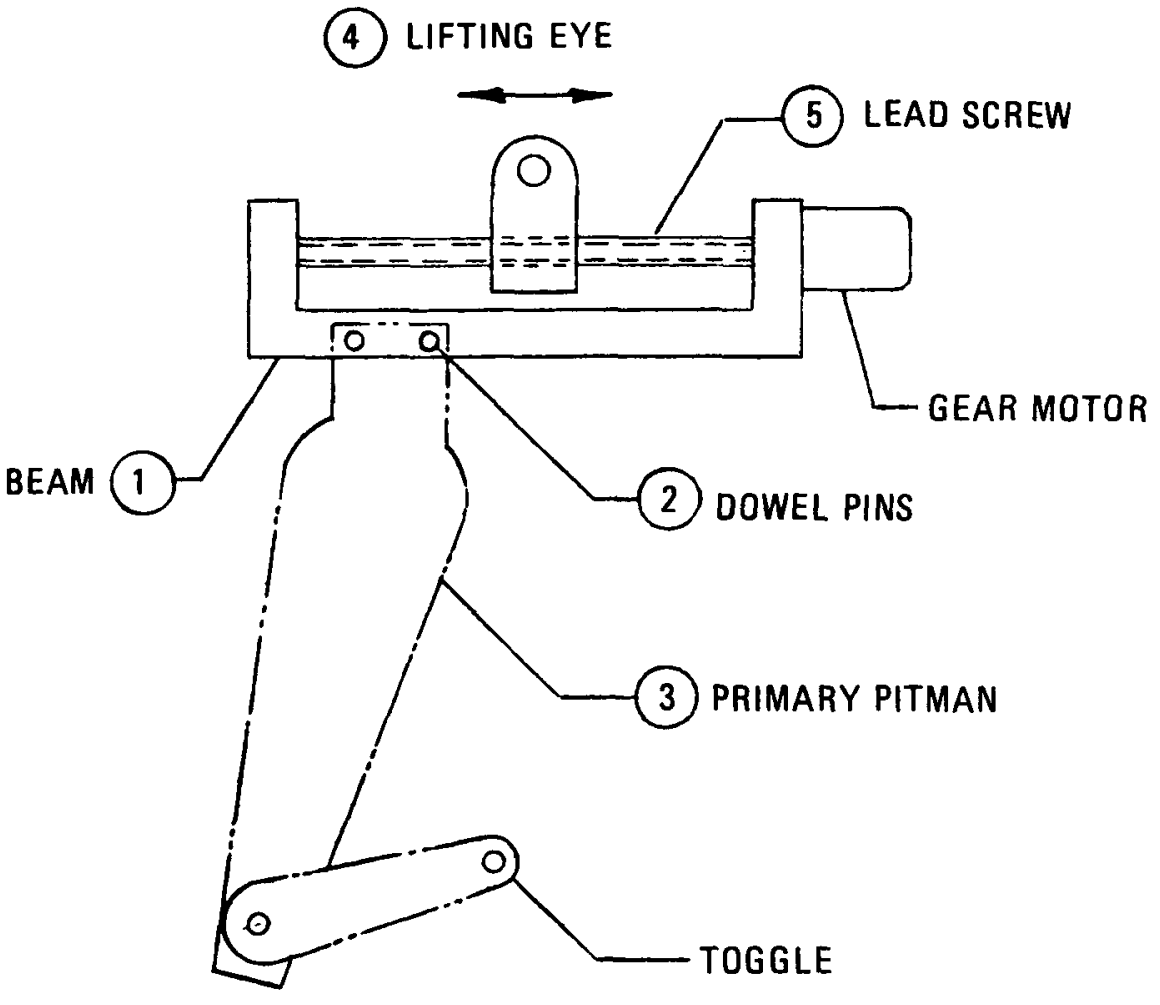

Fig. 3. Diagramatic representation of the mechanism for lifting the primary pitman assembly 
nut attached to the body of the slider and is supported at each end by an angular contact ball bearing. The 1/2-hp, 3-phase drive motor is mounted on one of the end plates and transmits its power to the lead screw via a torque limiting clutch.

A limit switch is positioned at each end of the travel of the slider. These switches interrupt the power to the motor to prevent overtravel of the lifting eye. Power is connected to the fixture by a 20-pin electrical connector via a cable carried on a self-winding drum on the crane platform. The motor can be energized in the forward or reverse direction to alter the position of the lifting eye.

As shown in Fig. 4, the primary pitman assembly is attached to the beam (1) by four expanding dowel pins. These pins penetrate two adaptor blocks (2), which are permanently fastened to the crown of the primary pitman assembly and enter corresponding holes (4) in the side frames of the beam. This part of the operation is manual at this time in the pilot plant. In the event of continued development of this fixture, the pinning operation can be performed in many established ways, i.e., independent pneumatic rams, electrical solenoid, electrically powered screw jacks, etc.

\subsubsection{Control System}

The crane platform carries a control center containing breakers for motor switching and protection. These functions can be initiated in two modes: manual and automatic. A control pendant [Fig. 4(5)] hangs from a self-winding drum on the crane platform and contains all the controls for the remote part of the fixture operation.

The pendant has a main power switch, a "hand/auto" switch, and two pairs of momentary switches to energize two motors in the forward or reverse direction. In order to manually balance the load carried by the fixture, the forward button or reverse button will be held long enough to move the lifting eye to a position vertically above the combined center of 


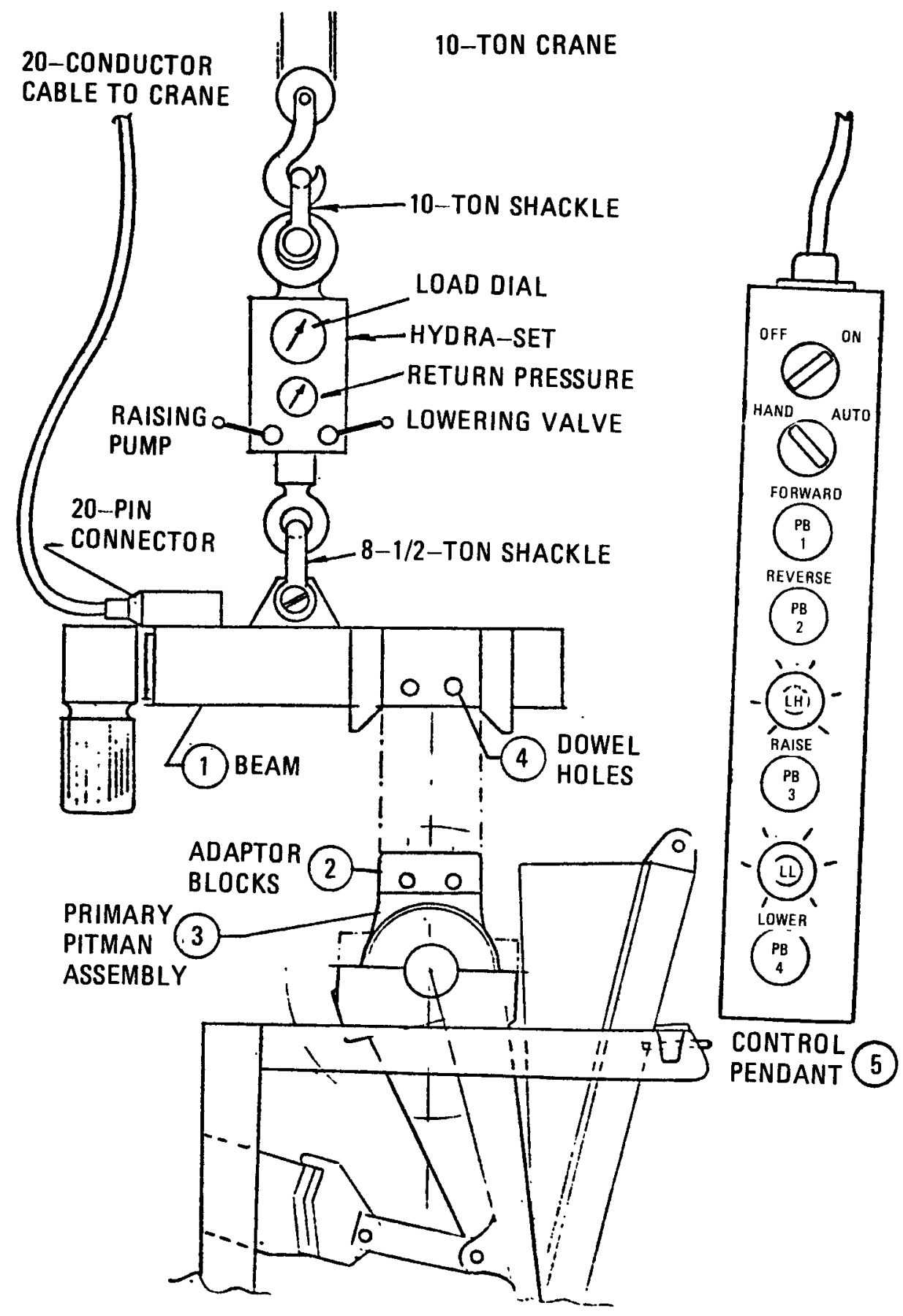

Fig. 4. Lift fixture for primary pitman assembly 
gravity. In the automatic mode, the switching function is provided by one of two sets of contacts on a mercury switch horizontally mounted on the outside of the side beam, depending upon which direction the beam is tilted.

Regardless of whether the manual pushbuttons or mercury switch are used, the electrical path is the same (Dwg. 5820043, Appendix C). The control switch energizes one of the coils of a 3-phase reversing starter via a travel limiting switch situated inside each end of the beam. As long as the control switch is closed, the motor will turn and move the lifting eye via the lead screw. Overtravel is prevented when the limit switch opens at the extremes of motion. Motion of the fixture in the vertical sense is via the bridge crane control pendant.

\subsubsection{Reliability}

Reliability of the fixture is promoted by the following factors:

1. Simple design of the fixture structure and mechanism (Section $2.1 .3)$

2. Detailed stress analysis with adequate safety factors (Section $2 \cdot 1.9 .1)$

3. Thorough structural tecting to $150 \%$ of the working load (Section $2.1 .9)$

4. Use of readily available proven commercial components

5. Detailed operating procedure

6. Properly trained and qualified operators

A preliminary failure mode analysis shows several areas where component failure can cause problems. The most important, because of the 
potential secondary effects, is failure of the screw support bearings at each end of the fixture beam. These angular contact bearings are employed to support the ends of the shaft and also to react to the thrust component of the lead screw. As the fixture beam is angled away from the horizontal plane by weight transfer, the thrust component on the bearing increases. The bearing has a safe thrust load capacity of $670 \mathrm{~kg}(1500 \mathrm{lb})$, which corresponds to a tilt of $9^{\circ}$. If this angle is exceeded by a substantial amount, or if shock loading is introduced, the bearing could fail. The result would be that the lead screw could pass through the bearing until the lift eye came to a stop against the end plate of the beam. In operation, the effect would be that the whole fixture and load may drop suddenly a maximum distance of approximately $0.25 \mathrm{~m}$ (10 in.) before being checked by the end plate. A secondary stress analysis is necessary to assess the effects of this kind of failure. Table 1 summarizes the preliminary failure mode analysis and indicates areas in which more investigation would be advisable.

Failure of the motor or motor starter system may jeopardize removal of the faw at a point in the procedure where no reversal can take place. This would require external assistance to extricate the fixture and pitman assembly. The motor starter equipment can be placed outside the cell in a prototypical installation. The motor is a 3-phase convervatively rated model, which would be expected to give 8 to 10 years of trouble-free life in a normal factory environment with daily 8-hour intermittent service.

The effects of slider bearing failure are similar to those of failure of the motor. The slider could possibly still be moved, allowing completion of the maneuver being performed.

\subsubsection{Maintenance}

Very 1ittle routine maintenance is required for this fixture. The prototype calls for sealed bearings treated with dry lubricant for 1ife. In the semiremote lift fixture, the bearings are open and will need oil 
TABLE

SUMMARY OF PRELIMINARY FAILURE ANALYSIS FOR PRIMARY CRUSHER PITMAN ASSEMBLY

\begin{tabular}{|c|c|c|}
\hline $\begin{array}{l}\text { Component Failure } \\
\text { During Operation }\end{array}$ & Immediate Effects & Secondary Effects \\
\hline Motor or starter system & $\begin{array}{l}\text { No corrections of fixture attitude are possible. } \\
\text { No damage to fixture or crusher should result, } \\
\text { but equipment will be nonoperational. }\end{array}$ & $\begin{array}{l}\text { May jeopardize completion of removal of } \\
\text { the jaw from the UNIFRAME or replacement } \\
\text { of the jaw. External assistance would } \\
\text { then be required. }\end{array}$ \\
\hline $\begin{array}{l}\text { Automatic leveling system: wiring, } \\
\text { relays, and mercury switch }\end{array}$ & $\begin{array}{l}\text { Fixture will not level automatically. No } \\
\text { anticipated damage to the fixture or the } \\
\text { crusher. }\end{array}$ & $\begin{array}{l}\text { The manual override controls will allow } \\
\text { completion of procedure. }\end{array}$ \\
\hline Any of the "expando" dowel pins & No effect. Any one pin can carry the load. & \\
\hline $\begin{array}{l}\text { Bearings for slider carrying the } \\
\text { lifting eye }\end{array}$ & $\begin{array}{l}\text { At worst, the slider will be jammed in posi- } \\
\text { tion. No catastrophic failure or damage to } \\
\text { crusher. }\end{array}$ & $\begin{array}{l}\text { If not jammed, maneuver can be completed. } \\
\text { If jammed, same as for motor or starter } \\
\text { system. }\end{array}$ \\
\hline Bearings for screw thrust & $\begin{array}{l}\text { Fixture near horizontal: No catastrophic } \\
\text { effects but possibly enough friction to } \\
\text { overcome torque limiting clutch. }\end{array}$ & $\begin{array}{l}\text { Some external assistance in guidance may } \\
\text { be necessary to complete maneuver. }\end{array}$ \\
\hline & $\begin{array}{l}\text { Fixture at extreme angle: Possibility of } \\
\text { complete bearing breakup causing the lift } \\
\text { eye to hit the end. Stop load may drop } \\
\text { several inches. }\end{array}$ & $\begin{array}{l}\text { Damage to jaw or crusher is possible when } \\
\text { jaw drops, if this occurs in limited } \\
\text { clearance space. }\end{array}$ \\
\hline
\end{tabular}


(mainly for rust prevention) at intervals to be determined. No appreciable degradation is anticipated at this time in structural strength; therefore, no requalification will be necessary. The only foreseeable major work would result from accidental damage or abuse. Close watch will be kept on the overall condition of the fixture in service to assess problem areas and improve maintenance scheduling. Routine maintenance will be scheduled as experience is galned with this fixture in the engineering-scale pilot plant. For ease of replacement in the case of component failure, these items are all readily available commercial products not requiring modification.

\subsubsection{Availability}

A good standard of reliability should result from detailed at tention to the factors outlined in Section 2.1.5. A contributor to this reliability is the use of performance criteria suitable for a continuous use application for a fixture intended for a very light duty cycle. These factors, together with a simple and flexible maintenance schedule, contribute to an excellent profected availability.

\subsubsection{Safety}

Freedom from accidents is assured by rigorous application of the following:

1. A good Quality Assurance program which includes inspection of manufactured parts and materials and structural test procedures

2. Training program for operators by cognizant engineer in accordance with GA Procedure DP-143-5, "Training and Qualifications"

3. Operation of equipment in conformance with the GA Accident Prevention Program Manual, with special reference to Section 18, "Mechanical Lifting Operations"

4. Maintenance program for the fixture 
2.1.9. Testing

2.1.9.1. Structural Testing. Stress calculations were performed to establish the level of stress on the principal members of the lift fixture (Appendix C, Dwg. 5820044), including the beam side members, "expando" pins, and Saginaw slide attachment, and to establish buckling loads on the screw. The power requirement for the drive motor was also calculated. Calculations were based on a 10 ad of $200 \%$ of the normal working load and a material strength of $60 \%$ of the yield stress for the steel.

The proof tests carried out in the pilot plant confirmed the calculations. A test procedure describes in detail the methods used. The proof loading was $150 \%$ of the normal working load. The dynamic tests involving the automatic leveling mechanism were established to check the ability of the drive system to cope with the changing load during balancing. The rigid nature of the test anchor in the pilot plant floor had little or no effect on the effectiveness of the system designed for a free hanging load.

2.1.9.2. Operational Checkout. The operational checkout consisted of interfacing the fixture with the appropriate $j$ aw to be removed, removing the jaw from the crusher, and subsequently replacing it into its operating position. This sequence of operations is to be performed with only the designated manual assistance. During the test, automatic leveling and full-range remote manual attitude adjustment were performed.

\subsubsection{Performance Evaluation}

The lift fixture was interfaced with the jaw without problems; however, due to limited overhead clearance, the Hydra-set could only be used for initial lifting to monitor interference and to gauge the total weight lifted. No interference occurred during initial lifting (Fig. 5) and the total lifted weight of 4.45 metric tons ( 4.9 tons) confirmed the calculated weight. 


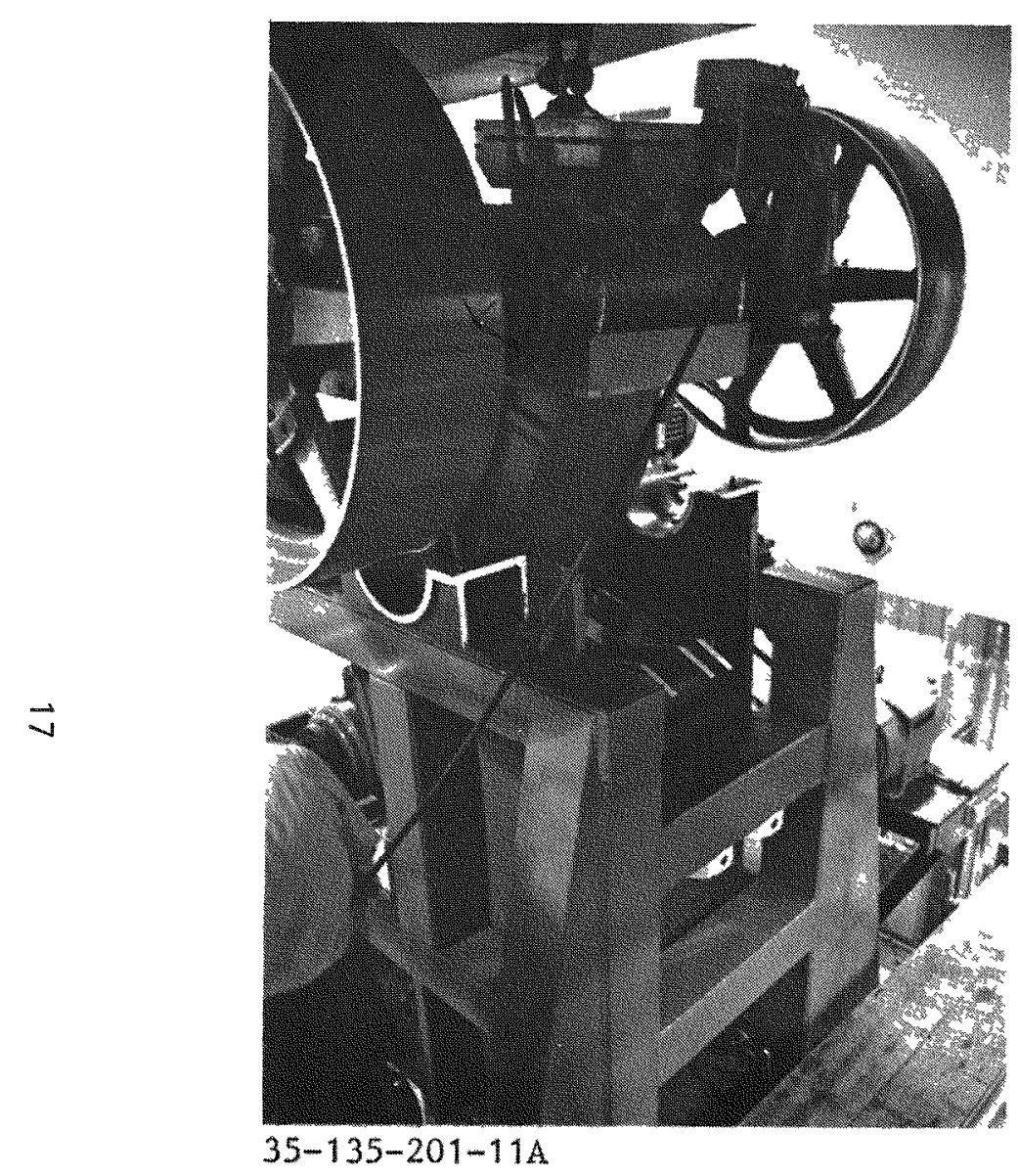

Fig. 5. Primary pitman assembly during removal from UNIFRAME

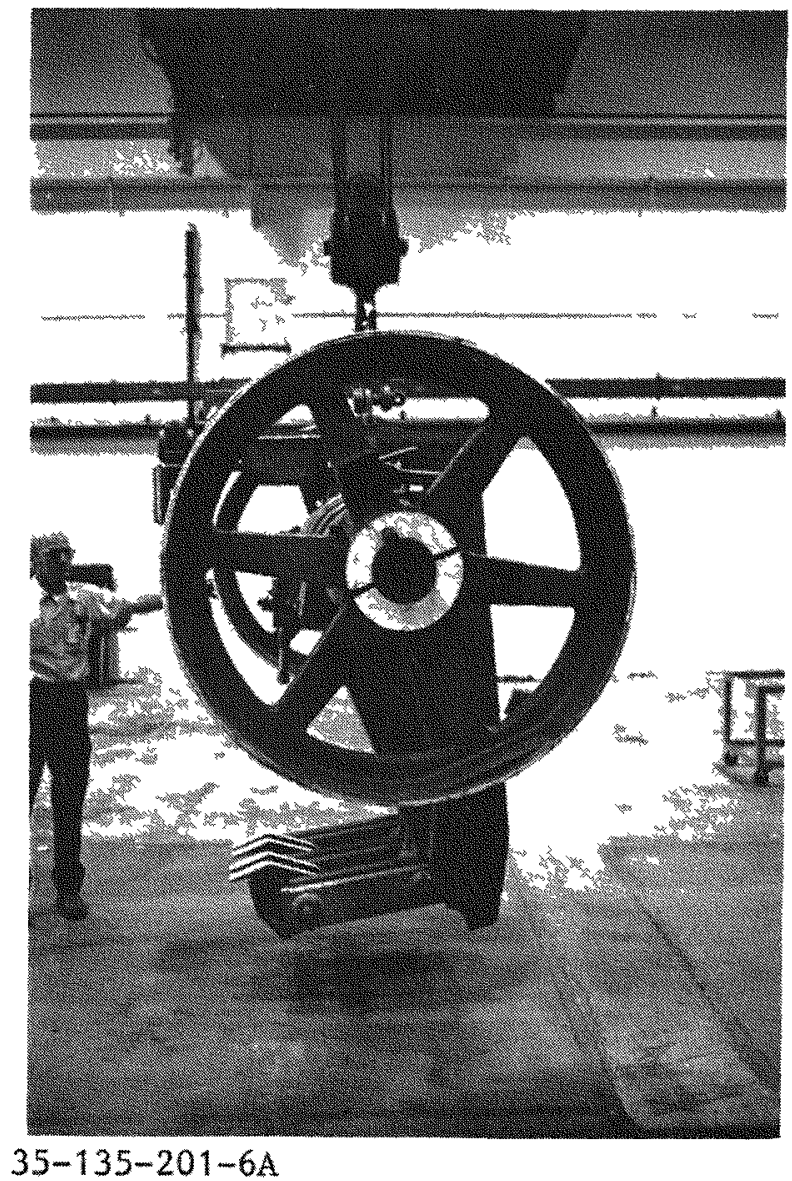

Fig. 6. Primary pitman assembly showing toggles 
A dimensional problem with the UNIFRAME reduced the clearance for the toggle assembly (Fig. 6). Instead of the UNIFRAME allowing this assembly to hang while being lifted, the toggle had to be secured close to the body of the jaw. This prevented a full test from being performed; however, the jaw was successfully lifted from the frame to the shop floor by the fixture. During this operation both the manual and automatic modes of attitude correction were successfully used. The only adjustment required was a tightening of the torque limiting clutch on the lead screw drive. The toggles are presently being replaced so that the correct relationship with the UNIFRAME will be established. This will allow full acceptance trials of the fixture.

A slight problem was experienced with the electrical control cable which is carried on an automatic takeup reel. The spring tension necessary to rewind the cable exerts a slewing force on the fixture. This was countered for the tests by tying off the cable to a scaffold, but corrective action is planned.

Very little application of the leveling capability built into the fixture was necessary after the basic balancing operation.

\subsubsection{Recommendations}

In order to improve the ability to handle the fixture, the control cable arrangement must be modified. Alterations will probably take the following form. The control cable reel will be moved from the bridge crane stationary platform to one of the trolleys. This will place the cable immediately above the fixture at all times. This change of position will require a second cable reel and cable to connect the moving trolley cable with the stationary control box on the crane platform. The control pendant with its reel w1ll remain in its present location.

The present interface between the lift fixture and the jaw is currently the most involved in manual input. The alignment of the dowel holes 
in the fixture with those in the adaptor blocks on the jaw is not automatic. Guidance provided by the cheek blocks on the fixture is not of close enough tolerance to achieve automatic alignment.

Placement of the "expando" pins is not an ideal manipulator application. An upgrading in this area would allow the fixture to "self-latch" upon location, and a suitable unlatching by remote means would disconnect the fixture for disengagement. An improvement is required in the bearings for screw thrust in the interest of safety and to reduce the chance of accidental damage to the fixture or crusher. The change would provide a more substantial bearing to take the axial thrust of $1257 \mathrm{~kg}(2769 \mathrm{lb})$ when the fixture is at its maximum angle of $15^{\circ}$ and under load. The opportunity may be taken to use a bearing which is dry lubricated for 1ife.

A detailed failure analysis should be carried out together with a search of motor and cable insulation suitable for service in a radioactive environment.

Operating experience indicates a review of the basic concept of this fixture may offer the possibility of considerable simplification.

\subsection{LIFT FIXTURE - PRIMARY CRUSHER STATIONARY JAW}

\subsubsection{Design Requirements}

The design criteria (Appendix B) specifies the following requirements:

1. The lifting fixture shall be designed to demonstrate, when used with the pilot plant bridge crane, the semiremote removal of the stationary jaw assembly from the UNIFRAME assembly and the semiremote reinstallation.

2. The entire stationary jaw assembly [Fig. 7(1)], consisting of the jaw, shafts, and cheekplates, shall be handled as a unit by the lifting fixture. 


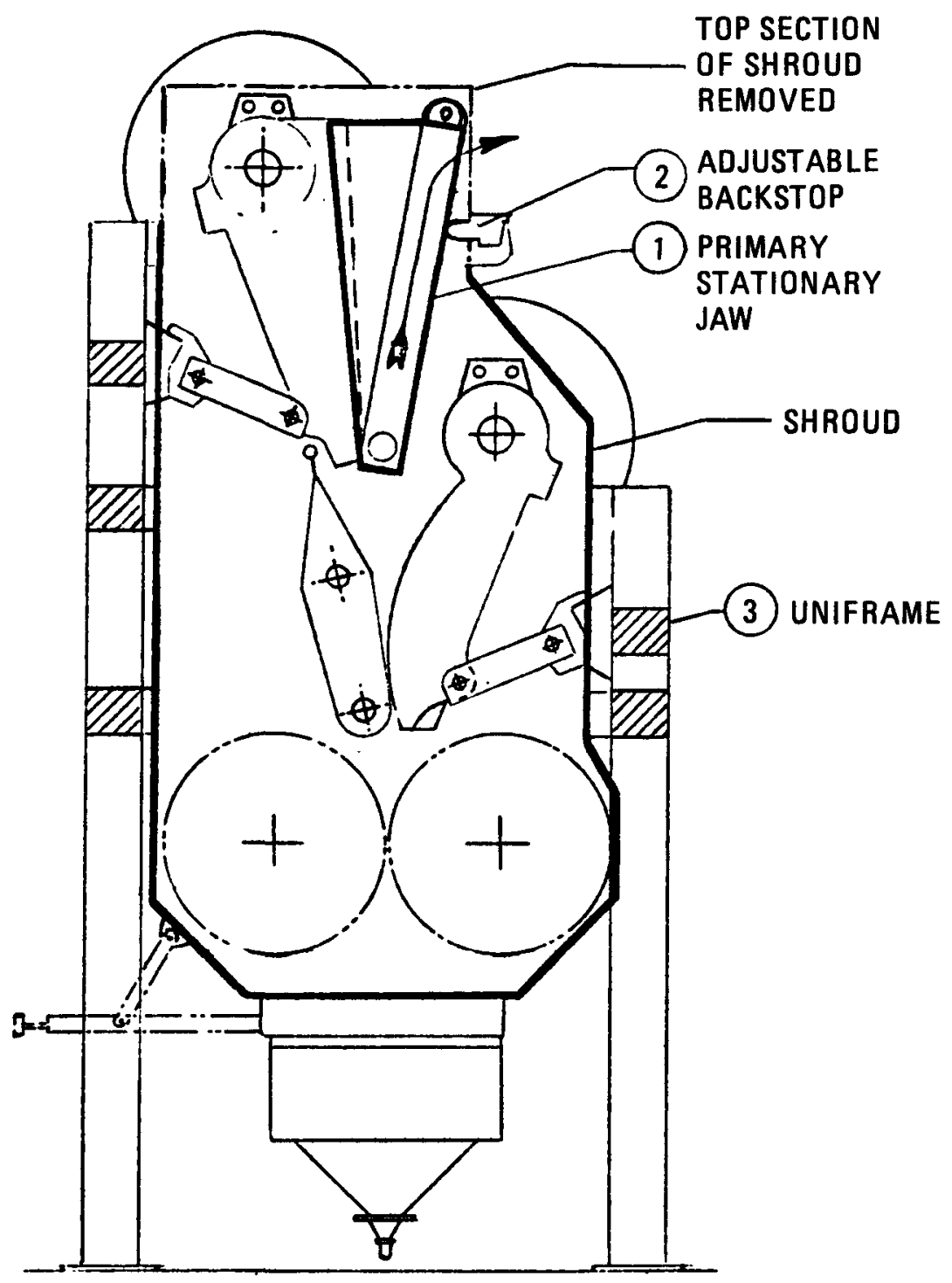

Fig. 7. Removal path for primary stationary jaw 
The weight of the assembly is approximately 1.14 metric tons ( 1.25 tons). Stress calculations are to be based on a working load of $4858 \mathrm{~kg}$ $(10,700 \mathrm{lb})$, with an allowance of $100 \%$ for impact loading, and must be within the stress allowable in the AISC specifications for structural steel for buildings. The safe stress for the steel is specified as $60 \%$ of the yield stress.

The fixture must be designed to ensure compatibility with the space available in the pilot plant. The attitude of the jaw must be controllable over a range of approximately $\pm 10^{\circ}$ from its working angle during the remova1 process. Due to limited headroom under the bridge crane in the pilot plant, removal of the adfustable backstop blocks [Fig. 7(2)] for the jaw is necessary to clear the jaw from the UNIFRAME [Fig. 7(3)].

\subsubsection{Design Principles}

The problems of attitude correction during removal of the jaw are very similar to those associated with the primary pitman, but the interface is different. The adopted design (Fig. 8) utilizes an adaptor (1) to interface with the jaw such that the fixture (2) designed for the primary pitman can be used to extract the primary fixed jaw. With this approach all the advantages of the self-balancing beam and the remote control of attitude are available by the addition of a simple adaptor.

\subsubsection{Functional Description}

The fixture, or adaptor (Dwg. 5820049, Appendix C), consists of four inverted L-shaped steel plates welded in parallel and spaced such that the upper part can be inserted into the beam of the lift fixture for the primary pitman assembly. The adaptor is located in the position normally occupied by the adaptor blocks on the primary pitman. The two fixtures are secured together by four "expando" pins [Fig. 8(3)].

To remove the primary stationary jaw, the combination fixture is lowered onto the jaw so that the back of the inverted L-adaptor contacts 


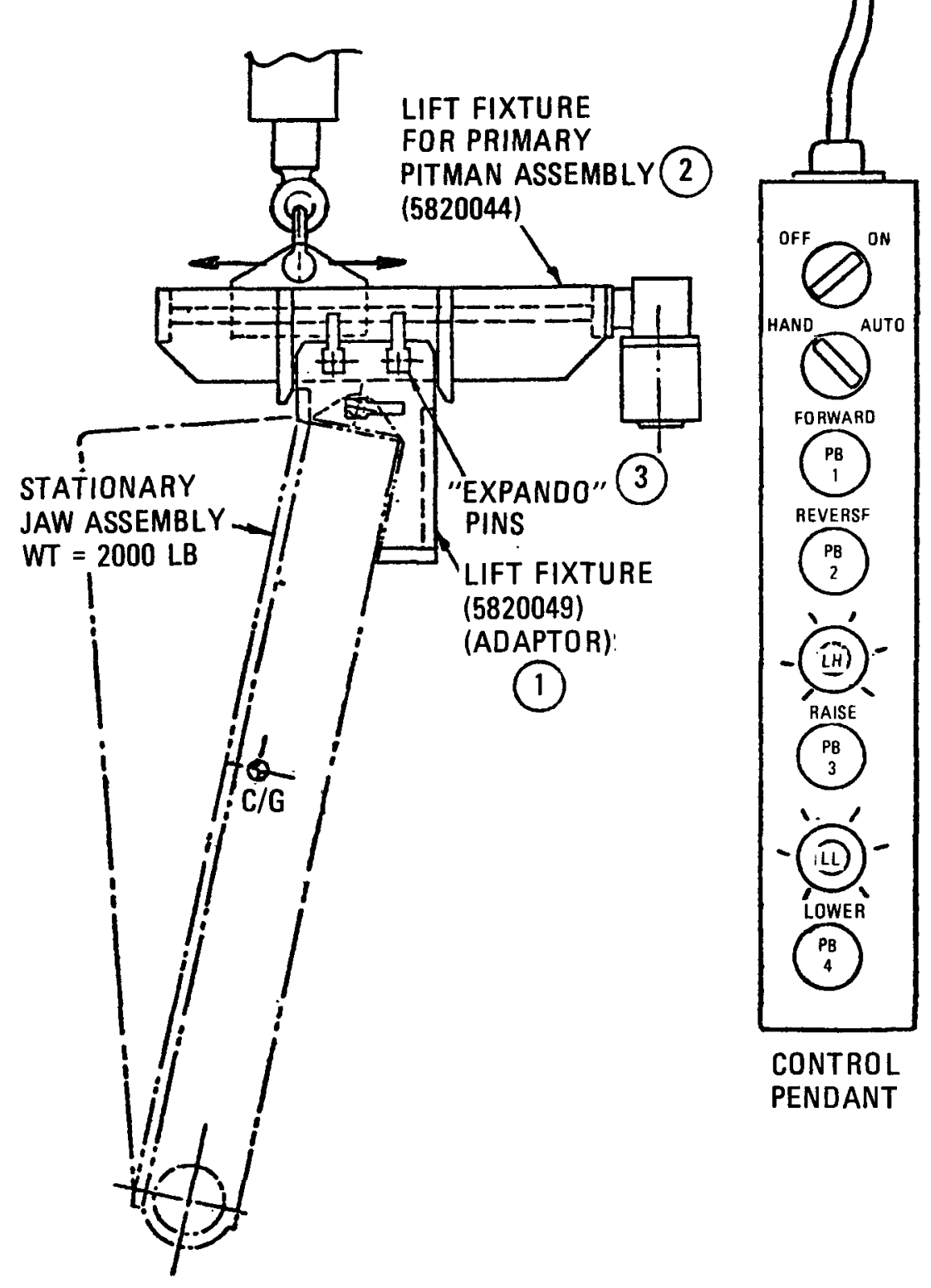

Fig. 8. Lift fixture for primary crusher stationary jaw 
the back (or outside) face of the jaw. At the same time, the lugs on the. top of the jaw w1ll be brought into line with the holes in the adaptor so that two short "expando" pins can be inserted. The insertion of the pins for this application is a manual operation and can be replaced in a prototypical installation by one of several remotely controllable actuators used to insert specially designed locking plungers.

\subsubsection{Control System}

A11 the control capability is contained in the upper part of the combination, which is the lift fixture for the primary pitman assembly. The control data and procedures which apply to the primary pitman lift fixture (Section 2.1.4) are thus applicable to the combination fixture for the removal of the primary stationary jaw.

\subsubsection{Reliability}

The static nature of the fixture leaves only structural strength as the criterion of reliability; this has been demonstrated to be adequate based on design calculations and structural testing.

\subsubsection{Ma1ntenance}

No routine maintenance is required.

\subsubsection{Availability}

The simplicity of the basic structure and freedom from moving parts enhance reliability and lessen downtime for maintenance; however, as the fixture depends for its function upon the lift fixture for the primary pitman assembly, its availability is therefore essentially equal to that of the latter. 


\subsubsection{Safety}

The operation of the fixture is almost identical to that for the primary pitman assembly and safe operation is governed by the same factors:

1. Quality Assurance, Quality Control, and testing of manufactured parts and materials

2. Operator qualification

3. Operation in conformance with the GA Accident Prevention Program Manual

\subsubsection{Testing}

2.2.9.1. Structural Testing. Stress calculations were performed to assess the stress at key points such as the coupling pins and housings and the transition on the L-frame. The calculations also accounted for the effects of angular displacement of the beam. All calculations were based on a load of $200 \%$ of the normal working load and material strength of $60 \%$ of yield stress for the steel. The structural proof tests performed (described in detail in Test Procedure TP5820047) consisted of $150 \%$ of the normal working load over the entire dynamic range of the fixture.

2.2.9.2. Operational Checkout. Following the operating procedure, the combination lift fixture was utilized to remove and replace the primary fixed jaw in the UNIFRAME. The operating procedure describes the sequence of events for the removal or replacement of the primary stationary jaw as it was designed to be removed from the UNIFRAME. The procedure used in the pilot facility has to deviate slightly from this because of limited headroom under the bridge crane. Instead of lifting the jaw up and over its adjustable back stops (Fig. 7), the two back stops must be removed, leaving the way clear for the jaw to be moved out between the frame members. 
To remove the blocks, the weight of the stationary jaw must first be relieved by use of the lift fixture on the easterly crane hook, drawing the jaw into an upright position against the primary pitman. The westerly crane hook is then employed to remove the back stops. This is a completely manual operation at present. When the back stops are removed, the lift fixture can complete removal of the stationary jaw. A simple tool may be designed as part of our future work which would interface remotely and support the stationary jaw in its normal working position. The back stop screws could then be backed off until the stop assemblies are removed by the crane. Only at this point would the lift fixture be deployed to remove the stationary jaw.

At the time of the initial checkout of the lift fixture for the primary stationary jaw, the primary pitman assembly had already been removed for modification. The procedure used in these circumstances was as follows. The lift fixture was interfaced with the primary stationary jaw and raised to the vertical position. A wooden beam was placed across the bearing housings for the primary pitman assembly to form a support for the primary stationary jaw. The stationary jaw was canted over and supported by the beam to release the crane for removal of the back stops. Upon removal of the back stops, the normal procedure was resumed.

When the primary pitman assembly was replaced in the UNIFRAME, the operational checkout of the primary stationary jaw fixture was repeated. No problems were experienced, and the faw was removed and replaced several times with no manual guidance apart from checking the slewing action caused by the electrical control cable.

\subsubsection{Performance Evaluation}

The primary pitman lift fixture was used in conjunction with the primary fixed jaw lift fixture to form a combination to interface with the primary fixed jaw. The operation went smoothly as designed, and the jaw was removed from the frame. Attitude maneuvers were performed manually and automatically without problems (Fig. 9). 


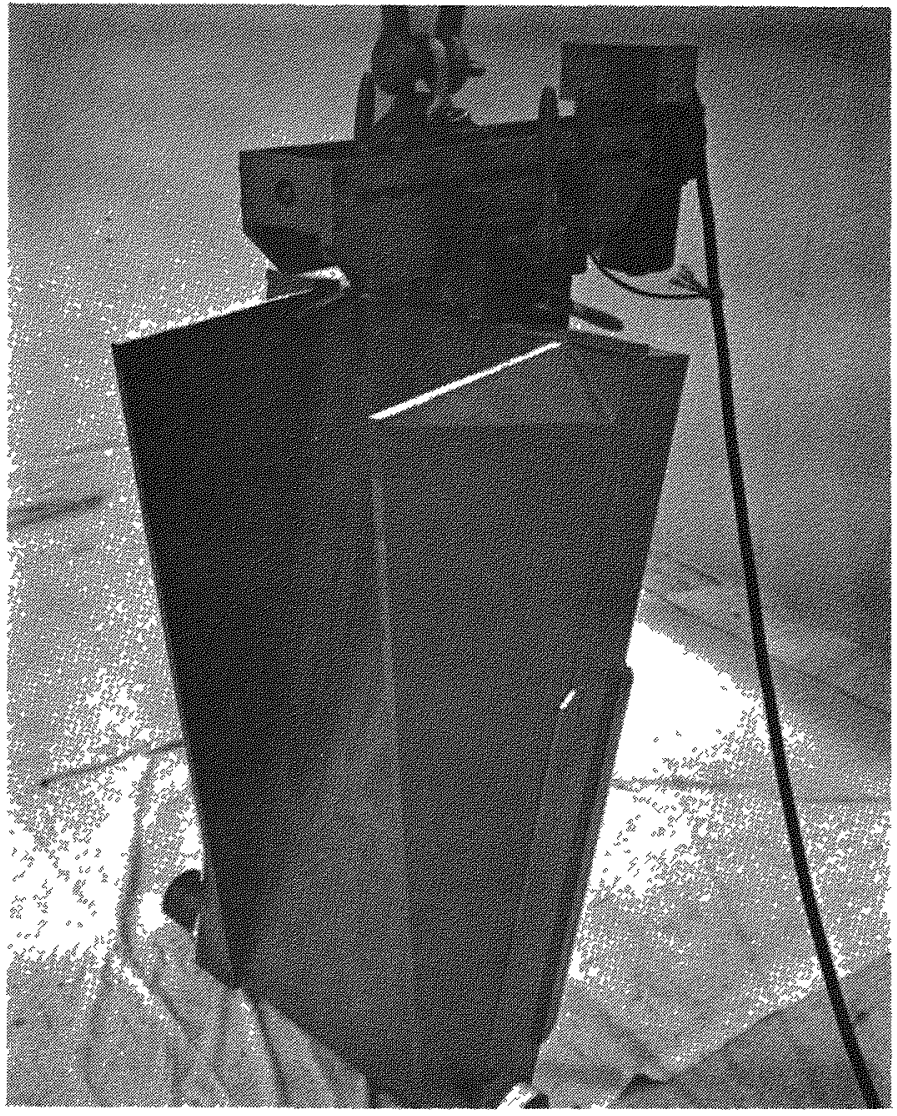

$35-135-200-11 \mathrm{~A}$

Fig. 9. Primary crusher stationary jaw with semiremote lift fixture 


\subsubsection{Recommendations}

One of the recomendations for the lift fixture for the primary pitman is that the attachment method should be modified to provide for remote interfacing. As the lift fixture for the primary stationary jaw utilizes the same attachment points, this fixture must be kept compatible with whatever change takes place. The interface between the lift fixture and the primary stationary faw should also be improved to permit remote mutual engagement.

\subsection{LIFT FIXTURE - SECONDARY CRUSHER PITMAN ASSEMBLY}

\subsubsection{Design Requirements}

The design criteria for the secondary pitman assembly (Appendix B) are very similar to those for the primary pitman. All of the design parameters discussed in Section 2.1.1 are applicable to the secondary pitman and therefore, to avoid repetition, this section will be confined to the relevant additional requirements.

The overhang of the primary stationary jaw causes a restriction in clearance for the removal of the secondary pitman assembly (Fig. 10). The toggle assembly (1) on the secondary pitman (2) must be retracted against the back surface of the jaw before lifting the assembly out of the UNIFRAME (3). This requires that a secondary feature on the lift fixture interface with the toggle to move it independently in an appropriate direction.

The weight of the secondary pitman assembly including the lift fixture is approximately 5 metric tons (5-1/2 tons).

\subsubsection{Design Principles}

Since many of the design requirements are common to the two pitman assemblies, the solutions will logically be related. The additional problem of separately handling the toggle assembly has been solved by 


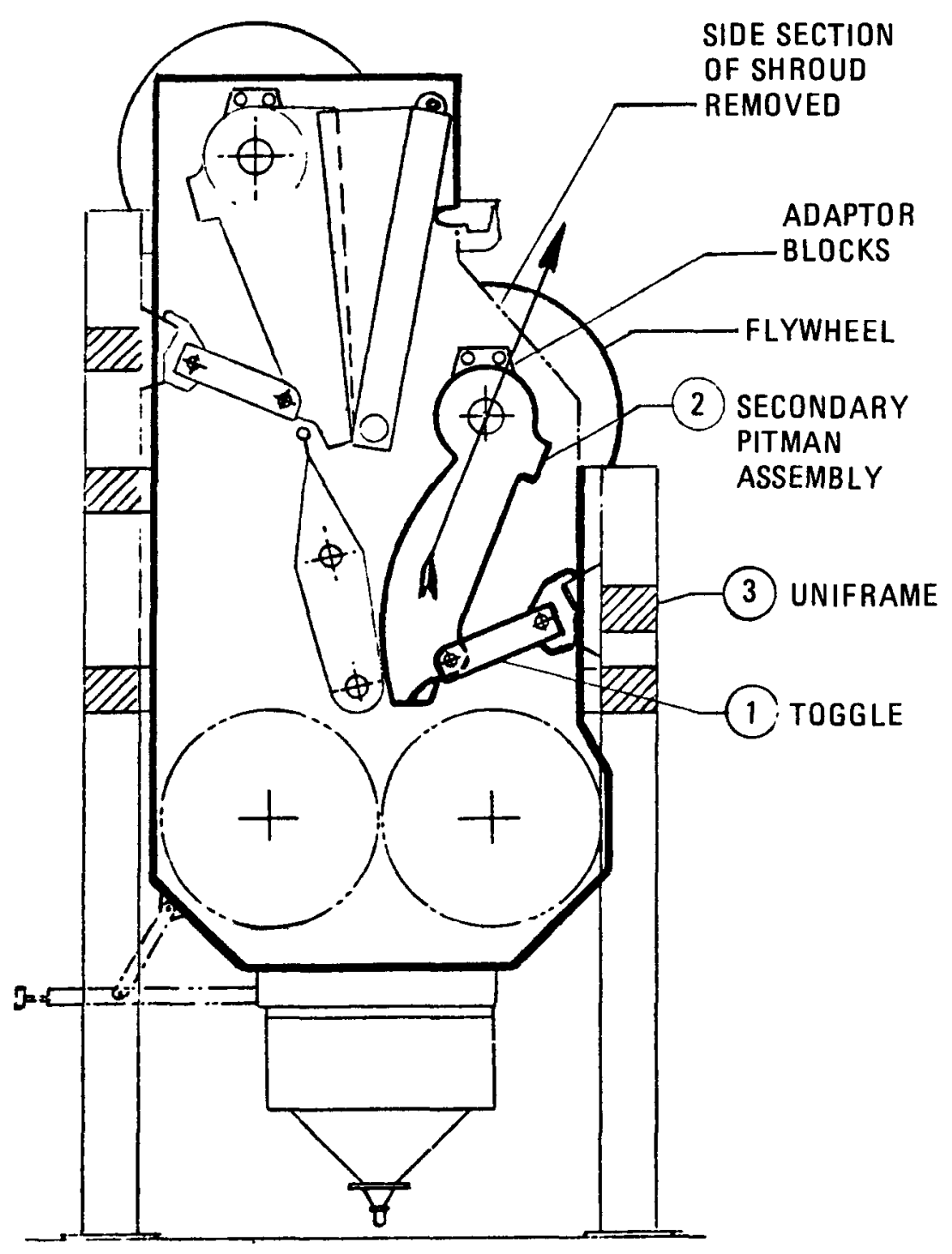

Fig. 10. Removal path for secondary pitman assembly 
utilizing a grappling hook actuated by a separate power source. The hook will extend, engage a bar attached to the toggle assembly, and haul it back into a more compact space to facilitate removal of the assembly from the frame.

Figure 11 shows the design approach, which is similar to that for the primary pitman. It embodies the doweled (1) connection of the beam (2) to the pitman and the lifting eye (3) moved by the gear-motor-driven (4) lead screw (5) to obtain balance of the assembly. A second gear motor (6) drives a vertical lead screw (7) to raise and lower the slider (8) which carries a hook arm (9) to handle the toggle (10).

\subsubsection{Functional Description}

The lift fixture construction (Dwg. 5820047, Appendix C) follows very closely that of the primary pitman fixture but with the addition of another mechanism housed between two side plates which are bolted at one end of the beam to form an inverted L-shape. The vertical member of the "L" accomnodates a lead screw with a crosshead sliding vertically between guides.

A rigid hook is suspended from the crosshead and is freely pivoted to allow movement in the plane of the "L" from horizontal to an adjustable stop position almost vertical. A 1/3-hp gear motor bolted to the outside of the vertical housing drives the lead screw, which raises or lowers the pivot point of the hook on the crosshead. Limit switches disconnect the motor power to either end of travel to avoid overtravel. As the crosshead approaches the bottom of the stroke, the back of the hook arm contacts the adjustable stop. Further movement of the crosshead toward the stop generates a couple which rotates the hook arm away from its near-vertical path.

To mate the fixture with the pitman assembly (Fig. 12) in the crusher, the fixture (1), suspended in a horizontal attitude from the crane, is positioned $152 \mathrm{~mm}$ (6 in.) above the pitman crown (2). In this position the hook (3) is lowered until it is firmly against its end stop and swung 


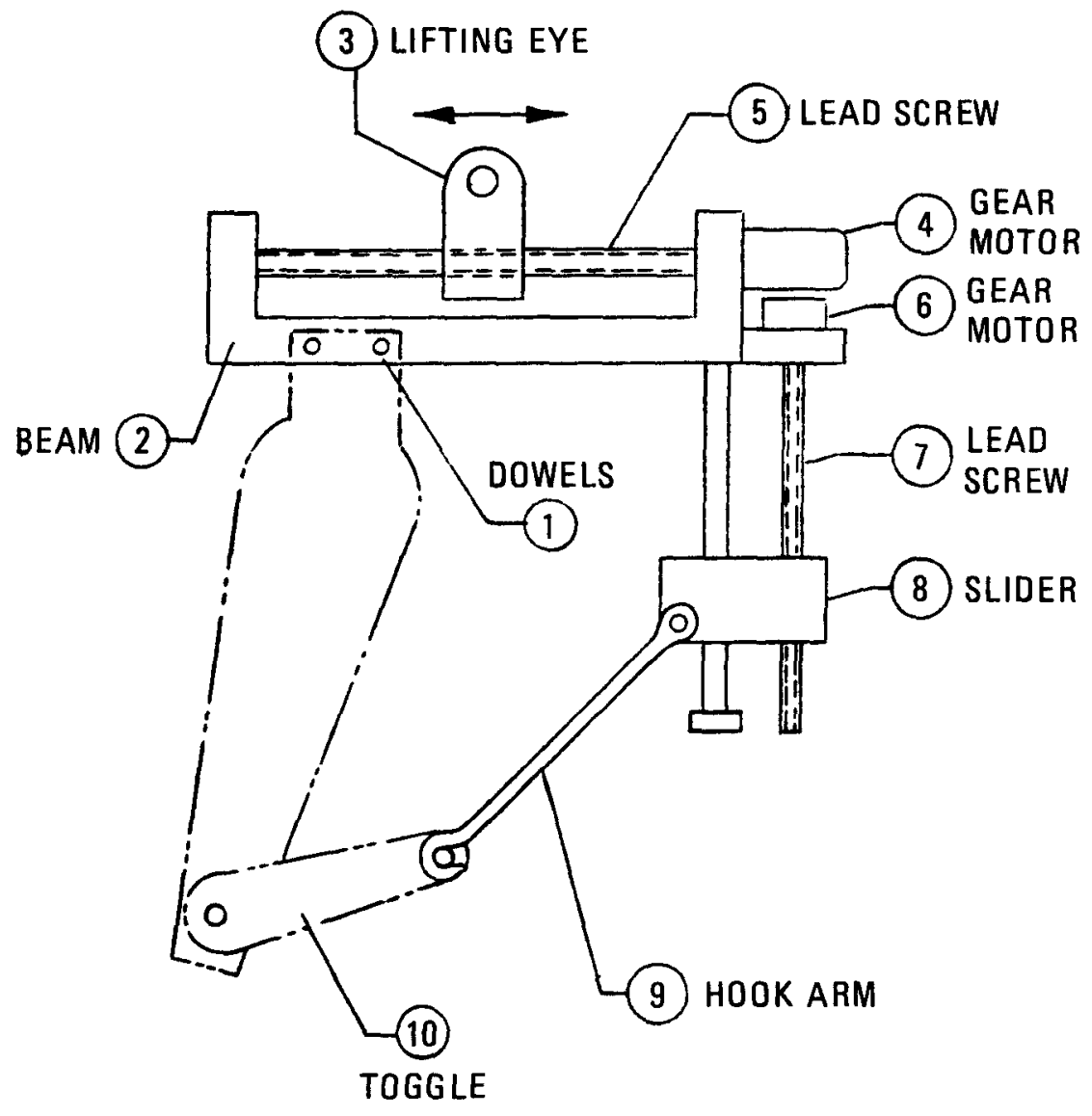

Fig. 11. Diagramatic representation of the mechanism for lifting the secondary pitman assembly 


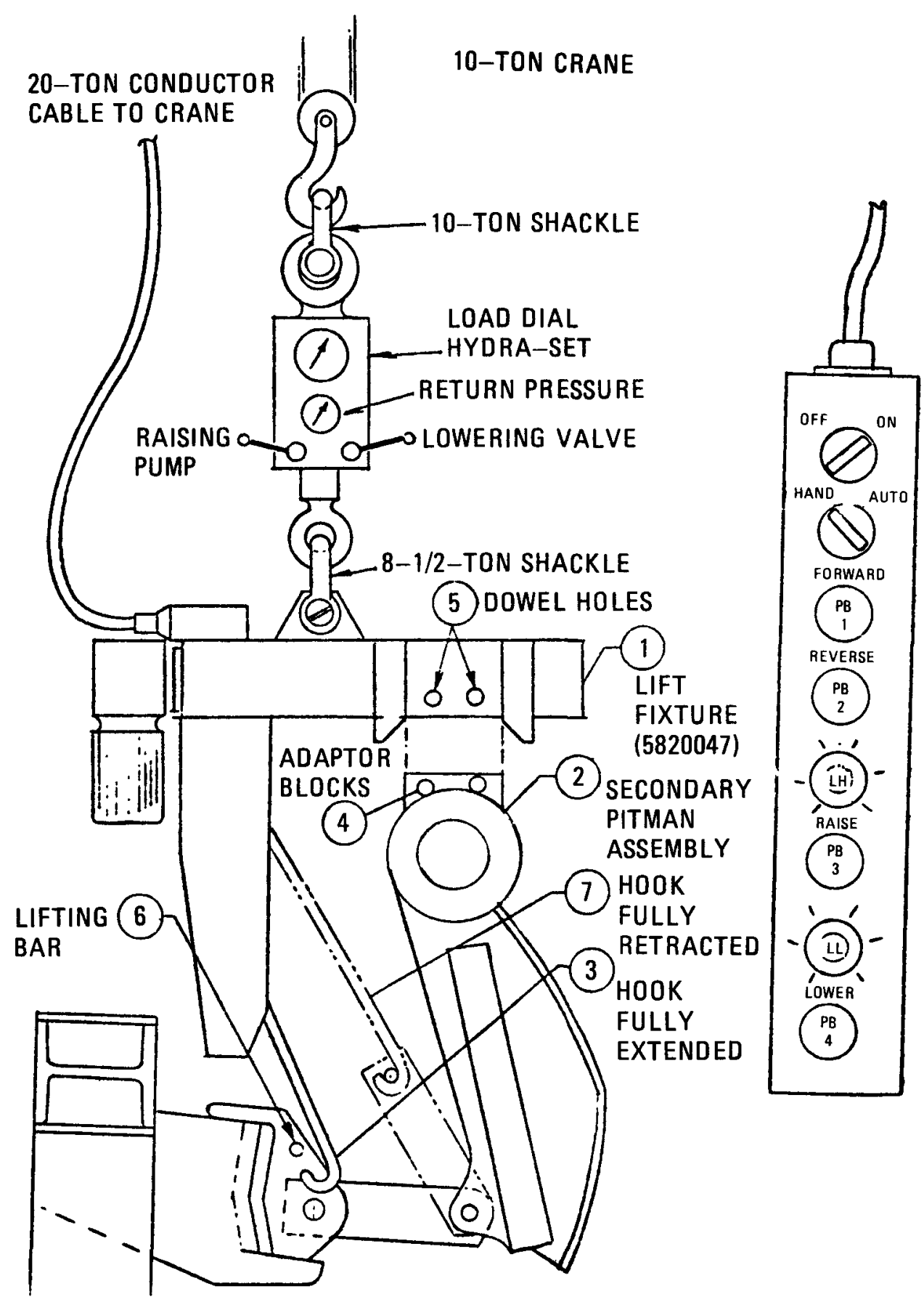

Fig. 12. Lift fixture for secondary pitman 
toward the pitman. The fixture is then lowered on to the adaptor blocks (4). When the "expando" pins which secure the fixture to the jaw are in place in the lower holes (5), the hook is retracted. As the hook retracts, it swings toward the vertical, which also brings the open side of the hook in contact with the lifting bar (6) on the toggle assembly. As the crosshead travels higher, the hook engages the toggle and raises it unt1l, at the top position of the jack, the toggle lies against the back of the pit$\operatorname{man}(7)$.

\subsubsection{Control System}

As with all crusher fixtures, control of the fixture is by the pendant control box via the control center on the crane platform. The controls for balancing the load on the fixture, both manually and automatically, are identical to those for the primary pitman.

Extension and retraction of the hook is achieved by use of pushbuttons "PB4 1ower" and "РB3 raise." In each case an indicator lamp will be on as long as the circuit to the starter switch is closed. When the hook is fully extended, a limit switch opens the circuit. At the other end of hook trave1, another limit switch prevents overrun.

\subsubsection{Reliability}

The factors contributing to reliable operation discussed in Section 2.1.5 apply equally to this fixture. Duplication of motors and control circuits increases the possibility of failure, but both the drive trains and control systems are overrated based upon normal industrial usage. The life expectancy in this light duty cycle application is therefore very good. Further evaluation of radioactive effects on electrical insulation and bearing lubrication is required.

Table 2 summarizes the preliminary failure analysis. 
TABLE 2

SUMMARY OF PRELIMINARY FAILURE ANALYSIS FOR CRUSHER PITMAN ASSEMBLY

\begin{tabular}{|c|c|c|}
\hline $\begin{array}{l}\text { Component Failure } \\
\text { During Operation }\end{array}$ & Immediate Effects & Secondary Effects \\
\hline Motor or starter system & $\begin{array}{l}\text { No corrections of fixture attitude are possible. } \\
\text { No damage to flxture or crusher should result } \\
\text { but equipment w111 be nonoperational. }\end{array}$ & $\begin{array}{l}\text { May jeopardize completion of removal of } \\
\text { the jaw from the UNIFRAME or replacement } \\
\text { of the jaw. External assistance would } \\
\text { then be required. }\end{array}$ \\
\hline $\begin{array}{l}\text { Automatic leveling system: wiring, } \\
\text { relays, and a mercury switch }\end{array}$ & $\begin{array}{l}\text { Fixture will not level automatically. No } \\
\text { anticlpated damage to the fixture or the } \\
\text { crusher. }\end{array}$ & $\begin{array}{l}\text { The manual override controls will allow } \\
\text { completion of procedure. }\end{array}$ \\
\hline Any of the "expando" dowel pins & No effect. Any one pin can carry the load. & \\
\hline $\begin{array}{l}\text { Bearlings for slider carrying the } \\
\text { lifting eye }\end{array}$ & $\begin{array}{l}\text { At worst, the slider will be jammed in posi- } \\
\text { tion. No catastrophic fallure or damage to } \\
\text { crusher. }\end{array}$ & $\begin{array}{l}\text { If not jammed, maneuver can be completed. } \\
\text { If jammed, same as for motor or starter } \\
\text { system. }\end{array}$ \\
\hline \multirow[t]{2}{*}{ Bearlngs for screw thrust } & $\begin{array}{l}\text { Fixture near horizontal: No catastrophic } \\
\text { effects but possibly enough friction to } \\
\text { overcome torque limiting clutch. }\end{array}$ & $\begin{array}{l}\text { Some external assistance in guidance may } \\
\text { be necessary to complete maneuver. }\end{array}$ \\
\hline & $\begin{array}{l}\text { Fixture at extreme angle: Possiblitty of } \\
\text { complete bearing breakup causing the lift eye } \\
\text { to hit the end. Stop load may drop several } \\
\text { inches. }\end{array}$ & $\begin{array}{l}\text { Damage to jaw or crusher is possible when } \\
\text { jaw drops, if this occurs in limited } \\
\text { clearance space. }\end{array}$ \\
\hline $\begin{array}{l}\text { Vertical drive motor or starter } \\
\text { system }\end{array}$ & $\begin{array}{l}\text { Hook for toggle assembly lnoperative. No } \\
\text { damage to flxture or crusher should result. }\end{array}$ & $\begin{array}{l}\text { May jeopardize completion of removal of } \\
\text { jaw from UNIFRAME. Replacement of jaw } \\
\text { may require deviations from procedure. }\end{array}$ \\
\hline \multirow[t]{2}{*}{ Hook or plvot } & $\begin{array}{l}\text { Toggle w11l fall to limit of freedom within } \\
\text { bearings on Jaw. No serious effect from } \\
\text { toggle. }\end{array}$ & $\begin{array}{l}\text { Operational effects simflar to those } \\
\text { for vertical drive motor or starter } \\
\text { system. }\end{array}$ \\
\hline & $\begin{array}{l}\text { Broken parts may fall into tertiary crusher } \\
\text { section. }\end{array}$ & $\begin{array}{l}\text { Crusher may have to be stripped to remove } \\
\text { broken parts. Damage could result to } \\
\text { rollers if operated. }\end{array}$ \\
\hline
\end{tabular}




\subsubsection{Maintenance}

The fixtures designed for the pilot plant are intended for contact maintenance. Lubrication by oil and grease is used and therefore must be replenished at regular intervals. In a radioactive environment, the friction surfaces would be coated with a suitable dry lubricant such as "Dycronite," and lifetime performance would be expected. The specific dry lubricant has yet to be selected based upon laboratory accelerated life tests.

\subsubsection{Availability}

No extended performance experience has yet been possible to augment the design, testing, and selection of components to substantiate the reliability estimates for this equipment. The preliminary maintenance schedule is flexible and w1ll allow maximum avallability of the fixture. Operational experience will point out shortcomings or the need for maintenance beyond the anticipated level. All occurrences bearing on reliability and maintenance will be logged as a reference for improvements.

\subsubsection{Safety}

Safe operation is assured by using only certified personnel in the operation of the fixture and application of the procedures specified in the General Atomic Accident Prevention Program Manual and those described in Section 2.1 .8 of this report.

\subsubsection{Testing}

2.3.9.1. Structural Testing. A test procedure describes the tests performed to establish the structural integrity of the fixture. The normal loading on the fixture is perpendicular to the track of the lift eye slider. The load is transmitted through the linear bearing and via the side plates to the pins connecting the fixture to the adaptor blocks on the 
pitman assembly. The calculations for this loading and for loadings at $15^{\circ}$ on either side of this position were based on loads of $200 \%$ of the normal working load and a material strength of $60 \%$ of yleld stress for the steel. Structural testing observed a proof load of $150 \%$.

\subsubsection{Operational Checkout. Initial operational tests were conducted} during a maintenance period when the jaws were required to be removed from the UNIFRAME. One of the reasons for stripping the secondary pitman assembly from the frame was to weld a bar onto the toggle assembly to interface with the lift fixture. This bar is grappled by the vertical hook on the fixture to raise the toggle before removal of the jaw. Thus, without the bar in place, the full procedure could not be performed. However, a rope strop was attached to temporarily substitute for the bar, and the jaw was lifted out by the fixture (Figs, 13 and 14). The weight, as read on the Hydra-set, was 5 metric tons ( 5.5 tons), which verified the calculated weight.

Although a slight interference with the shroud side plates was experienced, removal and replacement were considered successful as far as the procedure could be followed. The interference was caused by bowing of the shroud side plates near the bearing blocks when they were welded into place. During reassembly several lines of approach were tried to evaluate the advantages of each. The most successful was the "lowest possible" horizontal approach over the UNIFRAME side members, which was performed without manual assistance.

The UNIFRAME shroud was modified to provide the correct designed clearance and the interface bar was welded to the toggle. A full trial of the fixture followed these modifications. As with the other fixtures, some trouble was experienced with the control cable pulling the fixture out of line.

\subsubsection{Performance Evaluation}

The fixture performed all designed functions well except for the automatic balance mode. Cyclic oscillation of the beam, known as "hunting," 


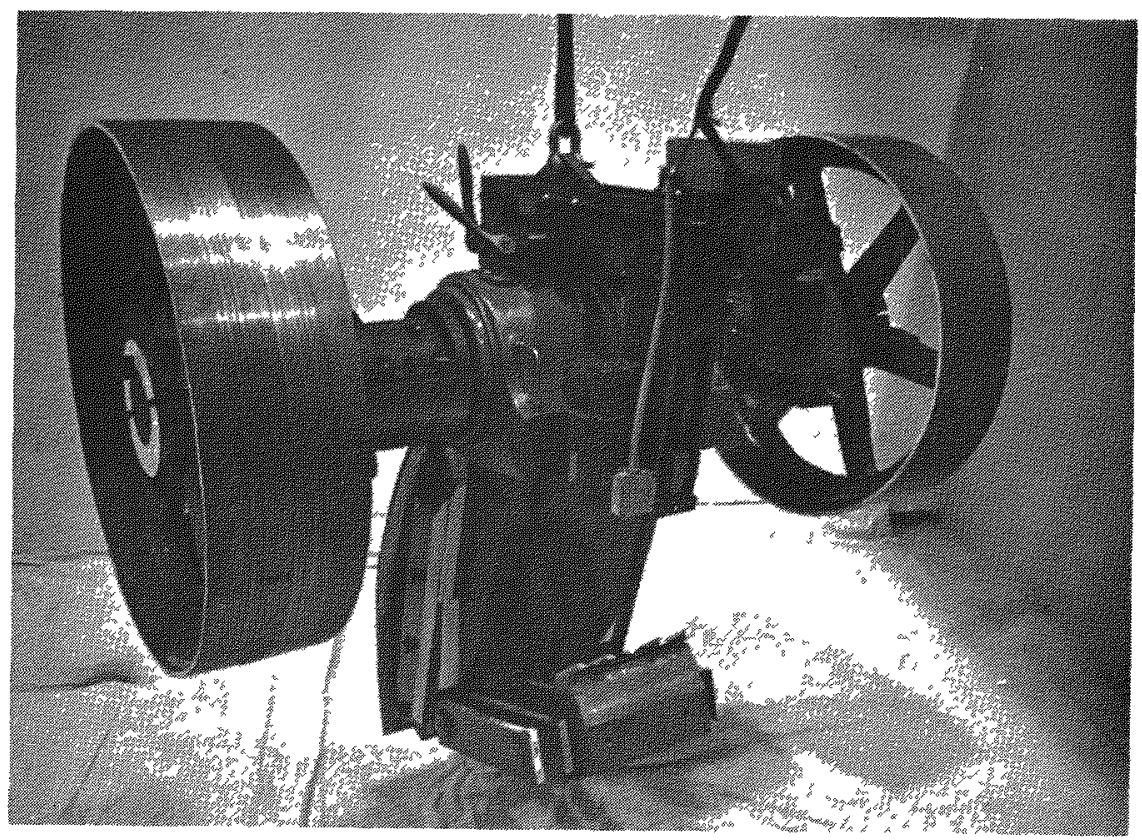

$35-135-200-5 A$

Fig. 13. Secondary pitman assembly showing toggles in the extended position

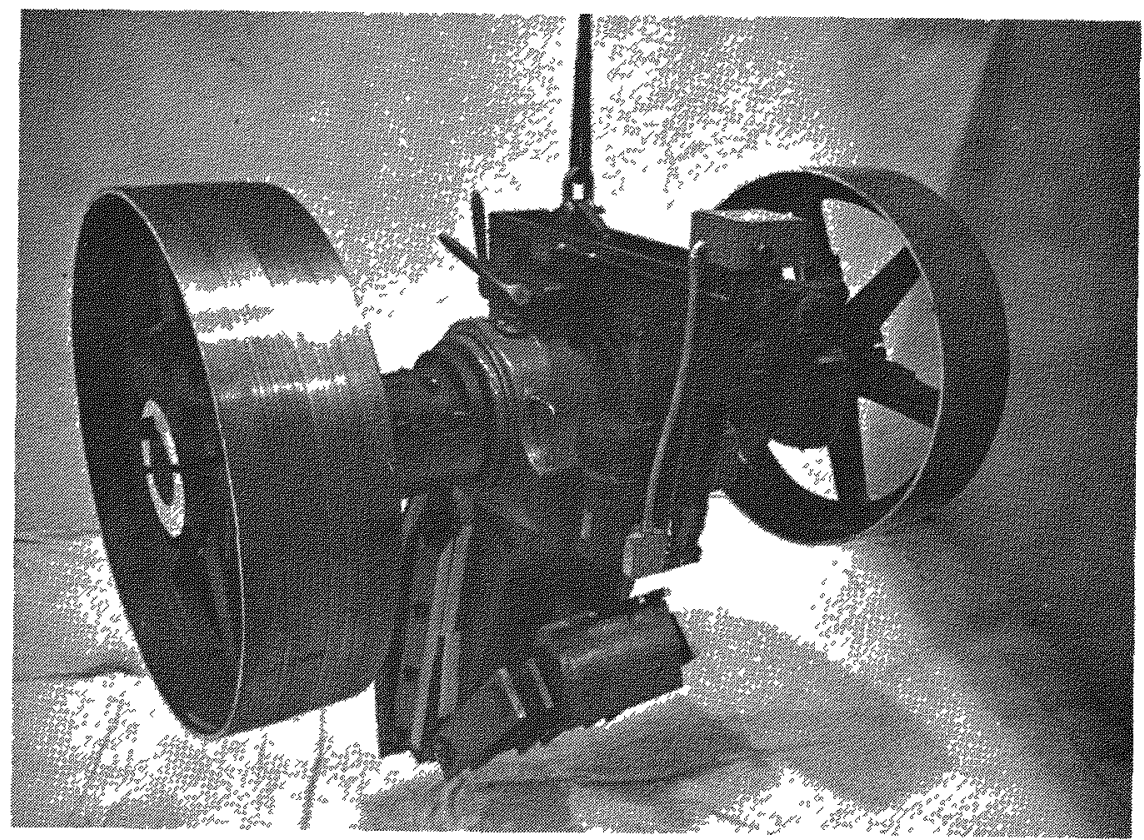

$35-135-200-3 \mathrm{~A}$

Fig. 14. Toggles fully retracted by the lift fixture hook mechanism - secondary pitman assembly 
could not be damped by changing the time decay in the motor switch gear to decrease response. The problem was traced to a mercury switch of an incorrect type. Instead of providing a "center-off" position, the switch was bistable, causing the motor to run in one direction or the other. The mercury switch will be replaced with the correct type as soon as it is available. Manual adjustment of the beam attitude was used to complete the tests.

Due to the offset weight of the vertical drive motor gear box, the whole fixture hangs slightly out-of-plumb. This affects the alignment of the dowel holes making it difficult to insert the "expando" dowel pins.

\subsubsection{Recommendations}

The area requiring fundamental development is the interface with the jaw. A foolproof engagement of the fixture is required over a large range of angular displacement of the jaw. This must be attainable without external aid.

Development of better ways to lead the control cable is necessary to avoid both damage to the cable and misalignment of the fixture.

Investigation of lubrication systems to avoid the necessity for this service during the life of the fixture is required.

A counterbalance weight equal in moment to the motor for the hook mechanism should be added to the fixture to restore the symmetrical loading about the centerline of the fixture.

Operating experience indicates a review of the basic concept is called for, with the possibility of simplifying the mechanism considerably. 


\subsection{HORIZONTAL REMOVAL FIXTURE - SECONDARY CRUSHER FIXED JAW (DWG. 5820079, APPENDIX C)}

\subsubsection{Design Requirements}

As shown in FIg. 15, the secondary crusher fixed jaw (1) is situated below the primary pitman assembly (2) in the UNIFRAME (3). Surrounded by the shroud (4), the jaw is accessible only by prior removal of the primary pitman or via a small window (5) In the UNIFRAME after removal of part of the shroud.

The jaw is a symmetrical, prismatic structure of roughly diamond section and weighs $817 \mathrm{~kg}(1800 \mathrm{lb})$. The exterior is completely smooth except for the mounting holes which are through the section and abut the sides of the shroud. Thus, there are no "hand holds" inherent in the design.

The window in the UNIFRAME through which the faw can be inserted or removed is of sufficient width but is only about two-thirds the height of the Jaw. Allowance must be made to accommodate posstble jaming of the jaw during removal by graphite particles forced by crushing into the side clearance spaces. A narrow flange (6) on the upper edge of the faw provides the only area in which small modifications may be made to provide handling purchase.

\subsubsection{Design Principles}

Any exit route for the secondary stationary faw from the UNIFRAME other than the window described above requires the removal of large sections of the crusher. The only gyration for the jaw in extraction in a horizontal path is the inftial one, 1.e., rotation.

Figure 15 shows the faw in its normal operating position held by axially opposing mounting shafts, one pair slightly above the center (7) and the other at the base (8). The latter shafts are almost perfectly 


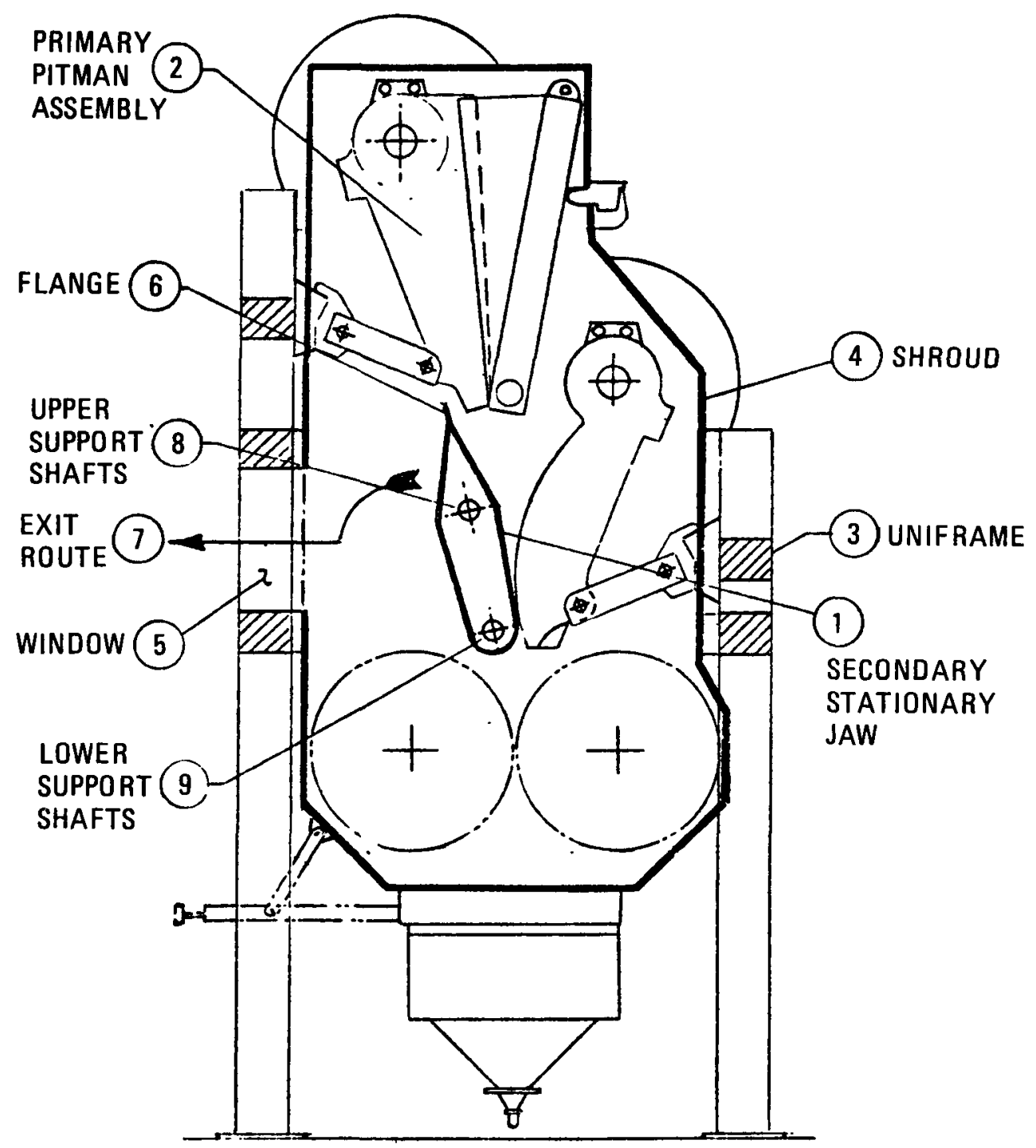

Fig. 15. Removal path for secondary stationary jaw 
located to act as a pivot for the rotation of the jaw into a nearhorizontal position.

The jaw can be supported by a suitable fixture while the upper mounting shafts are withdrawn; the jaw can then be pivoted on its lower mounting shafts until $1 \mathrm{t}$ is suitably angled to exit from the window. From this position, the jaw can be drawn by its upper end clear of the UNIFRAME subsequent to the removal of the lower shafts. The only nonremote operations should be withdrawal of the upper and lower mounting shafts, connection of the crane to the jaw for removal from the fixture, and connection of the fixture to the crane for temporary installation into the UNIFRAME.

All control should be via existing control circuitry on the crane platform. The design will incorporate screw jack drive mechanisms in preference to hydraulic actuation to facilitate the transition of the design to the requirements of a hot cell environment.

The first fully developed approach (Fig. 16) utilized a hydraulic lift table on ralls and carried a pivoting cradle to carry the jaw. All functions except horizontal translation of the cradle were hydraulic. The jaw pivoted by gravity against the restraint of a hydraulic cylinder. The decision to redesign was based upon several factors:

1. A hydraulic mechanism is not preferred in a hot cell environment.

2. The design was complex mechanically with a consequent effect upon reliability.

3. The many degrees of mechanical freedom required complex control circuitry.

4. The design was not easily adaptable to provide a downward pull on the jaw in the event that jamming of particles in the clearance space caused a problem in crusher operations. 


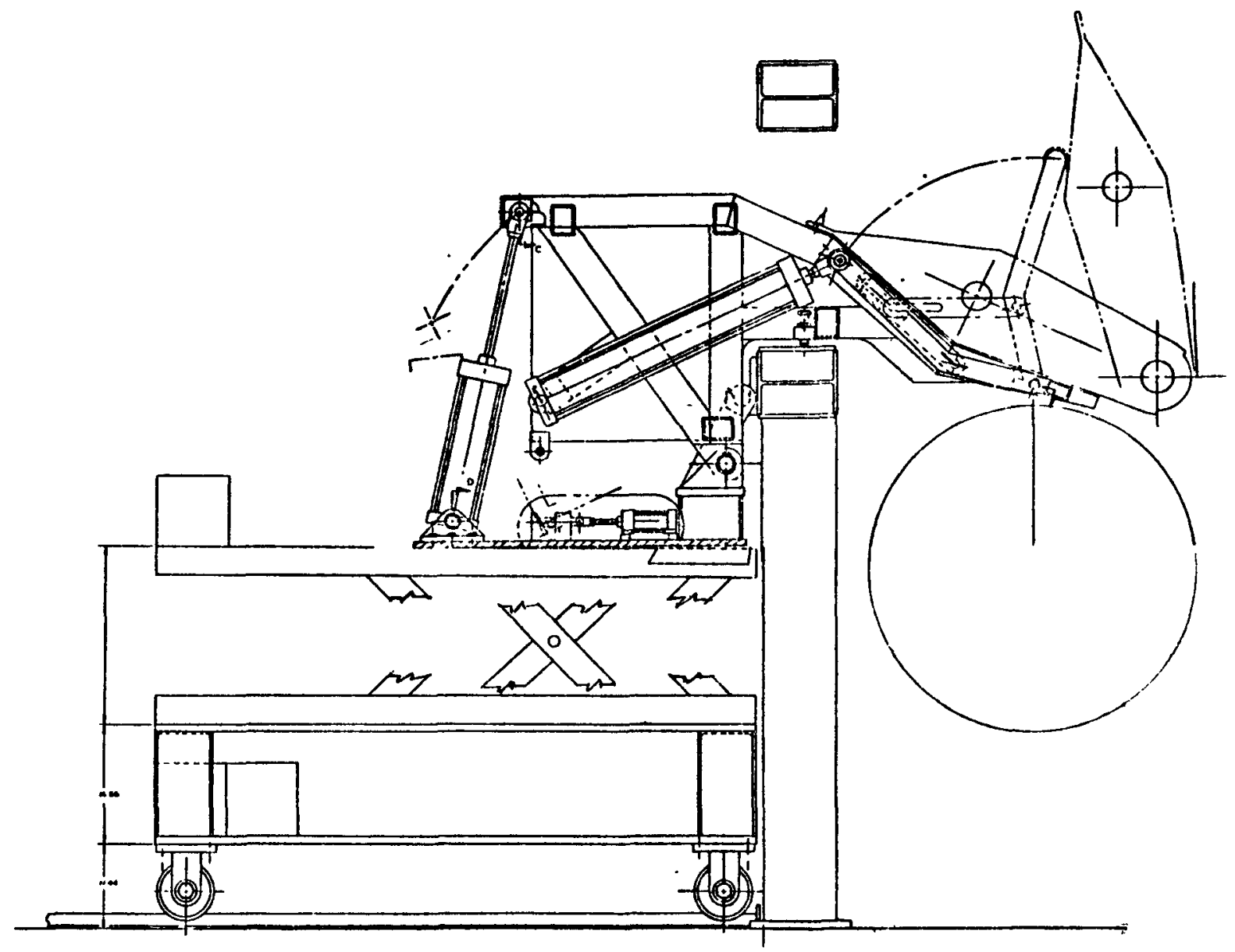

Fig. 16. Horizontal removal fixture for secondary stationary jaw, first version 
Several subsequent designs were examined. The design adopted is described below.

\subsubsection{Functional Description}

The fixture shown in Fig. 17 consists of a prismatic space frame (1) of triangular cross section, which is designed to hang on to the outside of the UNIFRAME (2) as a temporary extension of the UNIFRAME. The horizontal top member of the fixture will rest on the lower ledge of the window (3).

Projecting into the window space, a cantilevered section of the frame carries a pair of heavy duty rollers (4) at its extreme reach. These rollers support the jaw when it is pivoted down to a near-horizontal attitude.

The jaw is modified by welding onto the upper flange a specially designed steel handling bar (5) to permit the engagement of handling devices. A groove is machined at each end of the handling bar; these grooves correspond to the support channels (6) on the carriage (7). The grooves locate the jaw relative to the carriage to ensure alignment with the window upon replacement of the jaw.

The carriage is supported between the top members of the frame upon two slide rails and is moved by a lead screw electrically driven by a gear motor (8). A diagram of the carriage arrangement is shown at the left in Fig. 17. A screw jack (9) with a gear motor drive (10) is mounted on a trunnion between the jaw support channels on the carriage. The fack end is provided with a hook (11) (or open clevis) which is designed to engage a reduced diameter at the center of the jaw handling bar. This arrangement is a multipurpose mechanism which can be used to carry the weight of the upper end of the jaw during the lowering portion of the procedure. In case of jamming of the jaw due to crushed particles of graphite between the edge of the faw and the shroud, the fack can be used to pull down on the handIing bar to free the jaw. Once cradled into the support arms on the carriage, the upper portion of the jaw can be locked into position by the jack, which pulls down on the center of the handling bar. 

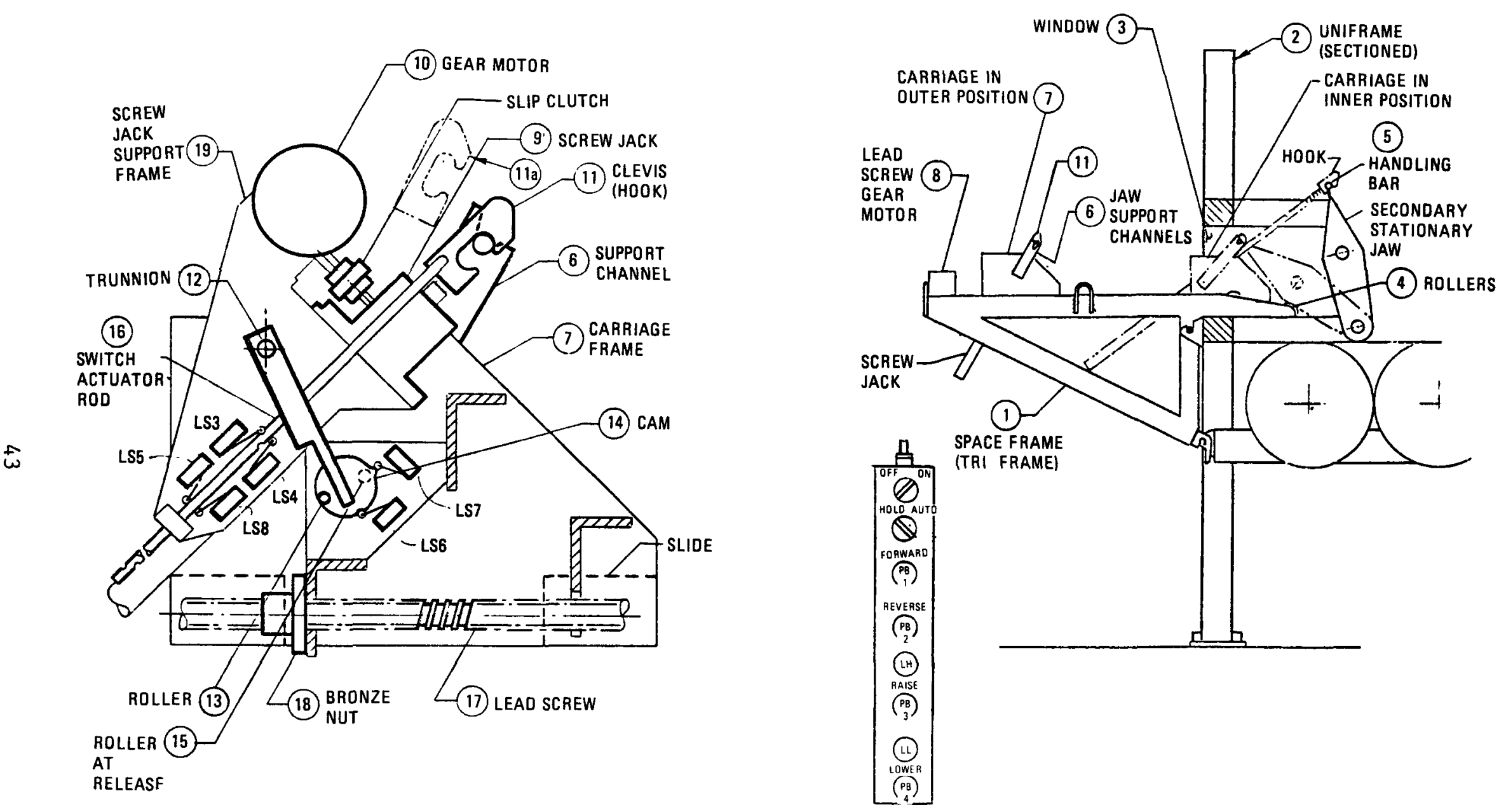

Fig. 17. Horizontal removal fixture for secondary crusher stationary jaw with detail of carriage assembly shown at left 
The trunnion (12) supporting the carriage jack has a limited degree of freedom to swing. This feature is incorporated for two reasons. The first is to allow the clevis end of the fack to follow the arc of the handing bar as it swings down about the lower jaw support shafts. The second reason is to allow the clevis to be swung clear of the handling bar to release the jaw in either the installed position or for removal by crane. The latter motion (clevis release) is provided by an eccentric roller (13) mounted on the shaft of a small gear motor attached to the carriage frame. The cam (14) is used to actuate two microswitches to stop the gear motor at the release position (15) and the engage position. Four limit switches (LS3, LS4, LS5, and LS8) monitor the position of the clevis via the switch actuator rod (16). These switches provide the signals for the control logic.

When the jaw is pivoted down on to the carriage and is locked into the support channel forks, the lower shafts supporting the jaw can be removed. At this point, the jaw weight is supported and balanced almost entirely upon the rollers at the cantilevered end of the fixture frame. Withdrawal of the Jaw is achleved by moving the carriage to the rear of the fixture, utilizing the $1 / 2-h p$ motor-driven lead screw (17) via the bronze nut (18). As the Jaw is drawn back riding on the front rollers, its lower end is automatically raised until, after passing over a second pair of rollers, it is nearly horizontal. For the remainder of the travel, the faw lower end slides on the top surface of the fixture.

The frame of the fixture is provided with lifting lugs to enable the crane to place the fixture into lugs on the UNIFRAME (Fig. 18). The design of the lifting arrangement angles the fixture away from the UNIFRAME so that the lower lugs on the fixture can be interfaced with those on the UNIFRAME (Fig. 19). Forward movement of the crane levels the fixture so that the upper lugs latch into place and support the whole assembly.

The normal operating procedure is described in Appendix D. 


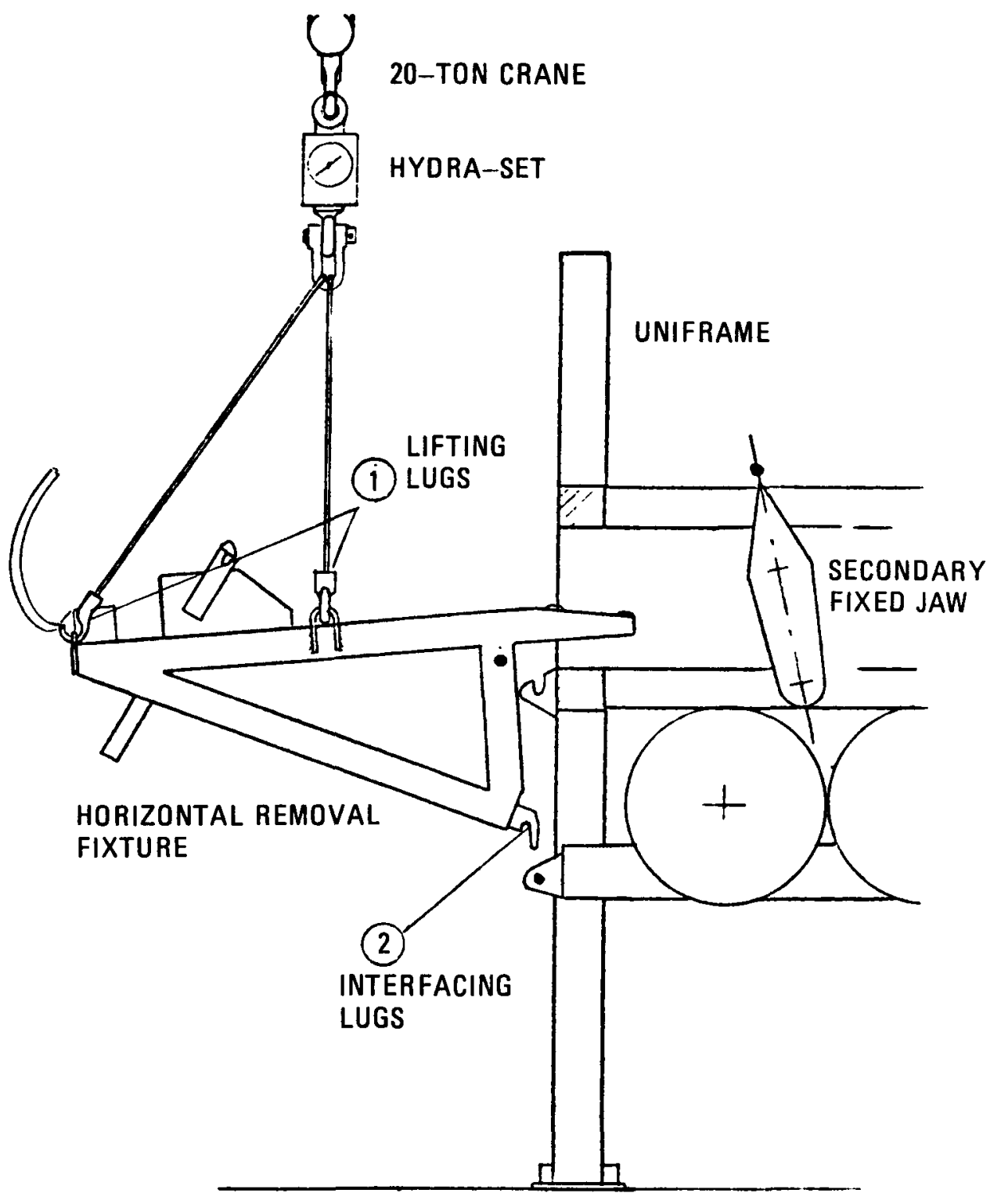

Fig. 18. Horizontal removal fixture: semiremote installation onto UNIFRAME stage one 


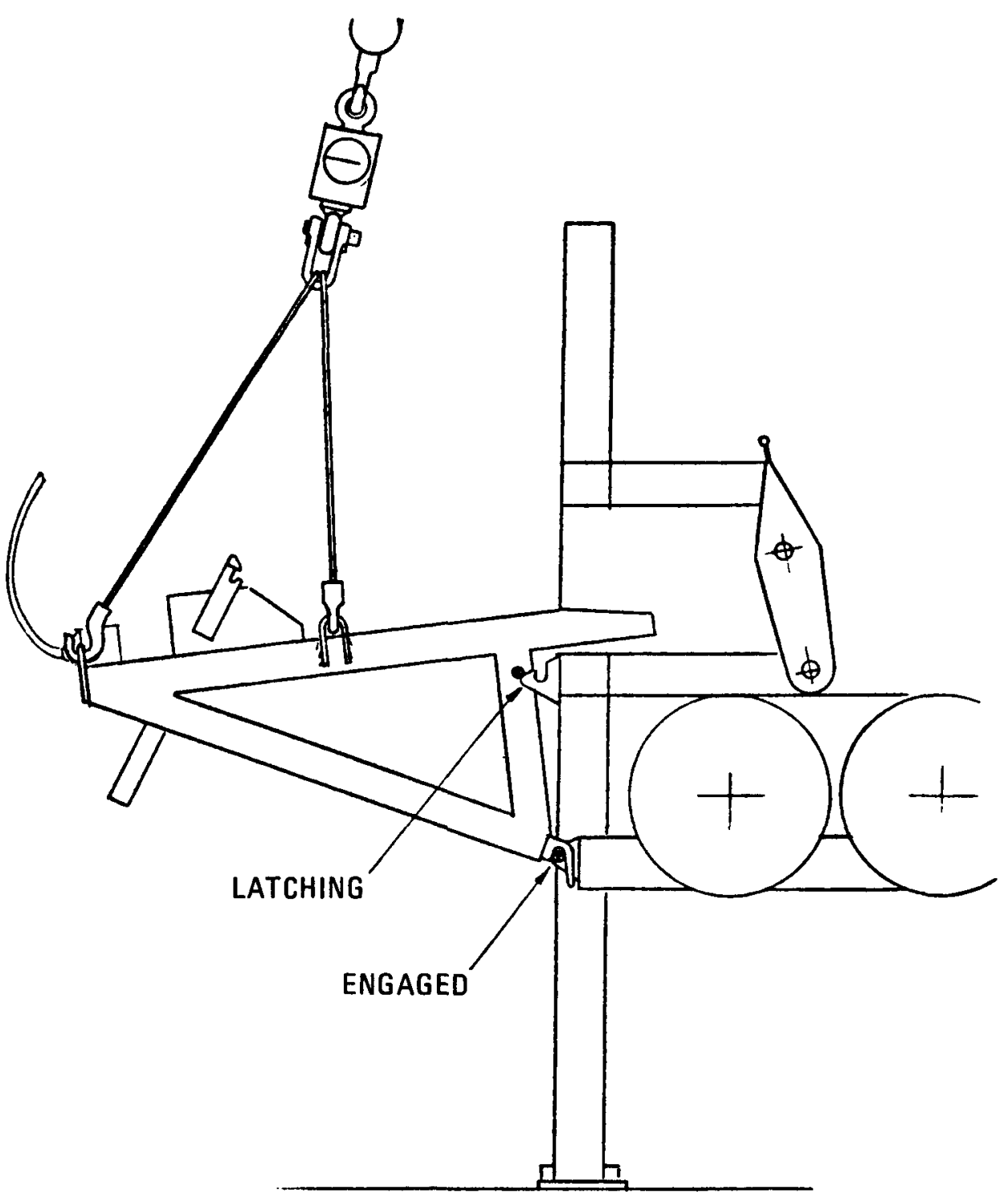

Fig. 19. Horizontal removal fixture: semiremote installation onto UNIFRAME stage two 


\subsubsection{Control System (Dwg. 5820108, Appendix C)}

Although the horizontal removal fixture was designed after the construction of the remote control system, it was considered desirable to utilize the avallable control system. The control pendant (Fig. 20), which hangs from a cable reel on the crane platform, is equipped with a power switch, a "hand/auto" mode switch, four pushbuttons for forward and reverse control of two motors, and two indicator lights.

The control functions required for the horizontal removal fixture for the secondary fixed $j$ aw are as follows: two 3-phase motors forward and reverse, one requiring two intermediate selectable stopping points; one single-phase motor with dual mode of operation; and a total of nine operations from the four pushbuttons available on the control pendant. The functions are separable by the position of the carriage at the time of requirement. At each end of travel of the carriage, a limit switch prevents overrun by interrupting the power to the appropriate motor control circuit.

These switches are dual purpose and also provide the switching for the function of individual pushbuttons on the control pendant, thus increasing the effective number of controls. The same principle of dual control switching is applied utilizing the limit switches on the carriage fack. This jack has four positions, each controlled by a limit switch, as follows:

1. Fully retracted

2. Fully extended

3. At upper release point for clevis

4. At lower release point for clevis

All four of these switches mount to the trunnion assembly and pivot with the jack; the actuator is a notched bar which is attached to and monitors the position of the clevis. 


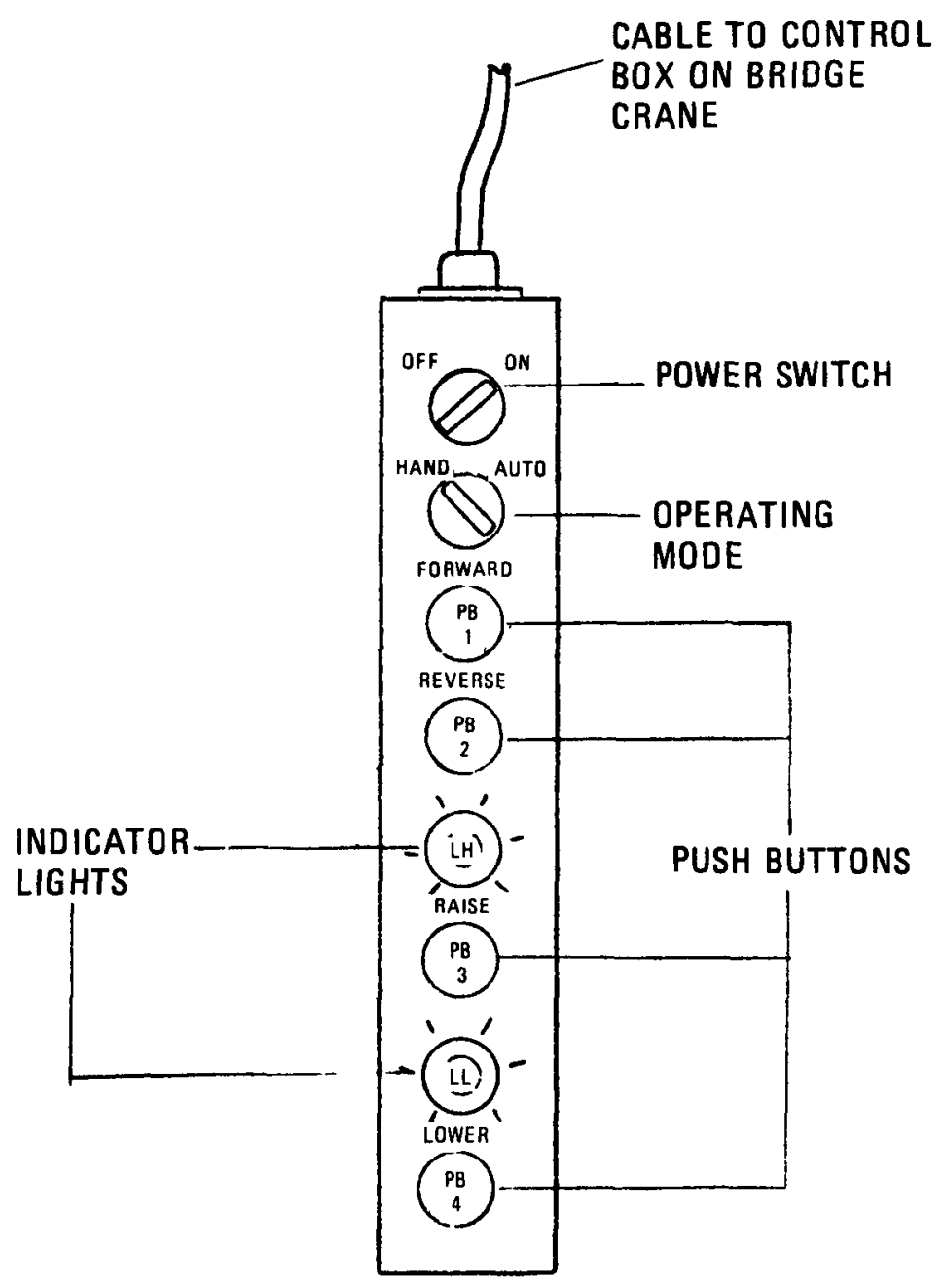

Fig. 20. Control pendant for crusher remote maintenance fixture 
The single-phase motor which pivots the trunnion to release the clevis is controlled by a simple switch logic to rotate half of its shaft rotation for each command. The command pushbuttons are automatically alternated to allow separate lock and unlock buttons. The functions "lock" and "unlock" are simplifications for control wording and correspond with "engage" and "release" functions in the carriage description. Appendix E contains a step-by-step analysis of the electrical sequence.

\subsubsection{Reliab1lity}

A detailed failure analysis has yet to be performed, but the completed stress analysis has revealed a high local loading on the screw jack in the carriage assembly. This has been redesigned and recalculated and an Engineering Change order is pending the decision to fabricate the fixture. The design has been aimed at simplicity in operation without dependence for its function upon close tolerances, thus reducing the likelihood of failure due to wear in service.

\subsubsection{Maintenance}

Observing the philosophy of the pilot plant policy, the design has been made suitable for easy conversion to hot cell maintenance constraints. The routine maintenance of the fixture consists mainly of periodic lubrication. The surfaces that require attention (lead and jack screw threads, linear sliding bearings, rollers, and pivots) are all susceptible to dry coat lubrication for life. The maintenance schedule will be based on experience in operational service.

\subsubsection{Availability}

This fixture has not been fabricated at this time and thus no working experience is available to reinforce any theoretical predictions. An effort has been made to build in good reliability and maintainability and, although some development has yet to be done, no serious problems are presently envisioned. 


\subsubsection{Safety}

Minimum hazards to personnel are associated with remotely operated equipment operated only by certified personnel in accordance with the General Atomic Accident Prevention Program Manual, with particular reference to Section 18. A full analysis has yet to be done to assess the direct hazards and the indirect consequences to the equipment being handled by the fixture.

\subsubsection{Testing}

2.4.9.1. Structural Testing. The maximum stress on the frame is that due to the cantilever loading of the jaw supported on the first set of rollers. This loading is reacted through the frame so that the top rectangular tube on each side of the tri-frame is in simple bending. The calculations show the stress due to this loading at two selected points on the cantilever arm. The maximum value of this stress is $176 \mathrm{~kg} / \mathrm{cm}^{2}$ (2500 psi).

The test for this loading consists of supporting the fixture on the fixed stands, or jacks, (Fig. 21) and applying the $150 \%$ load to the first rollers by means of a special yoke. The yoke is provided with V-blocks to interface with the rollers and is coupled at its center to a floor test anchor via the Hydra-set. [The Hydra-set is a self-contained hydraulic system capable of generating loadings of up to 9.1 metric tons (10 tons) over a $102 \mathrm{~mm}\left(4-1 \mathrm{n}_{\text {.) }}\right.$ range by use of a hand lever.] This setup will allow exact simulation of working conditions.

The second area for testing is the carriage fack system. The jack has a thrust capability of 1.8 metric tons (2 tons). The calculated maximum load when the jaw is supported by its lower shafts and the fack is almost retracted (prior to clamping) is just over $317 \mathrm{~kg}(700 \mathrm{lb})$. This is reacted by the trunnion assembly, the carriage track, and the frame support pins. The trunnion is designed to support the maximum thrust of the jack [1.8 metric tons (2 tons)] with a maximum stress of $370 \mathrm{~kg} / \mathrm{cm}^{2}$ (5252 psi). 


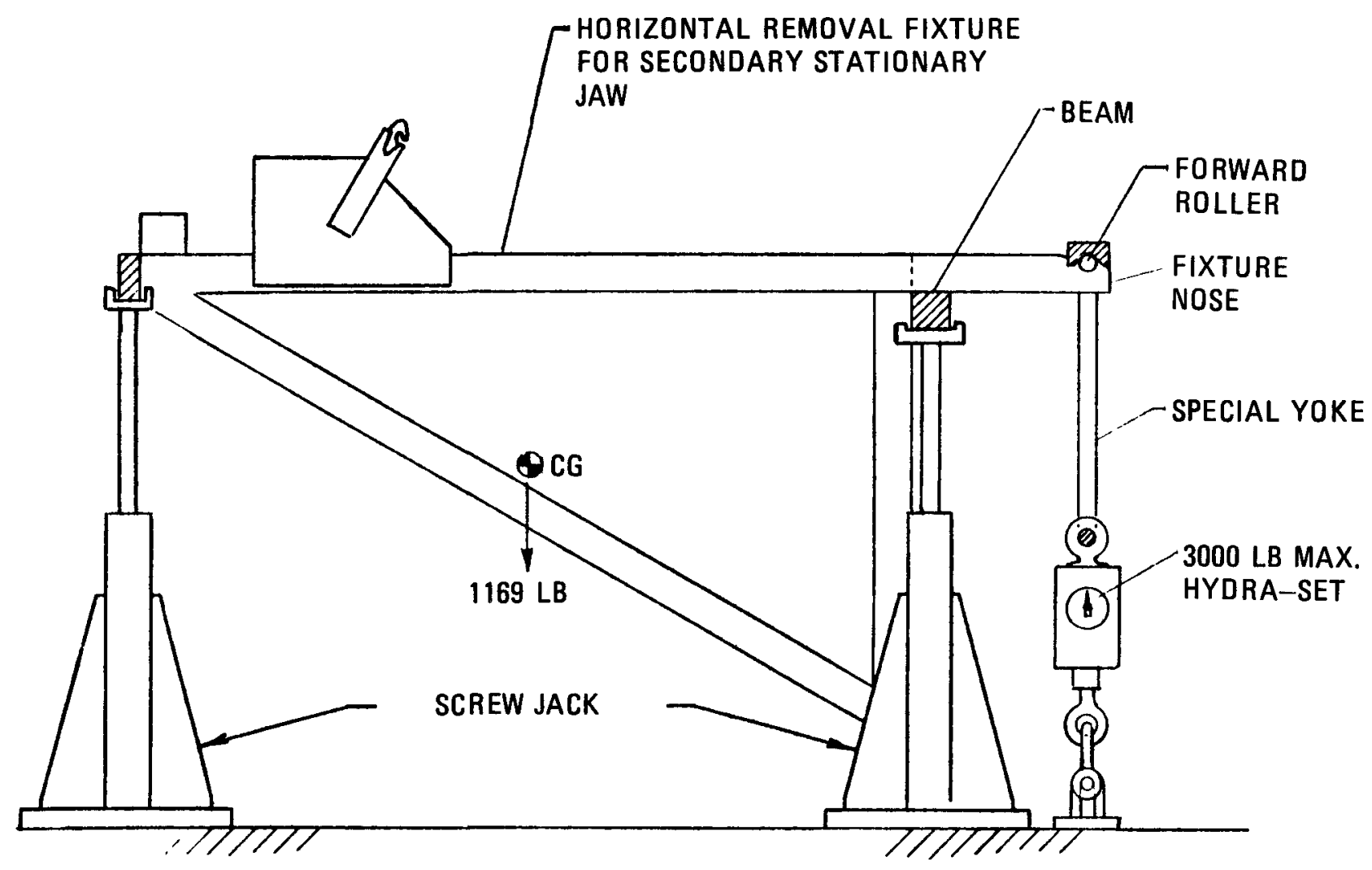

Fig. 21. Test anchor 
A test has been devised to place all of these areas in a stressed condition at one setting (Fig. 22). The fixture will be suspended by the crane via the Hydra-set coupled to the clevis on the carriage jack. The frame support pins will be used to couple the fixture to the floor test anchor. The crane can thus apply tension read by the Hydra-set load dial to the components in series.

2.4.9.2. Operational Checkout. Interfacing the fixture for the first time will require a setup procedure to establish the limit switches at optimum settings. Following this, the operating procedure will be followed to achieve removal and replacement of the secondary crusher fixed jaw.

2.4.10. Future Work

The design of this handling fixture, as with all of the crusher fixtures described in the report, was undertaken on the premise that each component should be removed independently from the others. This philosophy is being reconsidered in the light of experience; therefore, construction of this fixture will not be started until this has been resolved.

2.5. CRUSHER SHROUD SHUTOFF VALVE (DWG. 5820073 AND 5820099, APPENDIX C)

\subsubsection{Design Requirements}

The valve is intended as a closure for the bottom end of the crusher shroud [Fig. 23(1)] to prevent the escape of dust into the pilot plant area during the removal of the screener assembly. The design criteria call for a dual valve assembly which would function as a separable closure for both the bottom of the shroud and the top of the screener [Fig. 23(2)]. The separation for removal of the screener would provide a closed shroud and a closed screener for minimum release of dust.

Preliminary investigations into the space required for a $1.02 \mathrm{~m}$ (40in.) diameter valve showed that the pilot plant limitations precluded the use of a dual valve. The requirement was, therefore, changed to include a 


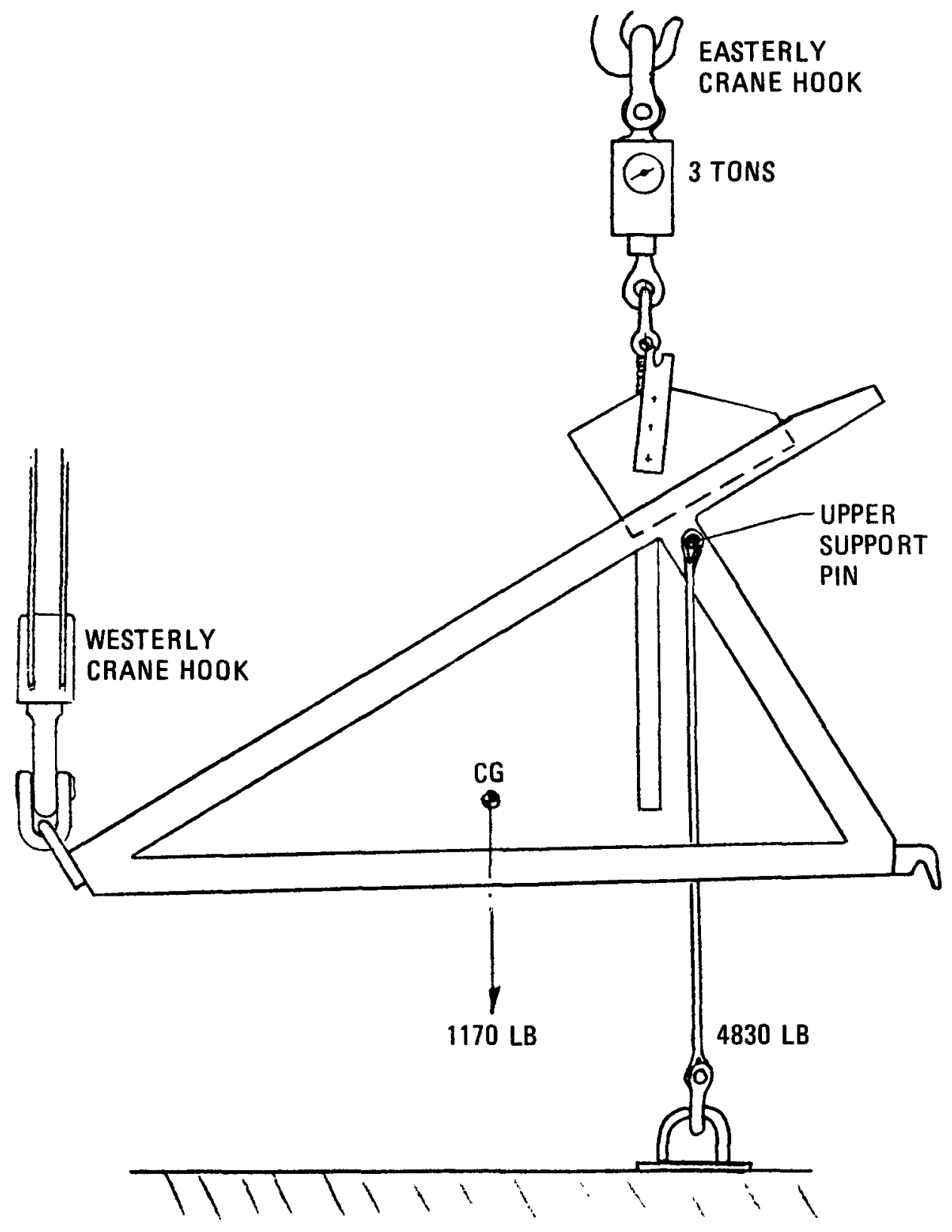

Fig. 22. Pul1-down test for carriage jack (6000 1b); horizontal removal fixture for secondary crusher fixed jaw 


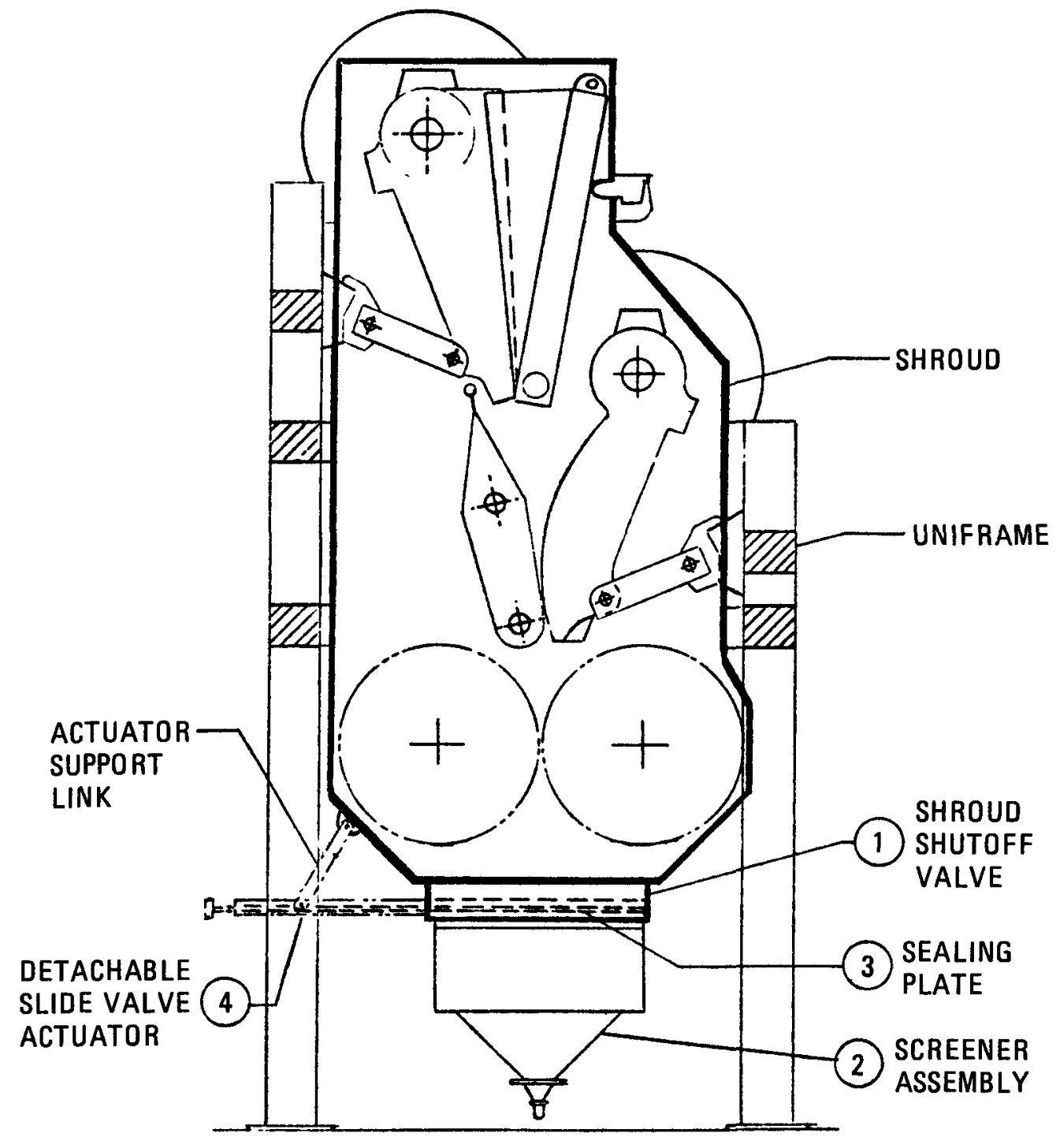

Fig. 23. Location of shroud shutoff valve 
single valve only as a feasibility demonstration in the pllot plant (agreements and commitments from the Design Readiness Review Meeting of February 9, 1976). The principal requirement of the valve is the integrity of the seal at any stage in the opening or closing procedure.

\subsubsection{Design Principles}

Many designs were made in an endeavor to overcome the space restraints. The simplest of these is that employing a flat sealing plate [Fig. 23(3)] that slides across the shroud opening. A sealing surface within the valve body would seal either to the plate or to the lower part of the valve body, depending on whether the valve was closed or open.

The mechanism required to operate the valve [Fig. 23(4)] could be removed in either the open or closed position to facilitate the removal of the assembly. The valve plate and operating mechanism are thus removable for service or disposal. A further advantage is that the operating mechanism does not have to be built to stand the rigors of vibration from the crusher or screener operation.

\subsubsection{Functional Description}

The valve is divided into three subassemblies (Fig. 24). The first is the valve body [termed transition ring assembly (1)], which comprises the link between the shroud (2) and the screener housing (3). The second part of the valve is the slide valve housing (4) which contains the guidance system and feed mechanism for the third part of the valve, the valve plate assembly. The valve plate assembly can thus be housed within the separable slide valve frame assembly when the valve is open, or within the valve when the valve is closed.

The valve body, or transition ring assembly, consists of a vertical cylindrical housing with a bolt flange top and bottom. The housing has a semicircumferential slot (5) near the lower end to accept the sliding valve 


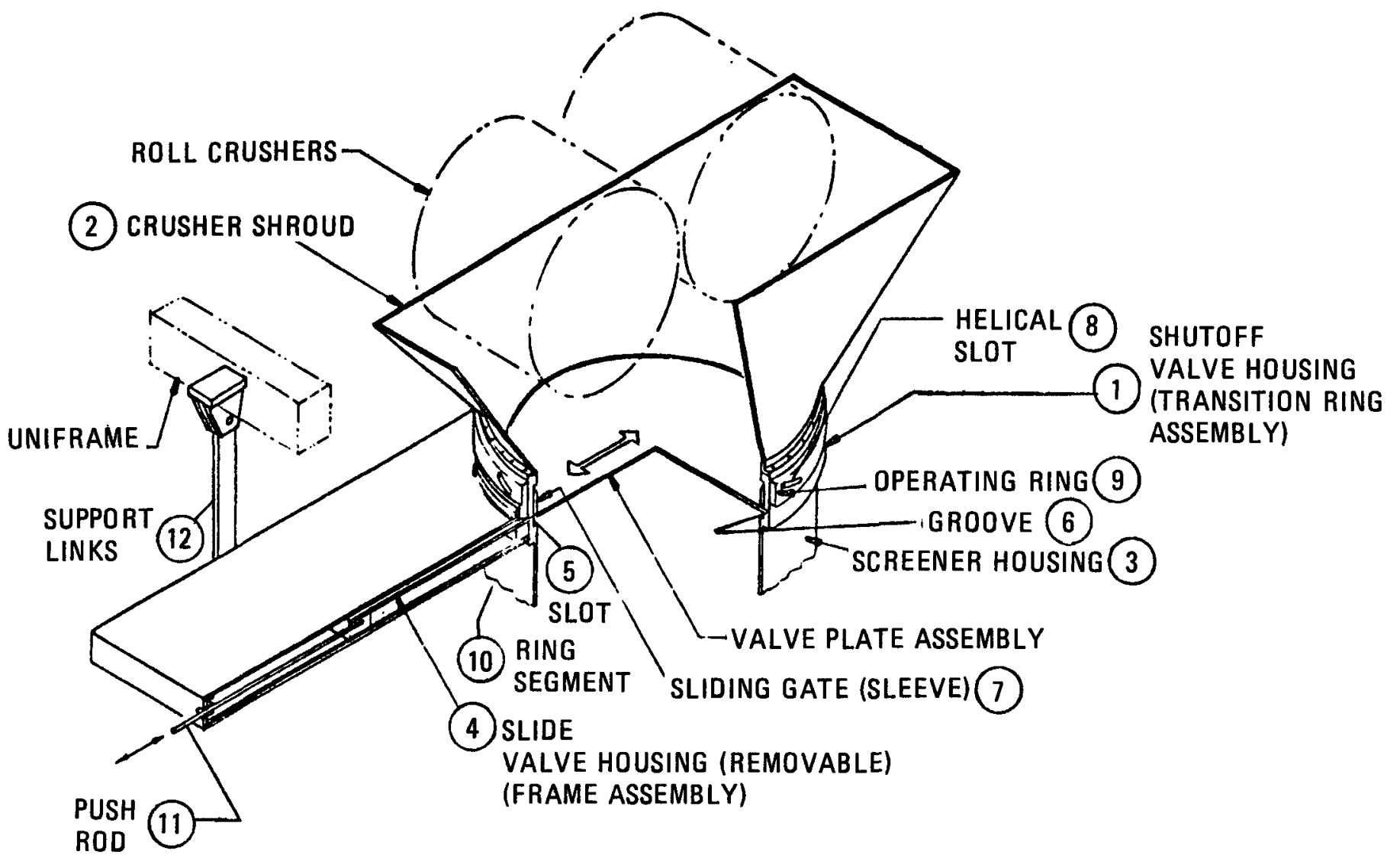

Fig. 24. Crusher shroud shutoff valve 
plate. Dlametrically opposite the slot is a groove (6) machined into the inside wall of the body to support the leading edge of the valve plate when the valve is fully closed.

On the inside of the valve body is a close-fitting split steel sleeve (7), which is located in position by eight radial posts. Each of the posts penetrates the valve wall via a short helically placed slot (8). On the outside wall of the valve body, a second ring (9), called the operating ring, is located on the circle of posts and is secured by eight nuts. When the nuts are loosened, the outer ring can be rotated through a small angle, thus turning the whole assembly in relation to the helical slots. The resultant axial component lifts or lowers the inner sleeve. The design of the inner and outer sleeves prevents uncovering of the helical slots. The lower edge and the periphery of the inner sleeve have sealing surfaces of Grafoil. In service, the lower edge seals against either the sliding plate when the valve is closed or against an internal flange on the valve body when the sliding plate is removed to open the valve. During withdrawal of the valve plate, the seal surface is in light contact with the plate, providing a "squeegee" action to prevent material from escaping via the slot.

A final feature of the valve body is the ring segment (10) located on the lower outside edge, which provides a register for the frame assembly for the slide valve. This housing (4) is a shallow box of rectangular section, the forward end of which is shaped to fit the outside of the valve body. A steel angle forming the mating edge of the frame assembly locates over the ring segment (10) on the valve body and is locked in place by "expando" pins at its extremeties. Teflon pads and rollers for vertical and horizontal alignment of the slide valve plate are spaced along both sides of the inside of the frame assembly. When the frame assembly is in place, the open end fits over the slot in the valve body (transition ring assembly) so that the slide valve plate is aligned and able to slide easily from the frame assembly into the valve body. 


\subsubsection{Reliability}

A detailed fallure analysis has yet to be performed, but the completed stress analysis has revealed no excessive loading likely to cause breakdown. A development program is scheduled to record and analyze problems as a continuing update on rellability techniques.

\subsubsection{Maintenance}

The valve assembly, which forms an integral part of the crusher shroud, is simple and extremely rugged. Routine maintenance of the working metal parts consists only of lubrication. The seal areas will require special attention during the life of the fixture in the prototype pilot plant to establish a maintenance schedule and the suitability of the materials used.

The frame assembly is easily detachable from the shutoff valve and thus presents few maintenance problems. However, experience with the assembly is expected to yield design improvements for simpler maintenance routines.

\subsubsection{Availability}

The shroud shutoff valve will be installed in the crusher frame in the near future and experience will be gained which will allow more accurate predictions of reliability and time schedules for maintenance. At this time, results from a theoretical examination of availability are very positive.

\subsubsection{Safety}

No particular safety hazards are associated with this equipment. Qualified operators will follow the code established in the General Atomic Accident Prevention Program Manual for safe operation. 


\subsubsection{Testing}

Structural tests w1ll be performed after installation because the vibration stresses are generated by the screener assembly and also the crusher machinery during operation. This will be a multimode excitation, both difficult and expensive to generate in a separate laboratory installation.

2.6. DUAL VALVE CONCEPT FOR CRUSHER SHROUD AND SCREENER (DWG. 5820103, APPENDIX C)

\subsubsection{Design Requirements}

The original design criteria called for a double valve to close both the shroud and the screener to prevent propagation of dust during separation. Scope changes due to space considerations have necessitated fabrication of a single valve and the preparation of a proposed layout for a dual valve with suitable means for remote separation. The dual valve design will utilize, as far as possible, the technology of the single valve with whatever modification is necessary to stack two valves and mate them remotely. Thus, the interface is the primary area of concern.

Existing remote handling techniques should be utilized to manipulate the fastenings. Both mating surfaces must be completely clear when interfacing. The fastenings must be capable of carrying the weight of the screener assembly in addition to the lower valve and of withstanding the vibration generated by the screener and crusher machinery.

\subsubsection{Design Principles}

The first approach considered for securing the two valves at the interface was to use commercially avallable toggle clamps. These are simple in use but bulky, and space is of primary concern. The simplest union considered was that utilizing a ring of captive bolts through the lower valve into the flange on the upper valve. The problem with this 
approach is that blind location of a sultable remotely operated tool would be difficult, especially since the heads of the screws would have to be recessed beyond the lower valve slot. A new simply operated latch must be sought, preferably a toggle mechanism which will be carried clear of the mating surface in one simple movement.

The first system selected utilizes a rotatable eccentric bushing to provide the closure stroke with a transition to friction drive to move the latch clear of the surface as soon as it has unclamped. The resilience required for overtravel is to be provided as a feature of the design. An alternative design is a U-shaped clamp, which has tapered jaws to provide a squeeze action perpendicular to the valve joint face.

\subsubsection{Functional Description (Dwg. 5820103, Appendix C)}

Each component of the dual valve design is fundamentally the same as the shroud shutoff valve described in Section 2.5.2. The lower or screener valve has been lengthened by $22.9 \mathrm{~mm}$ ( $0.9 \mathrm{in.}$ ) in order to provide sufficient space to accommodate the fastenings.

In the first system, the remotely operable fastenings are rotatable latches (F1g. 25) mounted near the upper surface of the screener valve (1). The lower part of the shroud valve (2) is provided with a corresponding set of passive latch plates (3). The principle of each independent latch is as follows. A spindle (4) fixed radially into the wall of the screener valve carries an eccentric bronze bushing (5) which is captured but free to rotate on the spindle. The steel latch body (6) rides on the outside diameter of the eccentric bushings and is also free to turn. Fixed into one end of the latch body is a short post with an assembly of Bellville washers (7) secured to its outer end, forming a spring of high compression rate.

Across the free end face of the bronze eccentric bushing is a rectangular slot (8) provided for the engagement of a handling tool to rotate the bushing. To close the fastening from its "clear" position (Fig. 25a), a handling tool is engaged with the eccentric bushing and the bushing is 

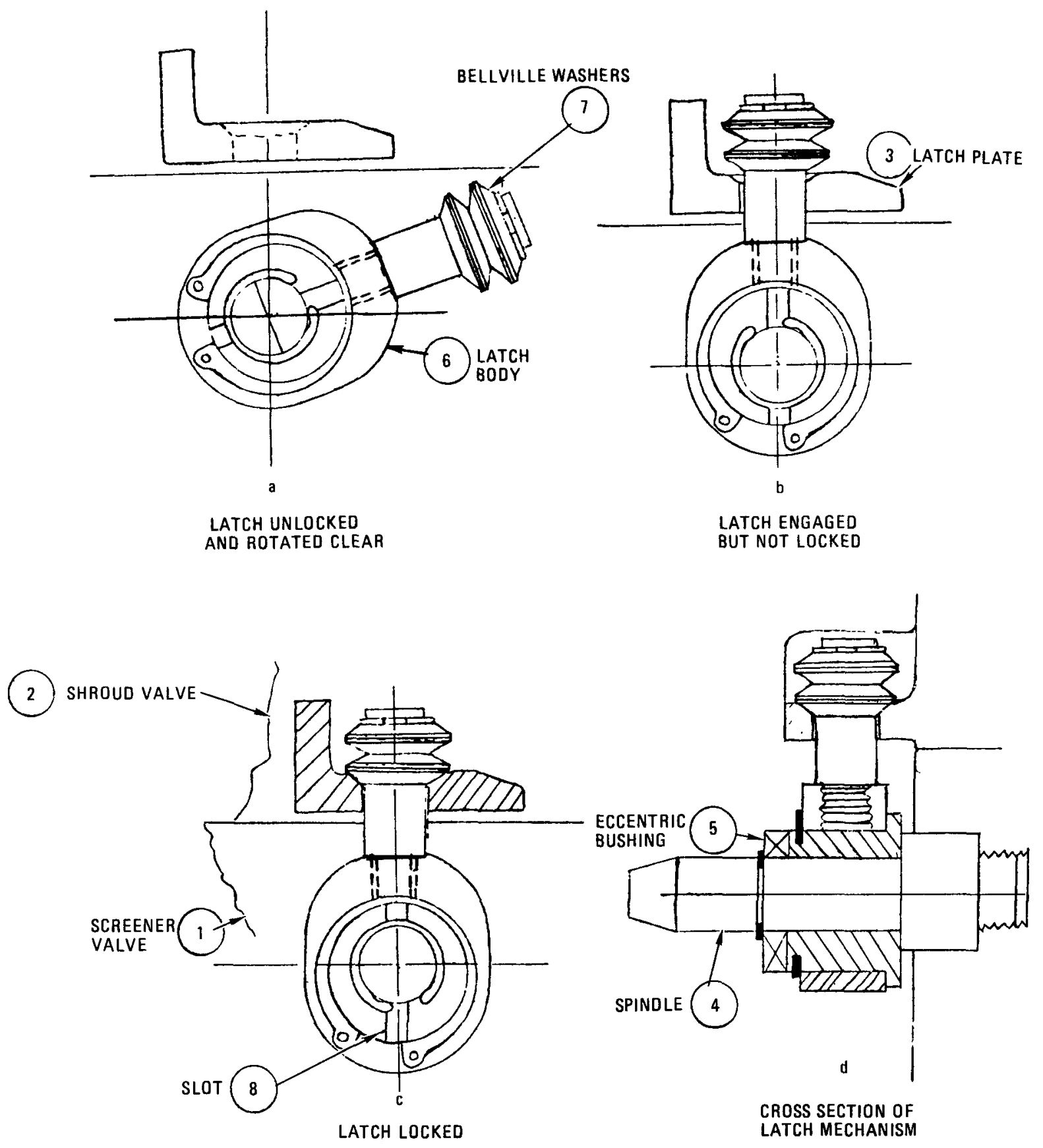

Fig. 25. Latch mechanism for crusher shroud and screener shutoff valves 
rotated. At first the friction between the outside of the bushing and the inside of the latch body will drag the latch around with the bushing. When the post on the latch body engages the end of the slot in the latch plate (Fig. 25b), the friction will be overcome and the eccentric bushing will revolve relative to the latch body. This action will draw the post downward until the lower Bellville washer seats in the recess in the catch plate. Further rotation of the eccentric bushing pulls the latch body down until the spring is compressed.

The final position of the eccentric bushing against its stop is "over center," allowing a slight relaxation of the spring. This ensures that no component of vibration can back the eccentric bushing against the spring. A further security lies in the capture of the bottom Bellville washer in the recess in the latch plate. Unlatching is the reverse rotation, which reverses the whole process.

The alternative latch is shown in Appendix C, Dwg. 5820103 at the right-hand side of the layout. The clamp (17) is U-shaped with tapered "jaws" which are designed to interface with tapered flanges on the two mating valves. A through bolt (19) draws the tapered jaws firmly into contact with the machining flanges. This action develops a component perpendicular to the draw bolt centerline and perpendicular to the valve flanges. The clamp is designed to rotate about the bolt when open so that as the clamp is drawn clear by the thrust transmitted by the retaining ring (16), it will tend to rotate with the bolt until it occupies a position against the stop pins (18) (shown in the unlatched view on the right of the layout).

\subsubsection{Recommendations}

As the proposal utilizes the duplicated basic design of the shroud shutoff valve now under construction, the only section which remains to be tested is the remote fasteners. At least one of these should be constructed for evaluation. 


\section{SUMMARY}

The foregoing sections have documented the engineering activities associated with the six semiremote handling fixtures for the size reduction system. Selection of the specific fixtures described was based upon the following parameters:

1. Process Equipment Configuration. The UNIFRAME crushing system was primarily designed to evaluate the crushing concepts and, although some concessions were made to remote maintenance, this was necessarily a secondary consideration. The equipment for semiremote handling was thus constrained to operate within the parameters set by the crushing system.

2. Pilot Plant Handling Requirements. The operation of the semiremote handing fixtures within the confines of the pilot plant area, using only the facilities and utilities available, formed a second set of design parameters.

3. Semiremote Hand1ing Demonstration. Selected fixtures were designed to demonstrate semiremote operations or techniques that were unique to the equipment. A semiremote philosophy was adopted whereby manual assistance could be employed to locate, align, or actuate the fixture. This approach was utilized where it could be judged that the manual operations required could be accomplished with the aid of conventional remote technology.

The fixtures described in this report were selected on the basis of the foregoing constraints and also the need to provide handing capability for use during the assembly and tests of the crusher system. 
This represents the initial phase of the development of a maintenance philosophy in which the remote maintenance is an integral part of the process equipment. Each section of the report contains specific recommendations for future design activities associated with the existing fixtures.

During FY-77 extensive development testing will be performed on the UNIFRAME. In addition, a program of design evaluation and maintainability analysis will be conducted to establish a baseline availability projection for the system. The results of these operations and design activities will be used to establish design upgrade requirements and indicated design improvements. Since this may modify the requirements for handling fixtures and possibly make current designs obsolete, any further development of current designs would not be justified at this time.

It is recommended that FY-77 remote activity be directed toward utilization of existing fixtures as required to obtain additional operating experience and toward identification of an overall maintenance specification for an upgraded UNIFRAME, from which the need for special remote tools and fixtures can be established. 


\section{ACKNOWLEDGMENTS}

The author wishes to thank all of the technicians, especially A. L. Gasparovic and A. H. Bond, for their expert assistance during the initial installation and operation of the crusher semiremote handling fixtures. A major part of the conceptual and design work is due to the efforts of R. W. Kee, W. C. Schmucker, J. Jack, and J. Teren. 
•

• 
APPENDIX A

DESIGN DOCUMENT INDEX 
GA 541 (Rev 5/74)

\section{GENERAL ATOMIC COMPANY}

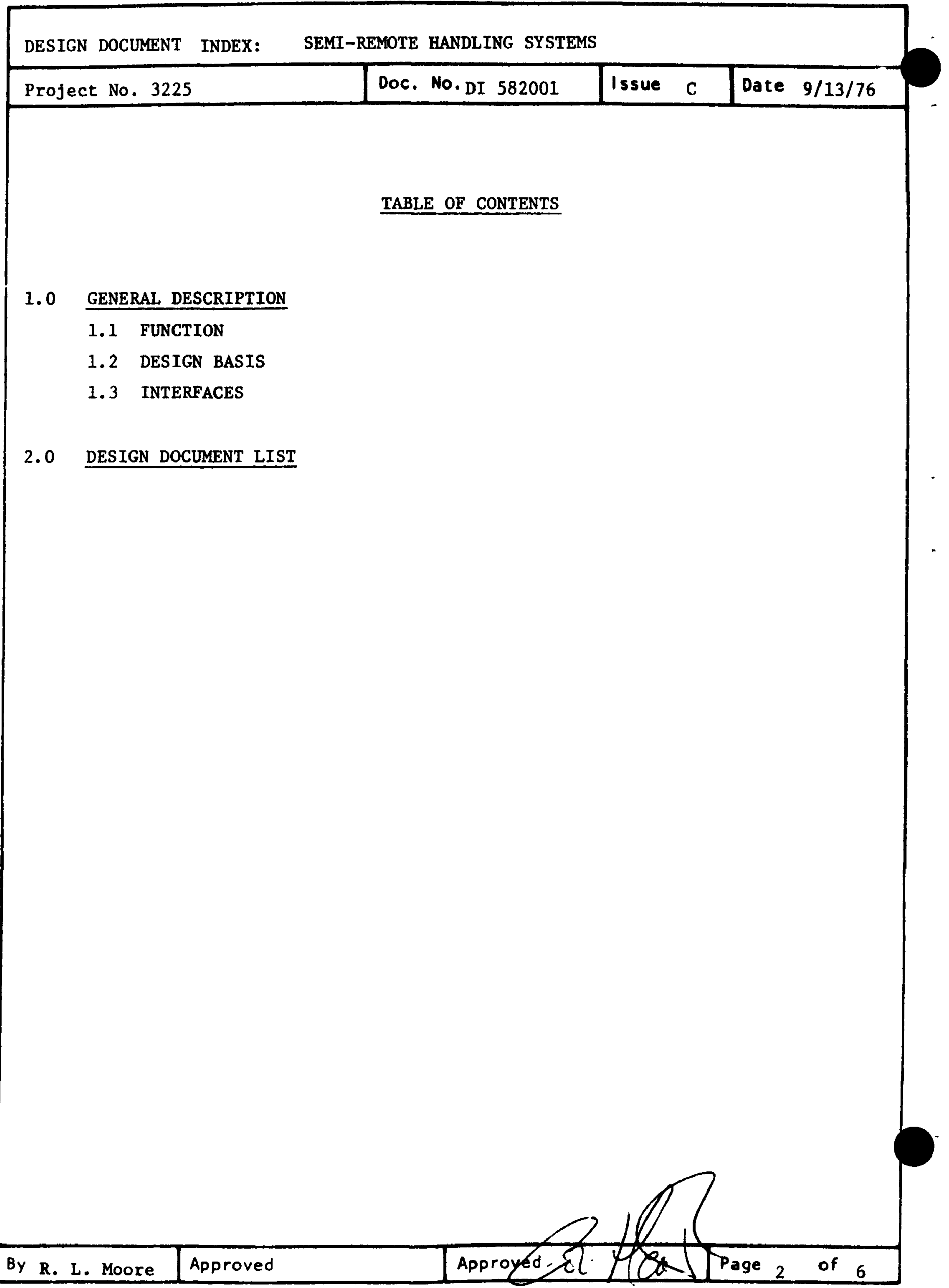


DESIGN DOCUMENT INDEX: SEMI-REMOTE HANDLING SYSTEMS

Proj. 3225

Doc. No. DI 582001

Issue $\mathrm{C}$

Date

$9 / 13 / 76$

\subsection{GENERAL DESCRIPTION}

\subsection{Function}

1.1.1 The semi-remote handling systems will be used to demonstrate the semi-remote assembly, disassembly and manipulation of specified parts and assemblies of the Fuel Element Size Reduction System (DI 521001), the 40-cm (16 1n.) Primary Burner (DI 524401) and the 20-cm ( 8 in.) Secondary Burner (DI 524701).

1.1.2 Semi-remote assembly or disassembly uses personnel to align and position a handling fixture to the plece of equipment that is to be moved, lifted or lowered.

\subsection{Design Basis}

1.2.1 The design of the fixtures and mechantsms that comprise the semiremote handling system shall be based on the size, shape and weight of the parts and assemblies to be handled and shall provide for the alignment, orlentation, and other manipulation of the parts and assemblies as required.

1.2.2 The design shall accommodate the slze, shape and location of hooks, lugs, connectors and other Interfaces on the parts and assemblies to be handled.

1.2.3 The handling systems to be incorporated Into the Reprocessing Pilot Plant will be those systems for which semi-remote operations require spectalized designs or techniques that have not been previously demonstrated.

1.2.4 The high radiation environment of a nuclear fuel reprocessing plant shall be considered, however, materials not suitable for a high radiation environment may be used to demonstrate semiremote handling in the pilot plant.

\subsection{Interfaces}

The fixtures and mechanisms that comprise the semi-remote handling systems shall be sized and otherwise designed to be compatible with the pllot plant layout, the pilot plant equipment and the pilot plant ut1lities and services. 
GA $541(\operatorname{ReV} 5 / 74)$

\section{GENERAL ATOMIC COMPANY}

DESIGN DOCUMENT INDEX: SEMI-REMOTE HANDLING SYSTEMS

Project No. 3225

Doc. No. DI 582001

Issue $\mathrm{C}$

Date $9 / 13 / 76$

\subsection{DESIGN DOCUMENT LIST}

The following list contains those documents, specifications and drawings that describe the semi-remote handling systems. 


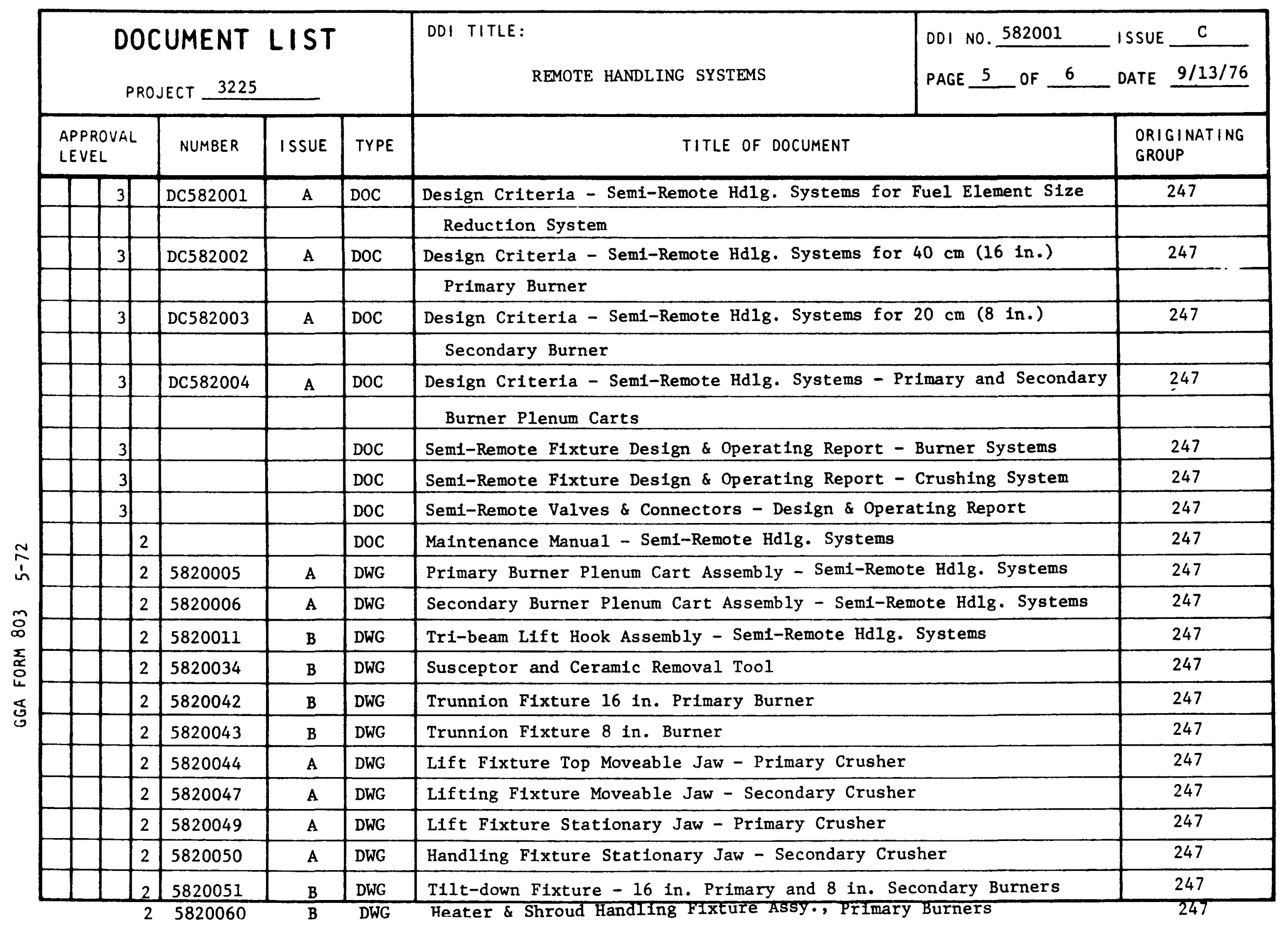




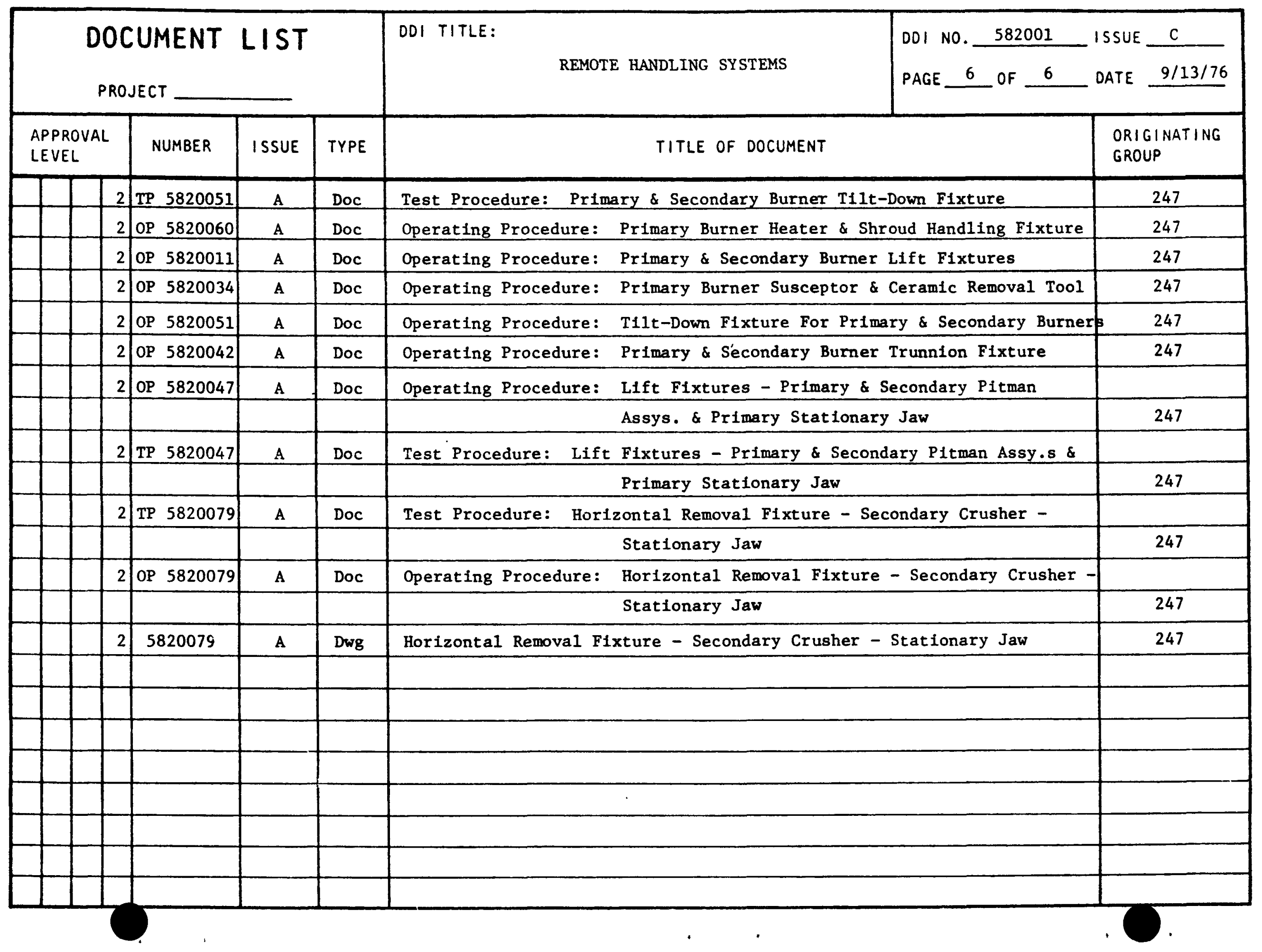


APPENDIX B

DESIGN CRITERIA 
GA $541(\operatorname{Rev} 5 / 74)$

\section{GENERAL ATOMIC COMPANY}

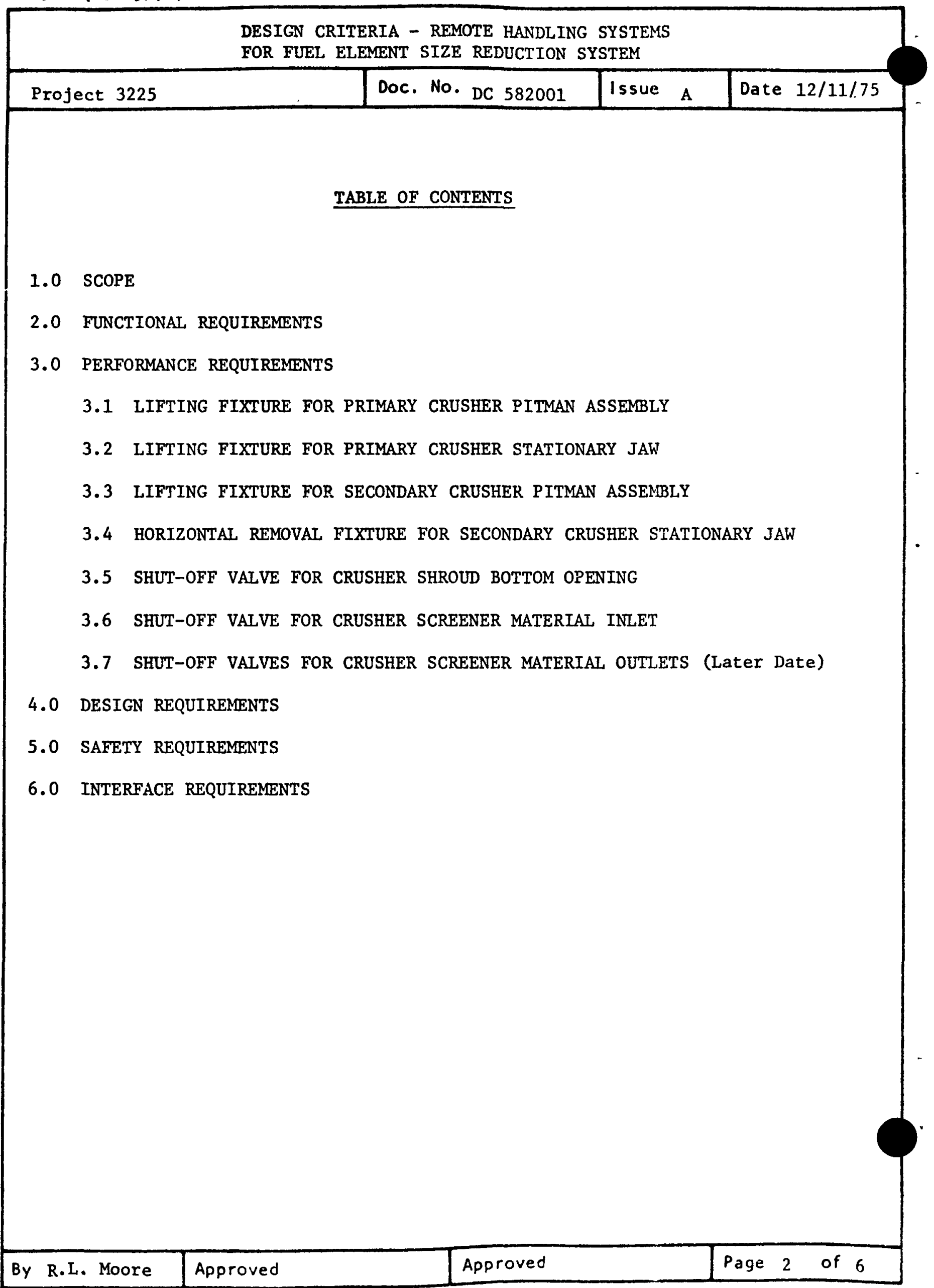




\title{
GENERAL ATOMIC COMPANY
}

\author{
DESIGN CRITERIA - REMOTE HANDLING SYSTEMS \\ FOR FUEL ELEMENT SIZE REDUCTION SYSTEM \\ Project 3225 \\ DoC. No. DC 582001 \\ Issue A \\ Date $12 / 11 / 75$

\subsection{SCOPE} \\ This document, together with the documents referenced in the sections that \\ follow, defines the design criterla for the Remote Handling Systems for the Fuel \\ Element Size Reduction System.

\subsection{FUNCTIONAL REQUIREMENTS}

2.1 The specialized handling fixtures and the shut-off valves, that comprise the remote handling system w11l be used to demonstrate the semi-remote assembly and disassembly of specifled parts and assemblies of the Fuel Element Size Reduction System as defined by Design Document Index (DDI 521001).

2.2 Semi-remote assembly or disassembly uses personnel to align and position a handling fixture to the piece of equipment that is to be moved, lifted or lowered.

\subsection{PERFORMANCE REQUIREMENTS}

\subsection{Lifting Fixture for the Primary Crusher Pitman Assembly}

3.1.1 The lifting fixture shall be designed to demonstrate, when used with the pilot plant bridge crane, the semi-remote removal of the pitman assembly from the UNIFRAME assembly and the semt-remote installation.

3.1.2 The entire pitman assembly consisting of the shaft, jaw, toggle, sleeves, bushings, out board bearing assemblies, oil reservoirs and flywheels shall be handled as a unit by the lifting fixture.

\subsection{Lifting Fixture for the Primary Crusher Stationary Jaw Assembly}

3.2.1 The lifting fixture shall be designed to demonstrate, when used with the pllot plant bridge crane, the semi-remote removal of the stationary jaw assembly from the UNIFRAME assembly and the semi-remote reinstallation.

3.2.2 The entire stationary jaw assembly consisting of the jaw, shafts, and cheekplates shall be handled as a unit by the lifting fixture. 


\section{GENERAL ATOMIC COMPANY}

DESIGN CRITERIA - REMOTE HANDLING SYSTEMS

FOR FUEL ELEMENT SIZE REDUCTION SYSTEM

Project 3225

Doc. No. DC 582001

Issue A

Date $12 / 11 / 75$

\subsection{Lifting Fixture for the Secondary Crusher Pitman Assembly}

3.3.1 The lifting fixture shall be designed to demonstrate, when used with the pilot plant bridge crane, the semi-remote removal of the pitman assembly from the UNIFRAME assembly and the semi-remote reinstallation.

3.3.2 The entire pitman assembly consisting of the shaft, jaw, toggle, sleeves, bushings, outboard bearing assemblies, oil reservoirs and flywheels shall be handled as a unit.

3.4 Horizontal Removal Fixture for the Secondary Crusher Stationary Jaw Assy. 3.4.1 The removal fixture shall be designed to demonstrate, when used with the appropriate pilot plant equipment, the semi-remote removal of the stationary jaw assembly from the UNIFRAME assembly and the semiremote reinstallation.

3.4.2 The entire stationary jaw assembly consisting of the jaw, shafts, and cheekplates shall be handled as a unit by the lifting fixture.

\subsection{Shut-Off Valve for Crusher Shroud Bottom Opening}

3.5.1 The shut-off valve shall be designed to demonstrate the semiremote closure of the bottom opening in the UNIFRAME shroud.

3.5.2 The shut-off valve and the associated seals shall be designed to prevent the escape of dust into the pilot plant atmosphere when the shutoff valve is either open or closed and minimize the escape of dust during the opening or closing of the shut-off valve.

3.5.3 The lower portion of the shut-off valve shall be designed as the top half of a separation joint, which will demonstrate the semi-remote attaching and detaching of the screener.

3.5.4 The shroud shut-off valve and the screener shut-off valve (section 3.6) will be opened and closed simultaneously by a mechanism. 


\begin{tabular}{|l|l|l|l|}
\hline Project 3225 & Doc. No. DC 582001 & Issue A & Date 12/11/75 \\
\hline
\end{tabular}

3.5.4.1 The mechanism shall be designed to demonstrate connection to and disconnection from the shroud and screener shut-off valves in either the open or closed position.

\subsubsection{The mechanism shall be designed to demon-} strate semi-remote connection to the seal system, operation of the seal system and disconnection from the seal system.

\subsubsection{The mechanism shall be designed as a unit}

that can be attached to or alfgned with the UNIFRAME assembly.

\subsection{Shut-off Valve for Crusher Screener Material Inlet}

3.6.1 The shut-off valve shall be designed to demonstrate the semiremote closure of the top opening of the screener.

3.6.2 The shut-off valve and associated seals shall be designed to prevent the escape of dust into the pilot plant atmosphere when the shut-off valve is either open or closed and minimize the escape of dust during the opening or closing of the shut-off valve.

3.6.3 The upper portion of the shut-off valve shall be designed as the bottom half of a separation joint which will demonstrate the semiremote attaching and detaching of the screener.

\subsection{DESIGN REQUIREMENTS}

The spreader bars, lifting beams and other structural members of the remote handling systems shall be designed in accordance with the specifications and codes of the American Institute of Steel Construction (AISC) "Manual of Steel Construction," except that the design load shall be twice the actual load and include the weight of the lifting fixtures involved. 
GA $541(\operatorname{Rev} 5 / 74)$

\section{GENERAL ATOMIC COMPANY}

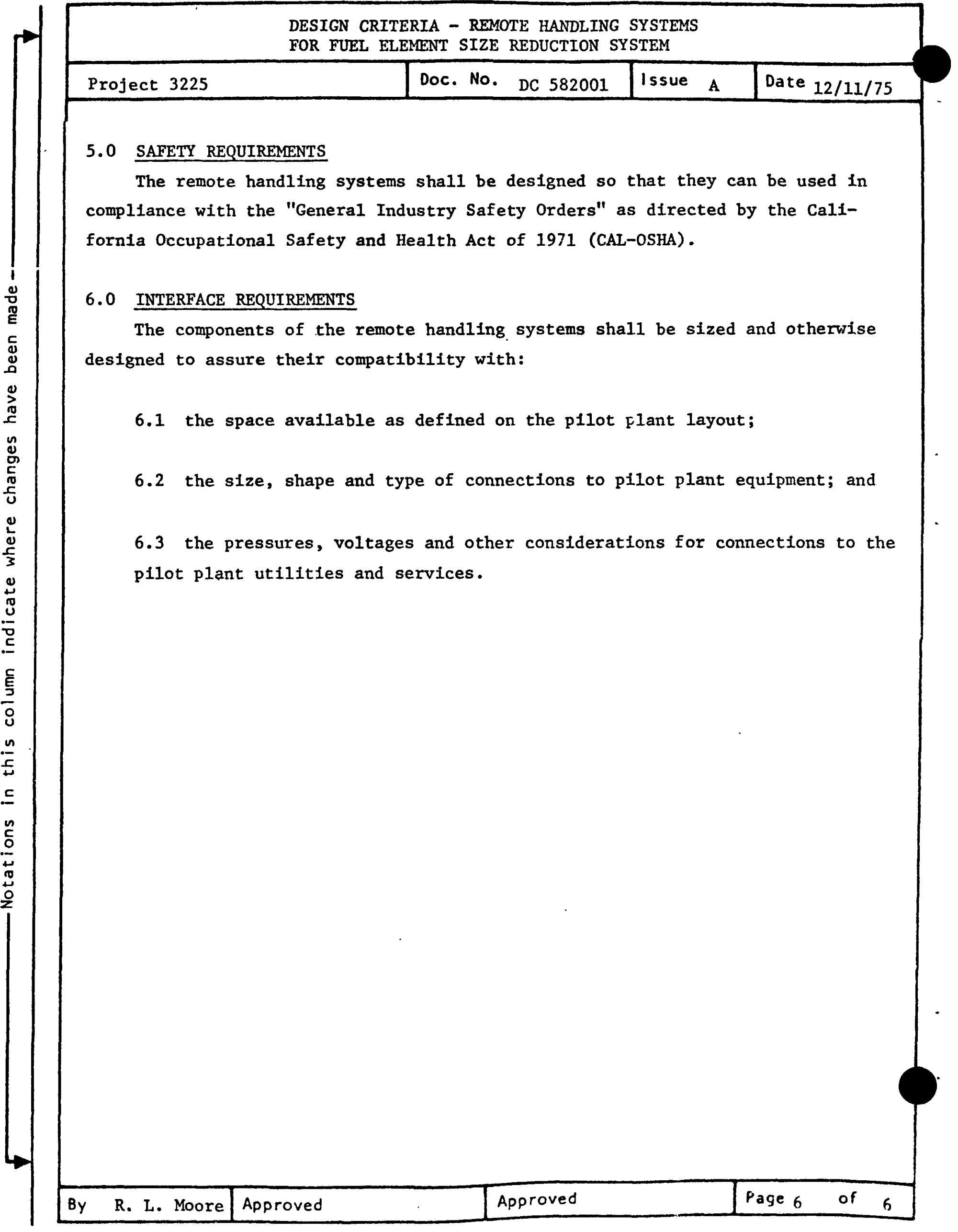




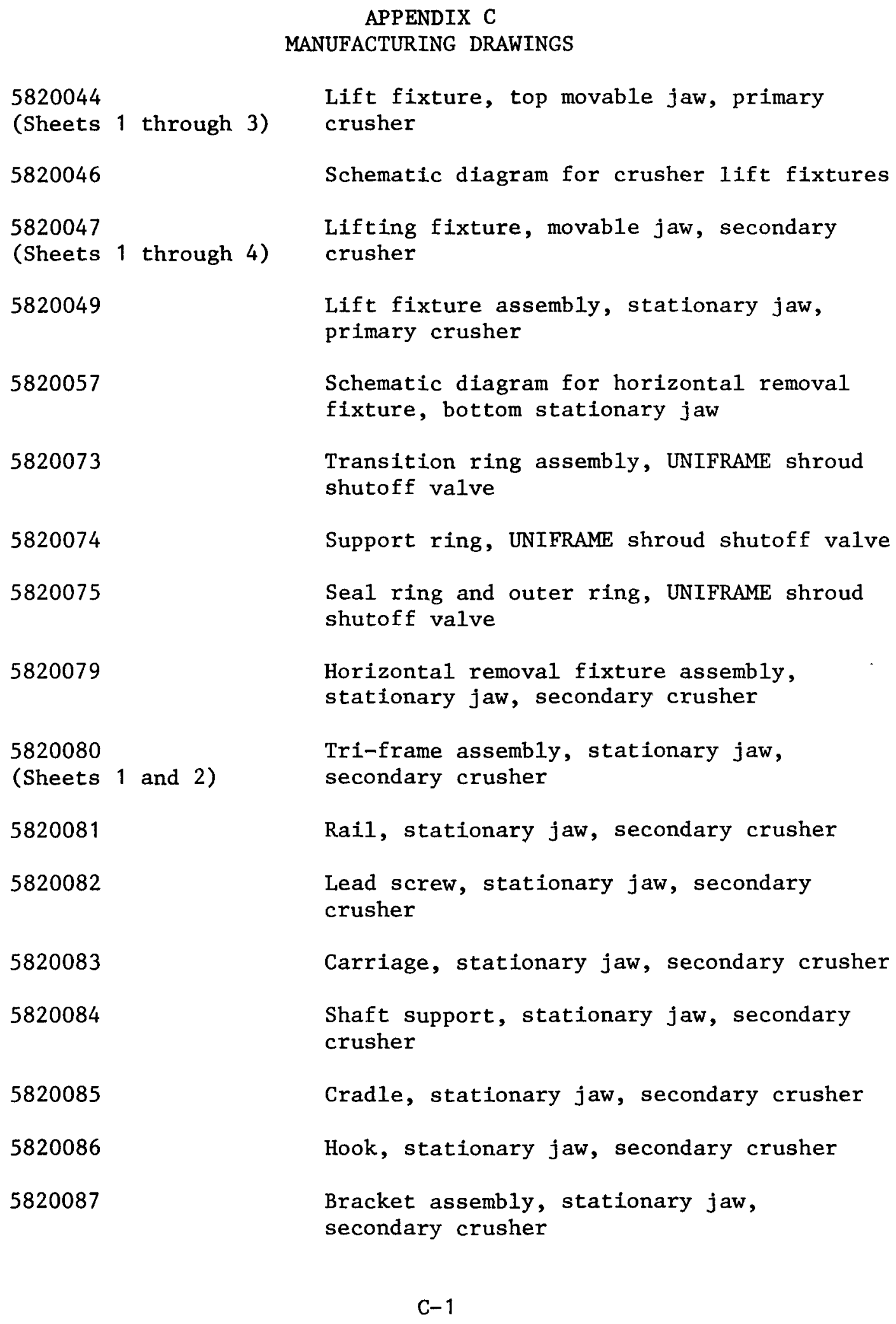


5820088

5820089

5820090

5820091

5820092

5820093

5820094

5820095

5820096

5820098

5820099

(Sheets 1 and 2)

5820100

5820101

5820102

5820103

5820104

5820105

5820106

5820107

5820108
Channel, stationary jaw, secondary crusher Clevis, stationary jaw, secondary crusher Slide, stationary jaw, secondary crusher Pivot bracket, stationary jaw, secondary crusher

Support ring, weldment shroud, shutoff valve

Rotary disc, stationary jaw, secondary crusher

Torque arm, stationary jaw, secondary crusher

Eccentric, stationary jaw, secondary crusher

Screw, modified, stationary jaw, secondary crusher

Ring segment, UNIFRAME shroud shutoff valve Slide valve assembly

Frame assembly, slide valve assembly

Cover assembly, slide valve assembly

Details, slide valve assembly

Dual valve for crusher shroud and screener, outline

Shaft, microswitch, stationary jaw, secondary crusher

Shaft, connector, stationary jaw, secondary crusher

Bracket, microswitch, stationary jaw, secondary crusher

Retainer, stationary jaw, secondary crusher

Schematic diagram, secondary fixed jaw removal fixture 
APPENDIX D

OPERATING PROCEDURE FOR HORIZONTAL REMOVAL FIXTURE FOR SECONDARY CRUSHER FIXED JAW 
• 


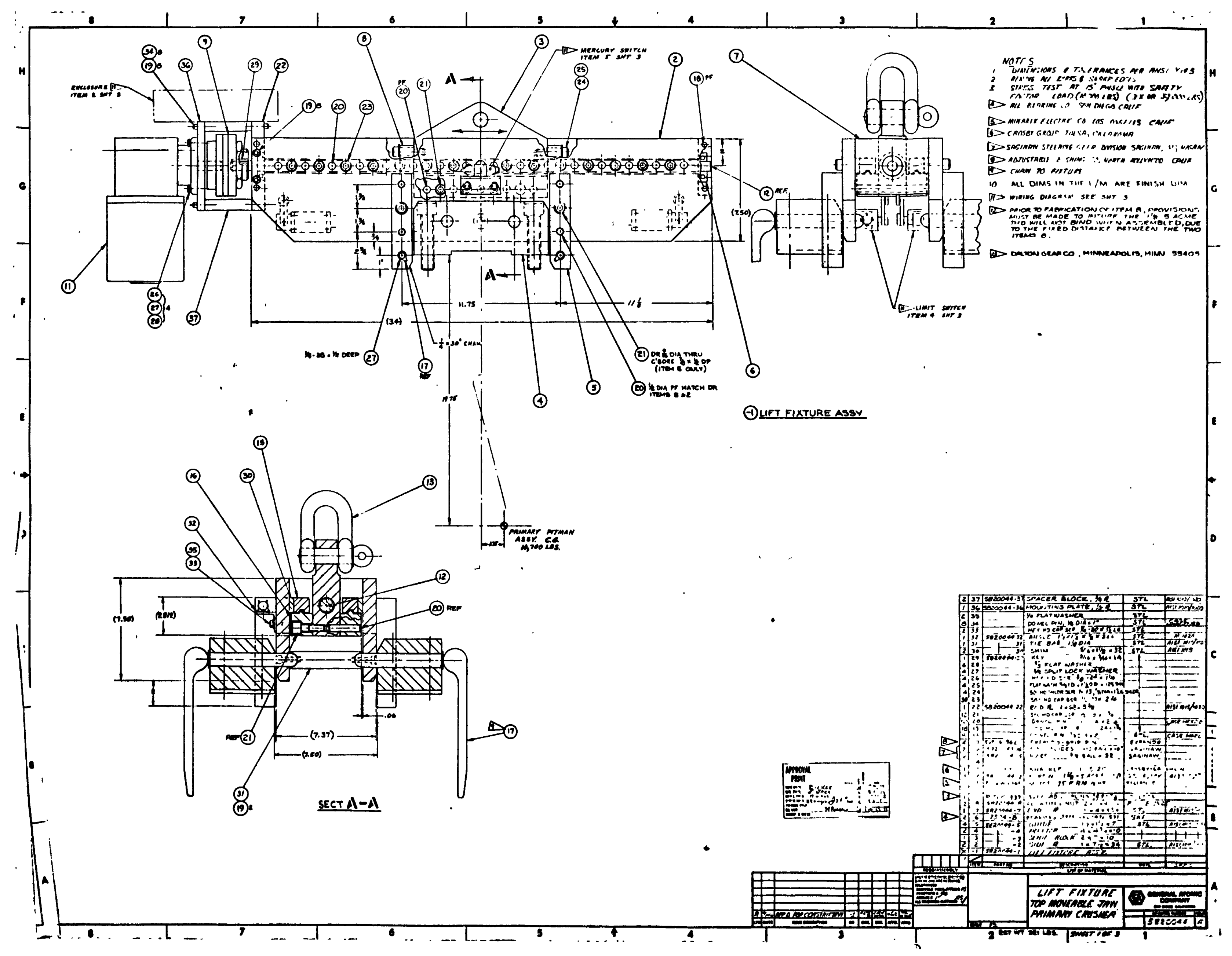




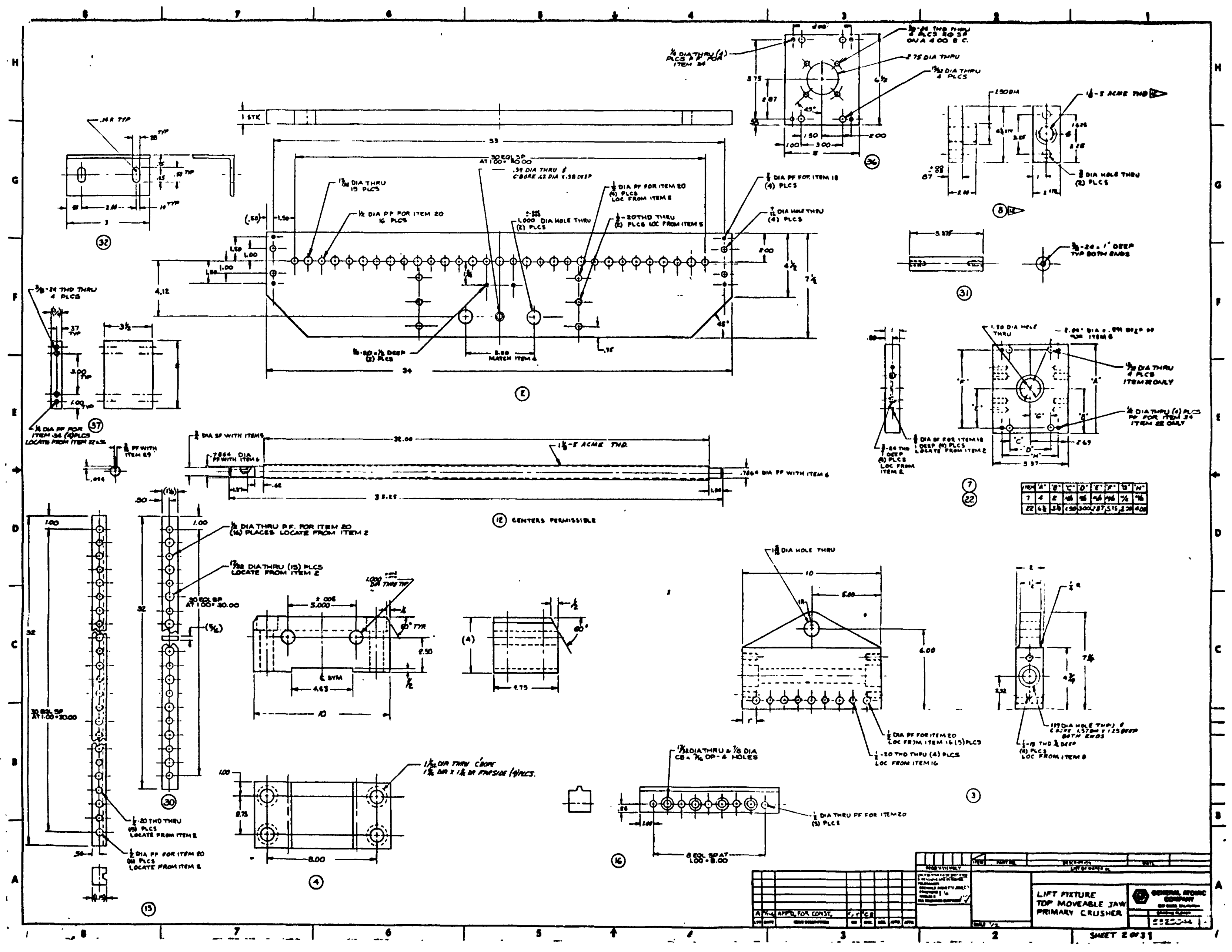




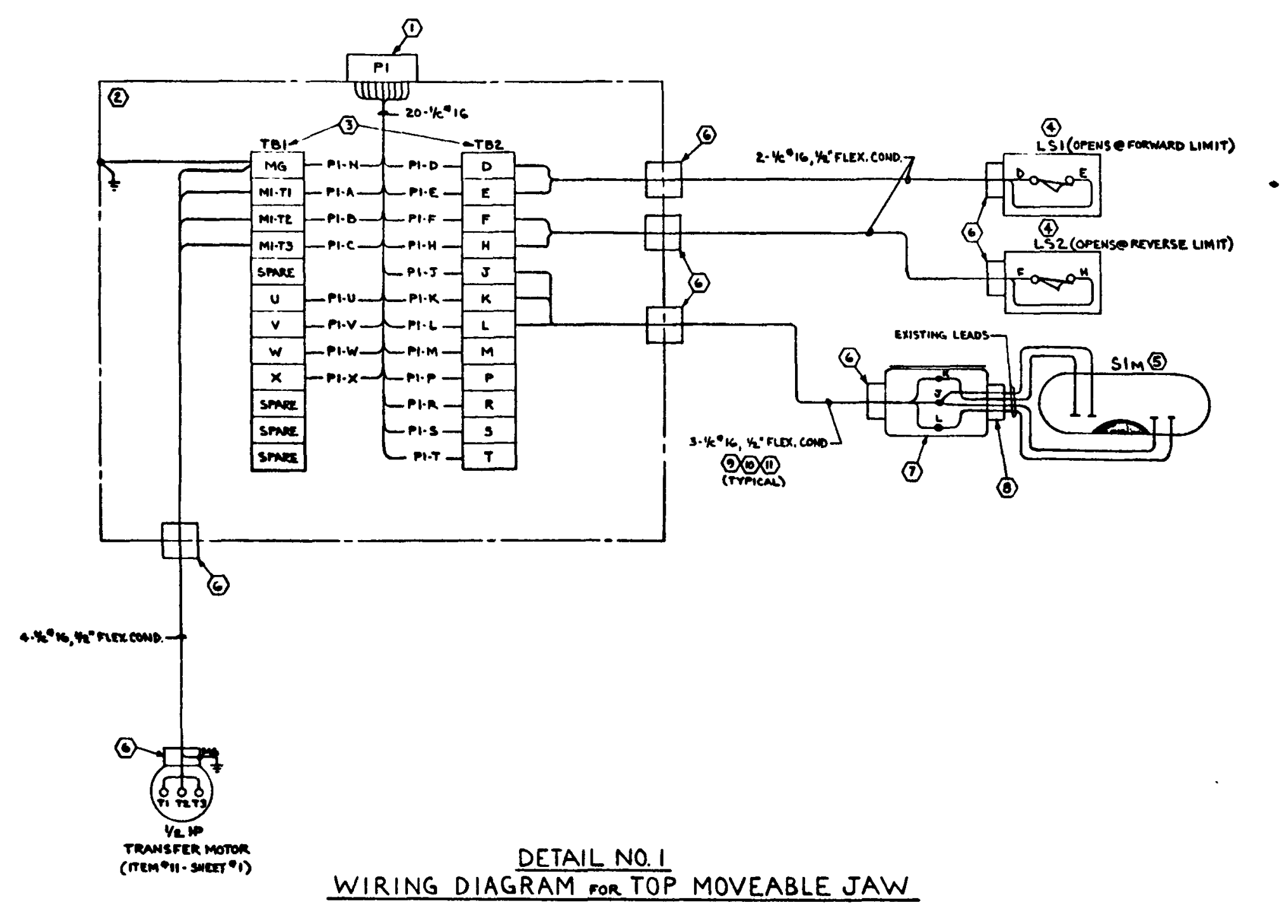

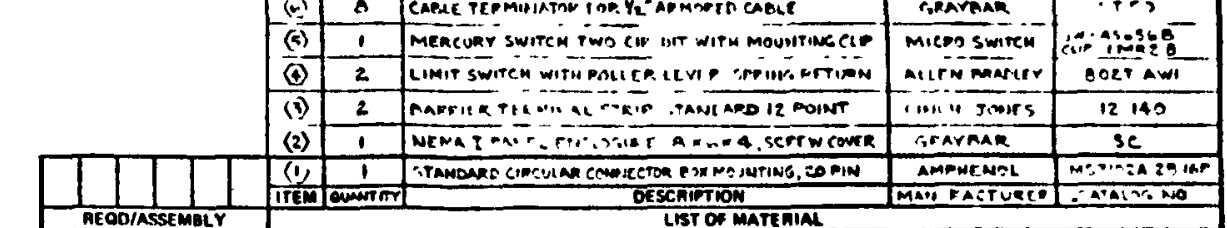

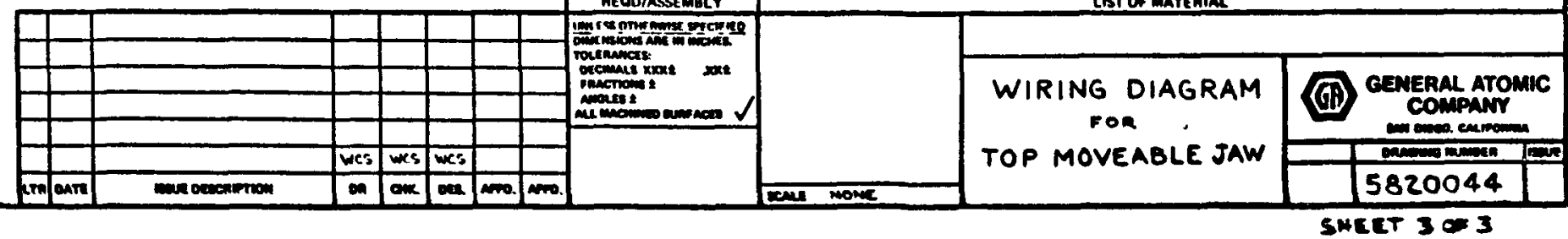




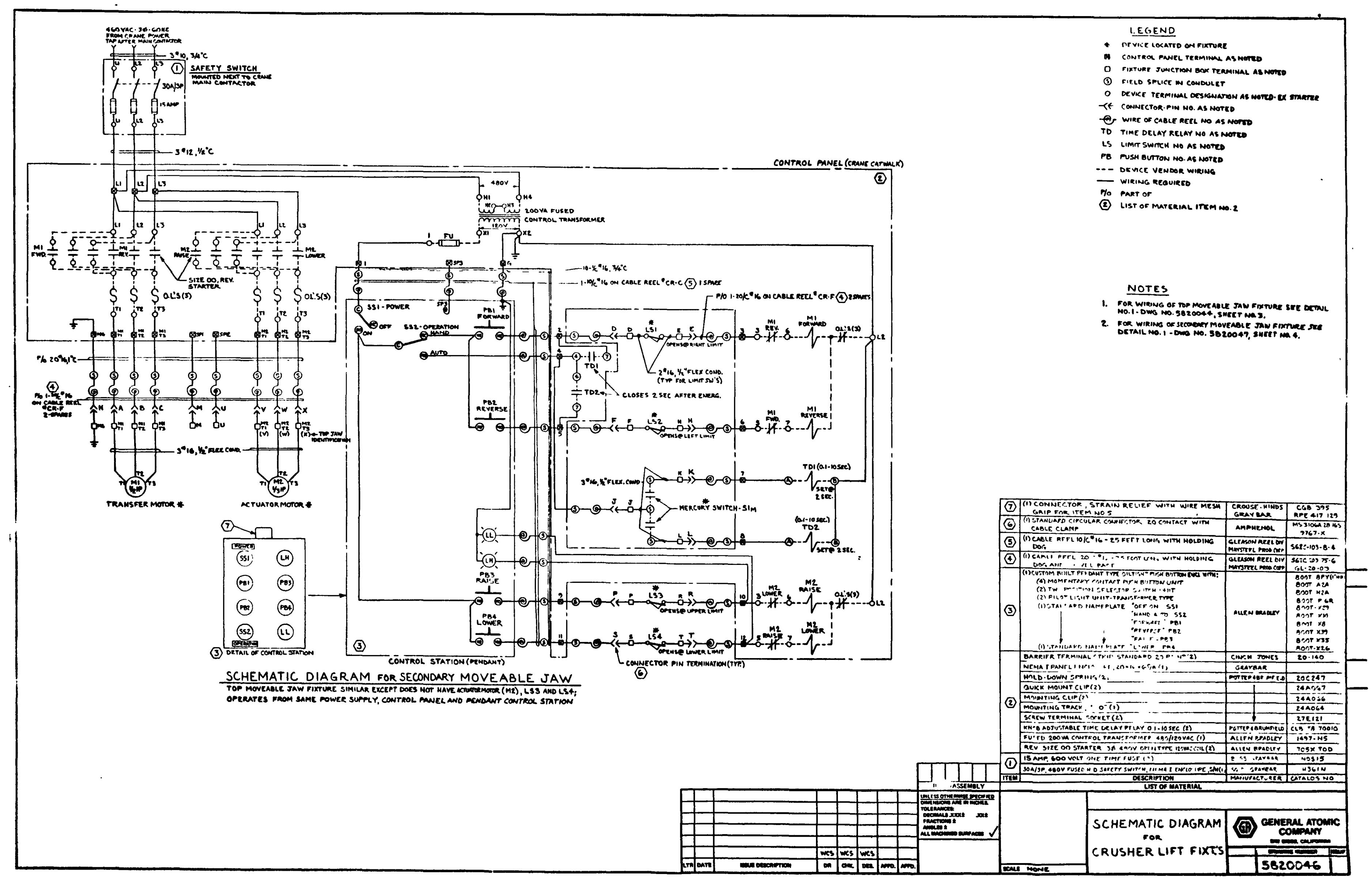




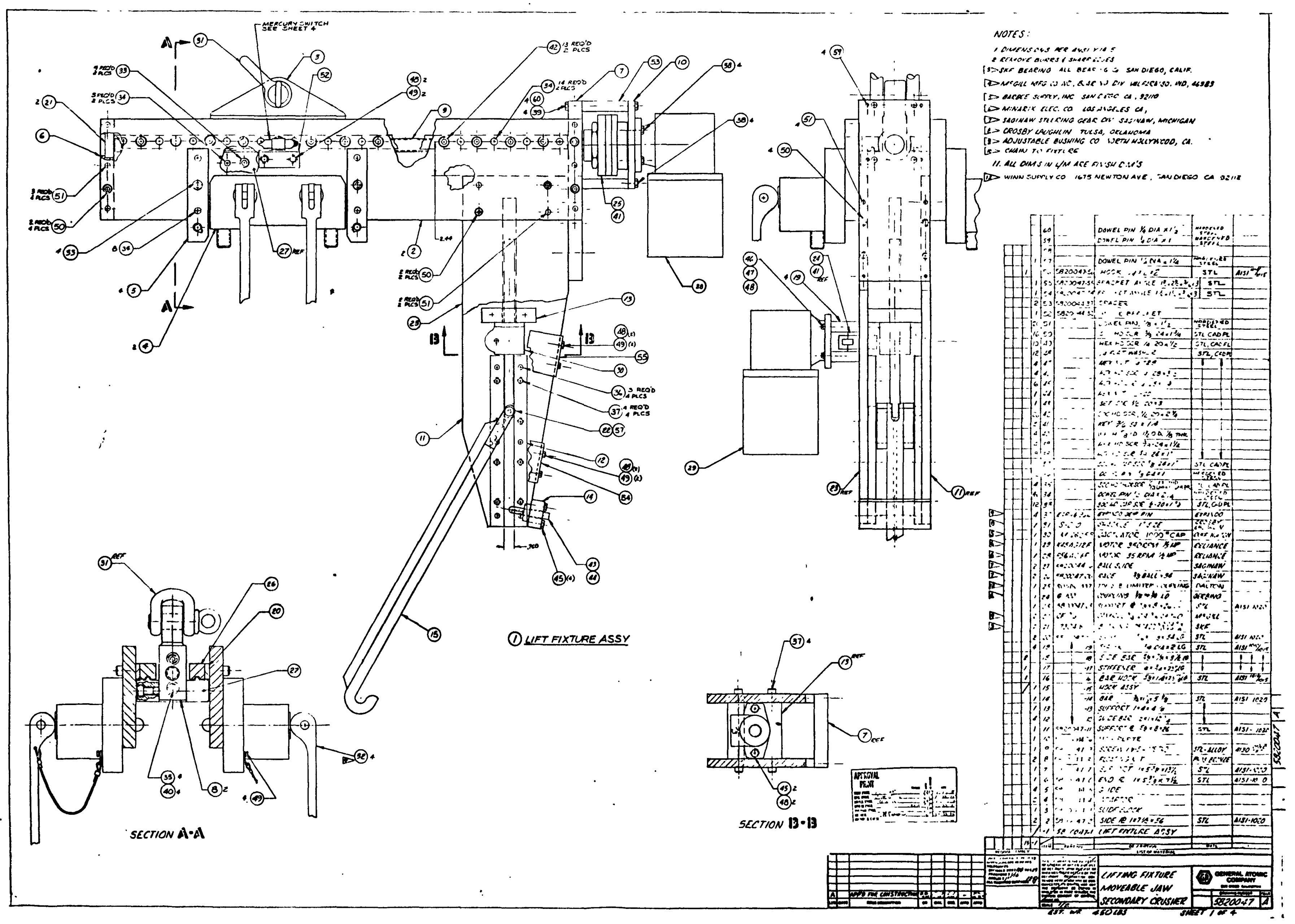




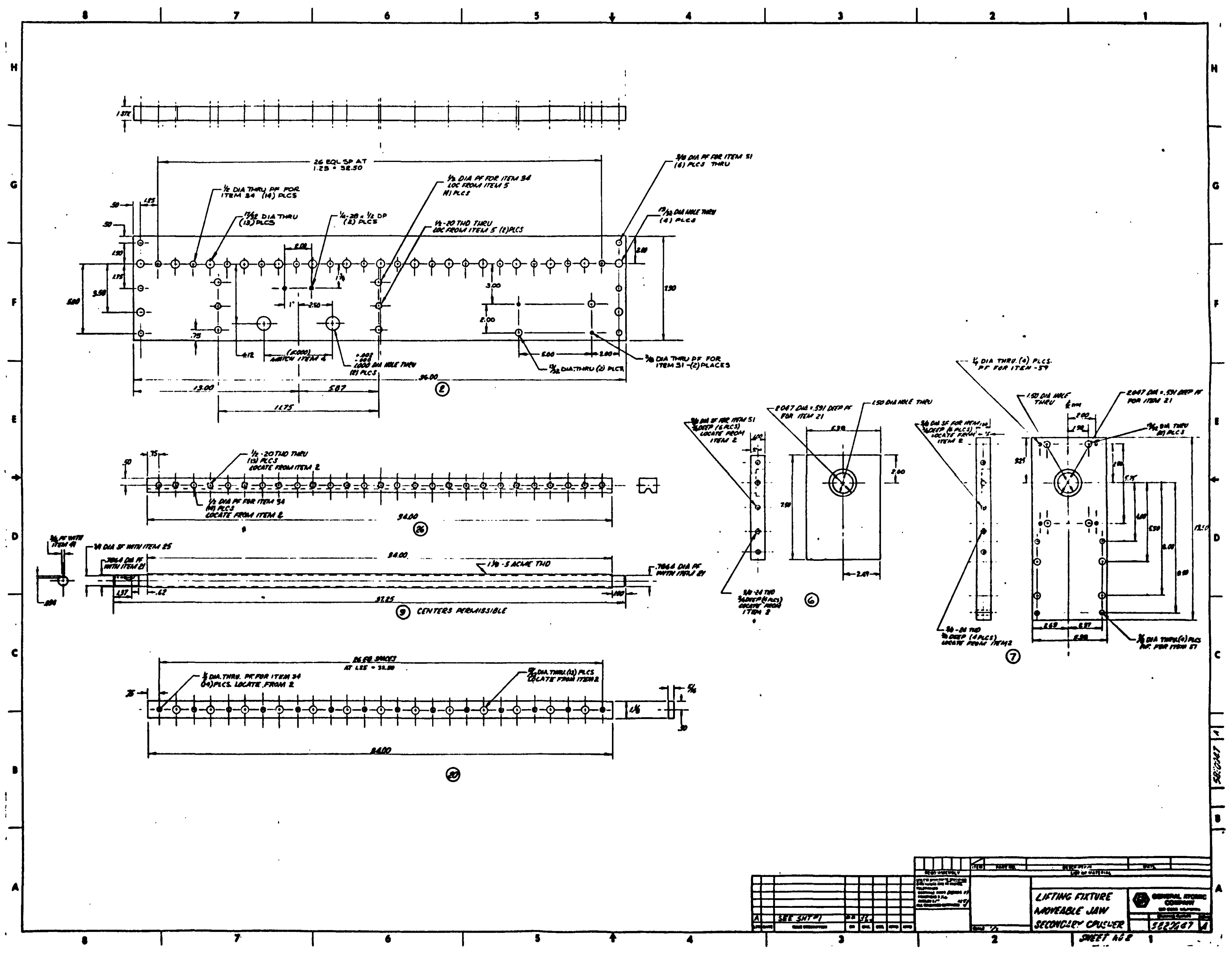




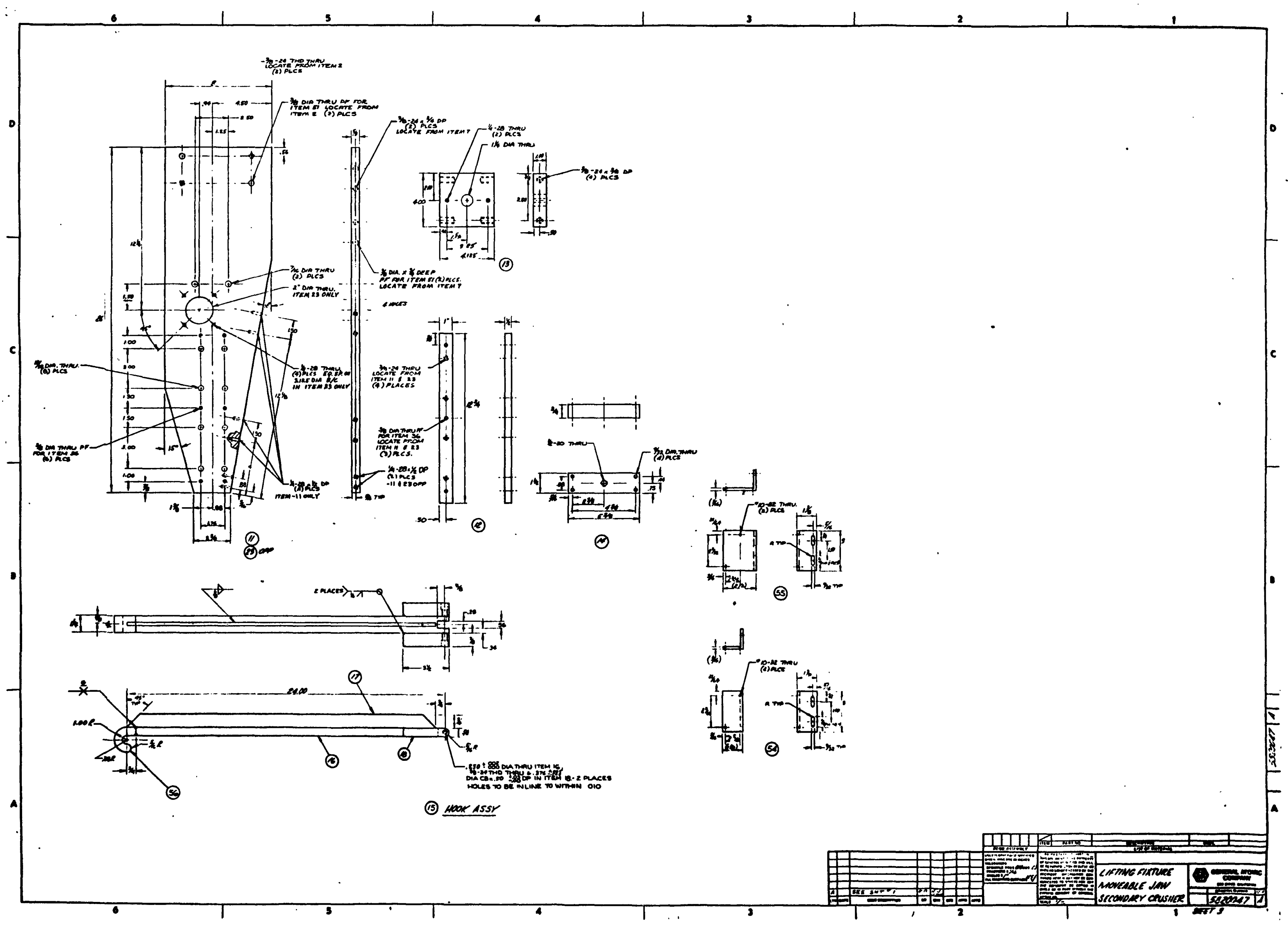




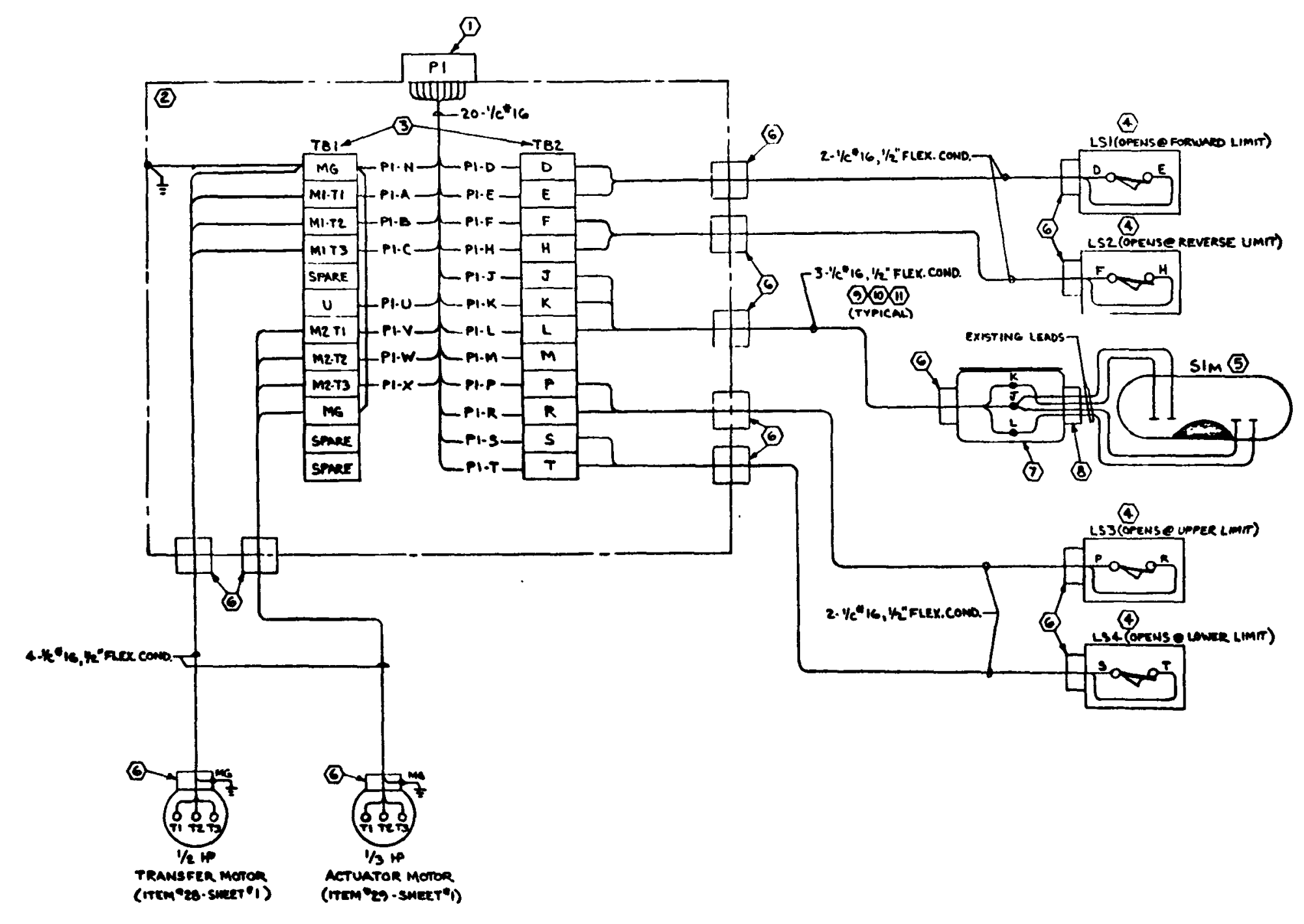

DETAIL NO.1.WIRING DIAGRAM FOR SECONDARY MOVEABLE JAW 


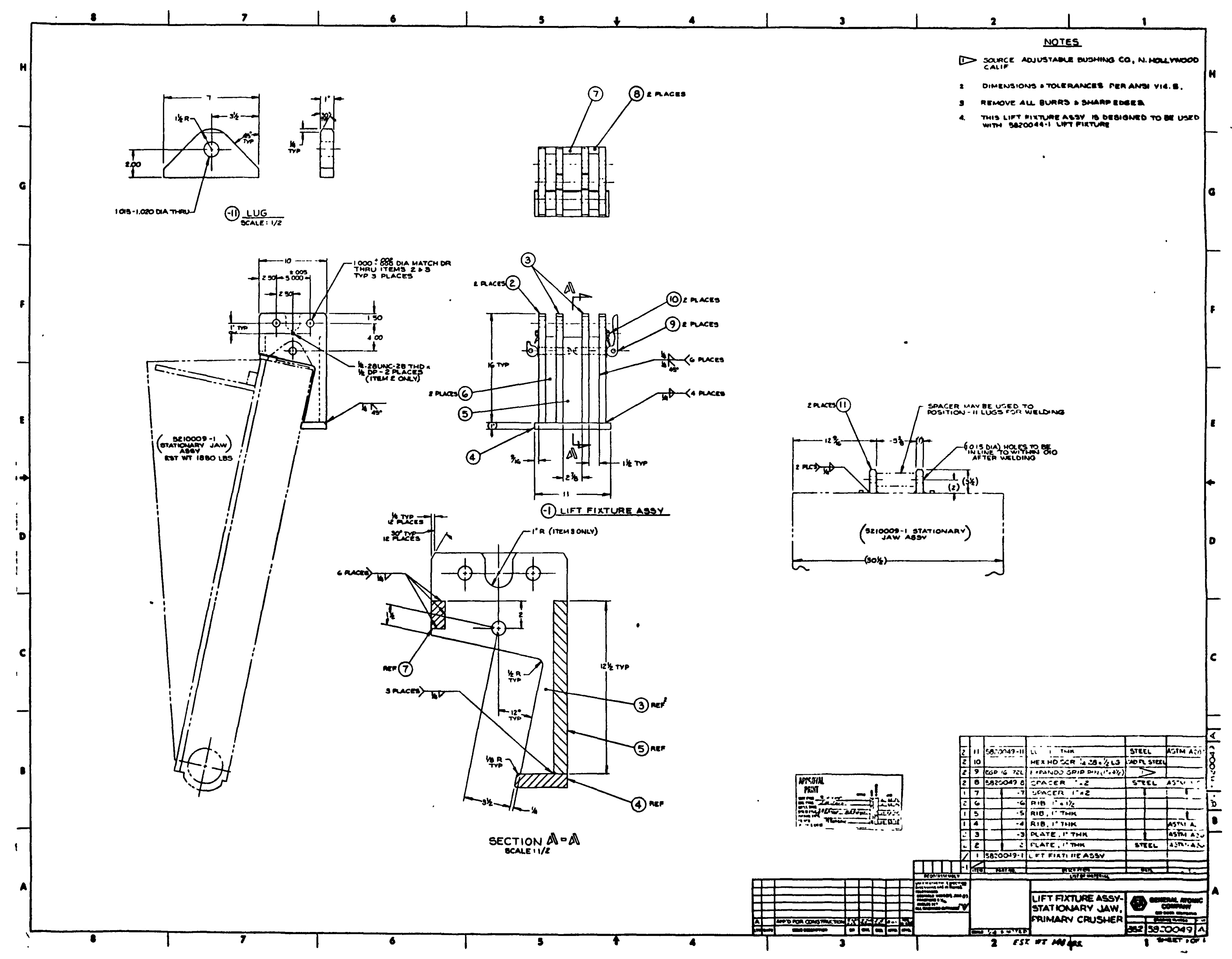




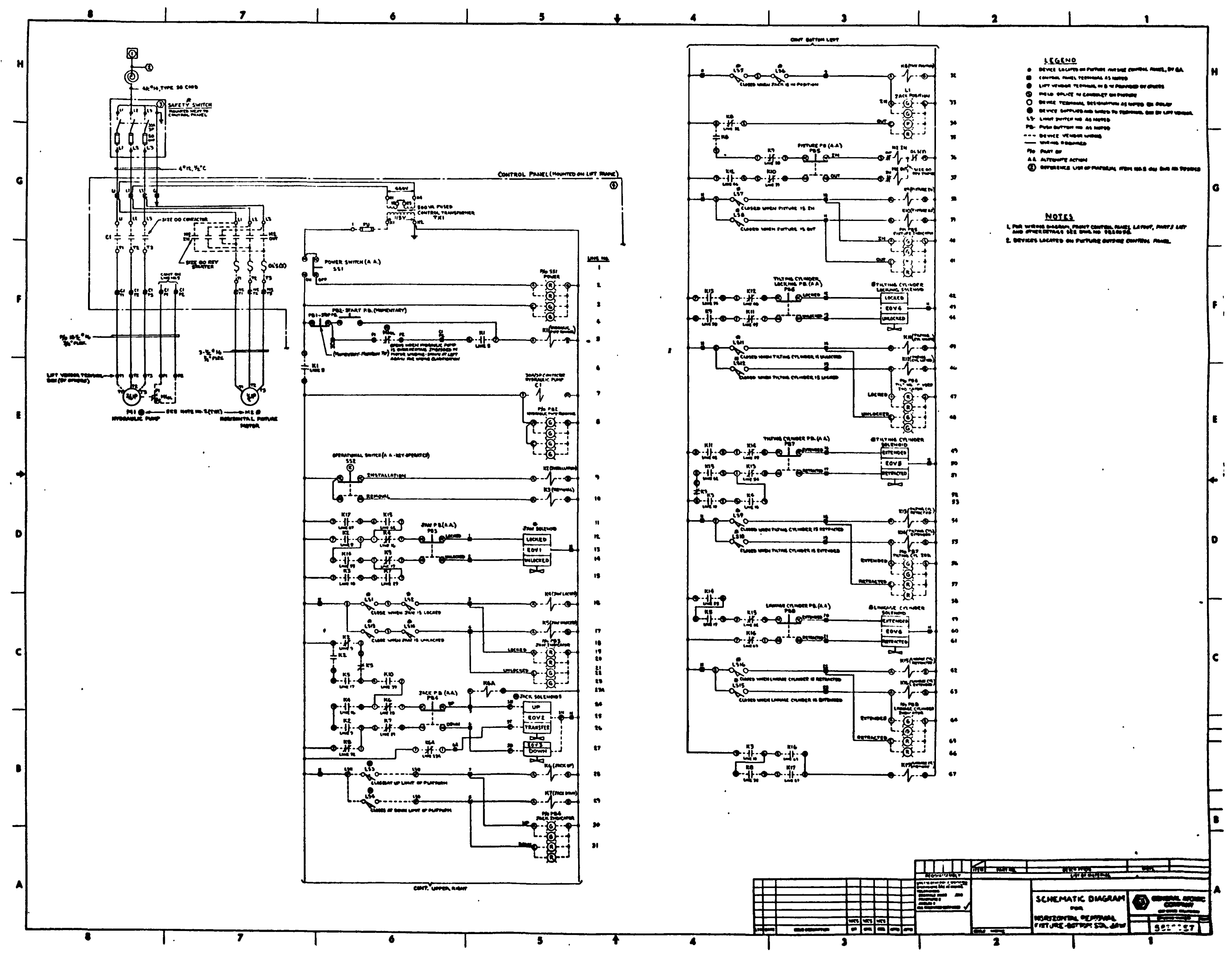




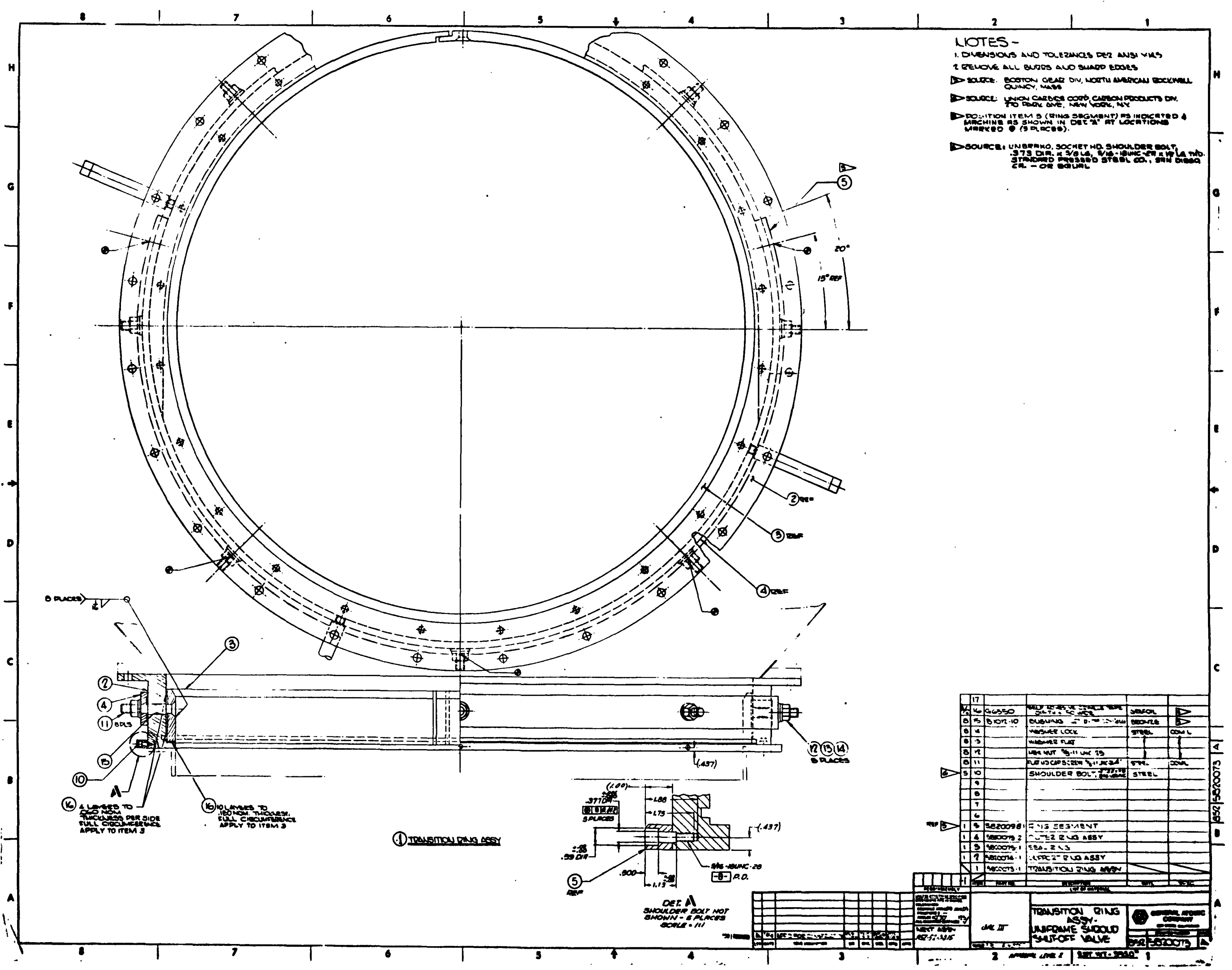




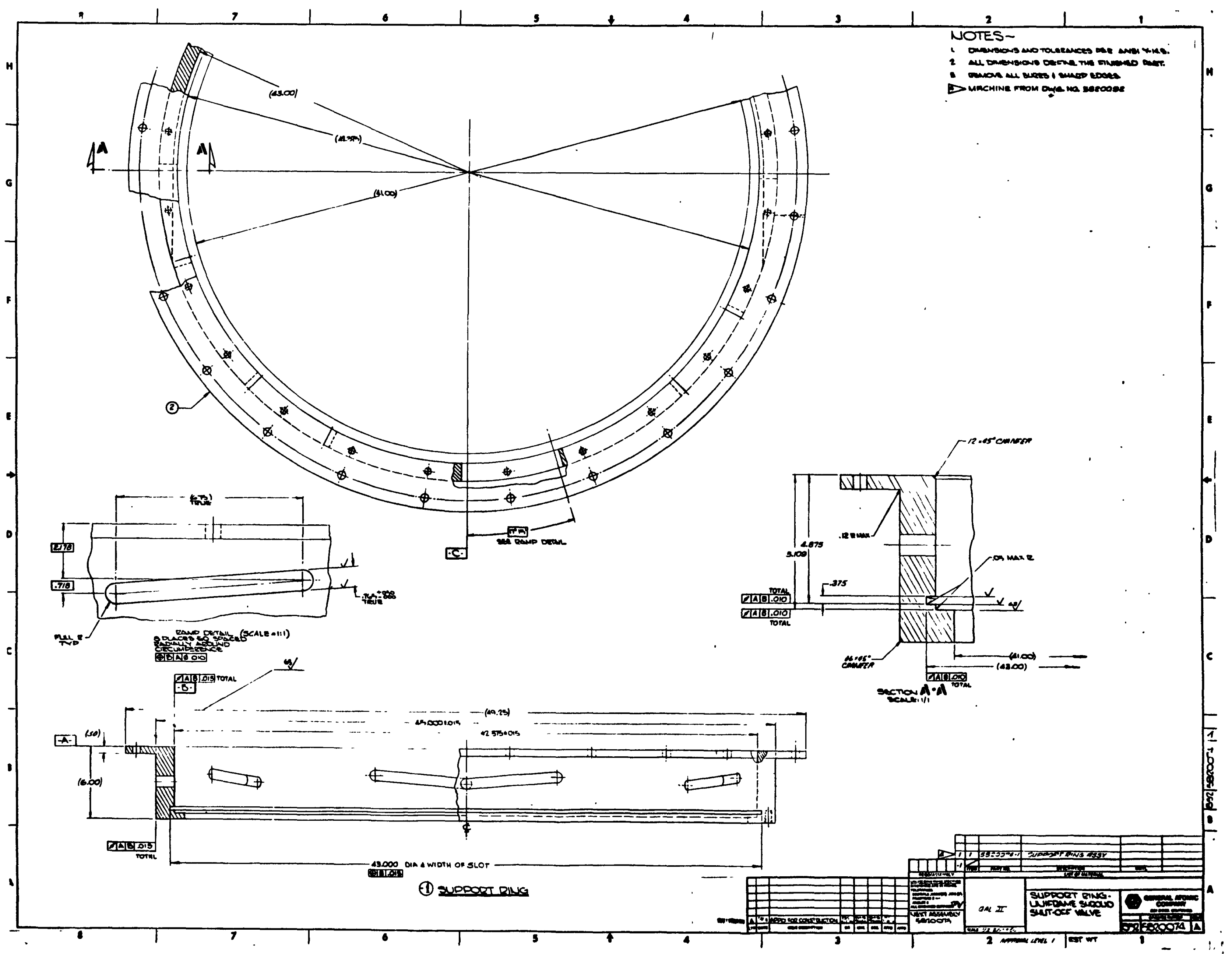




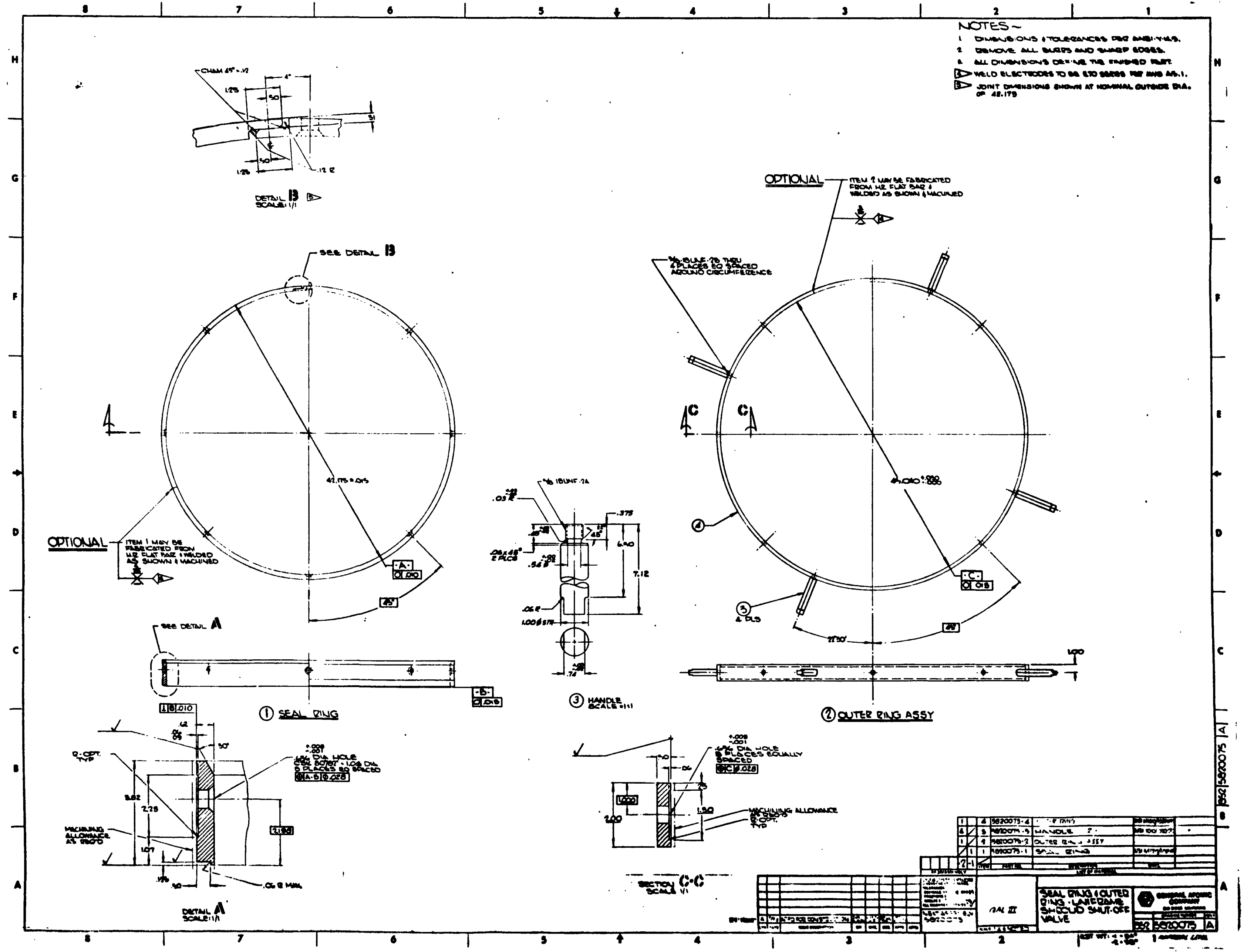




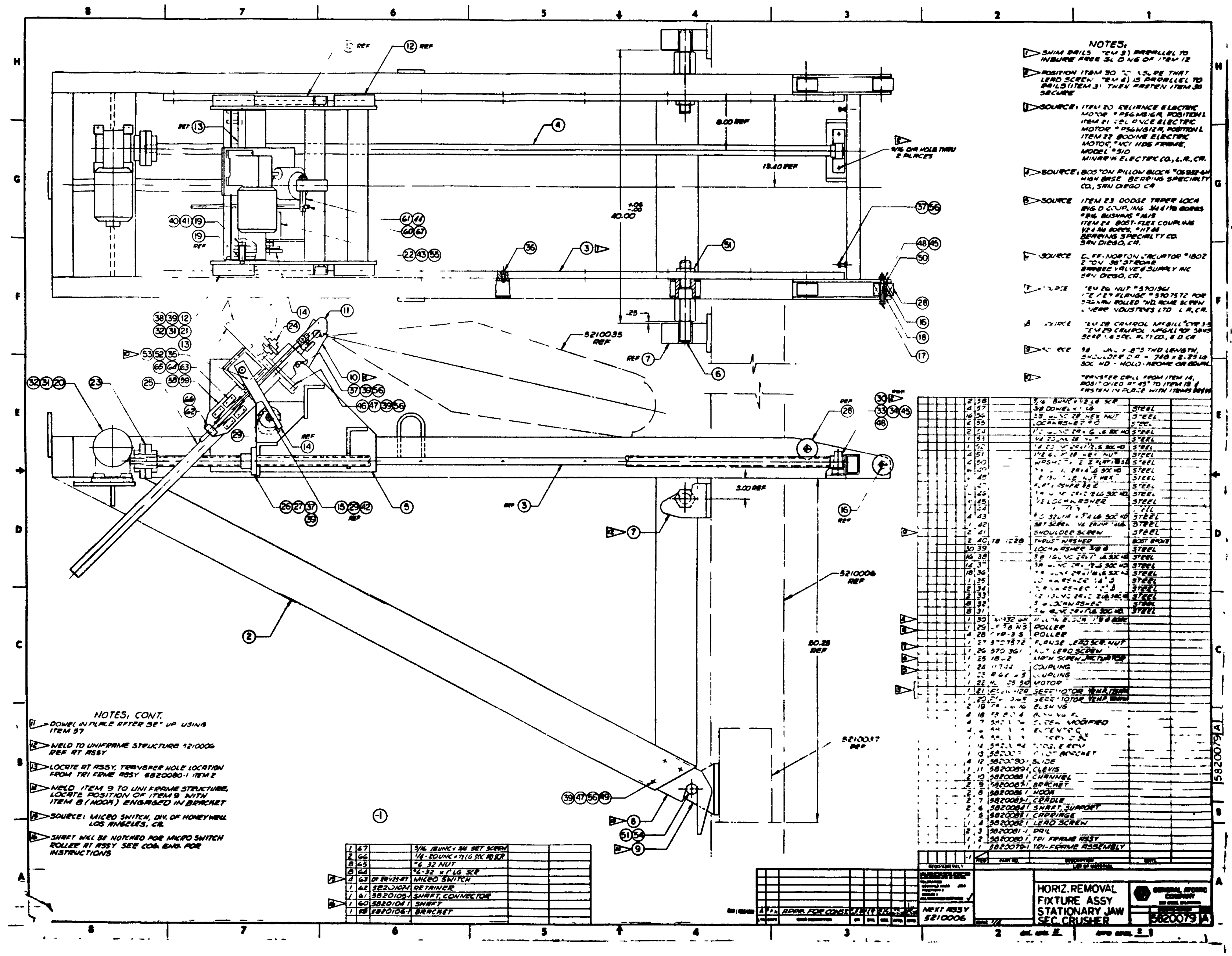




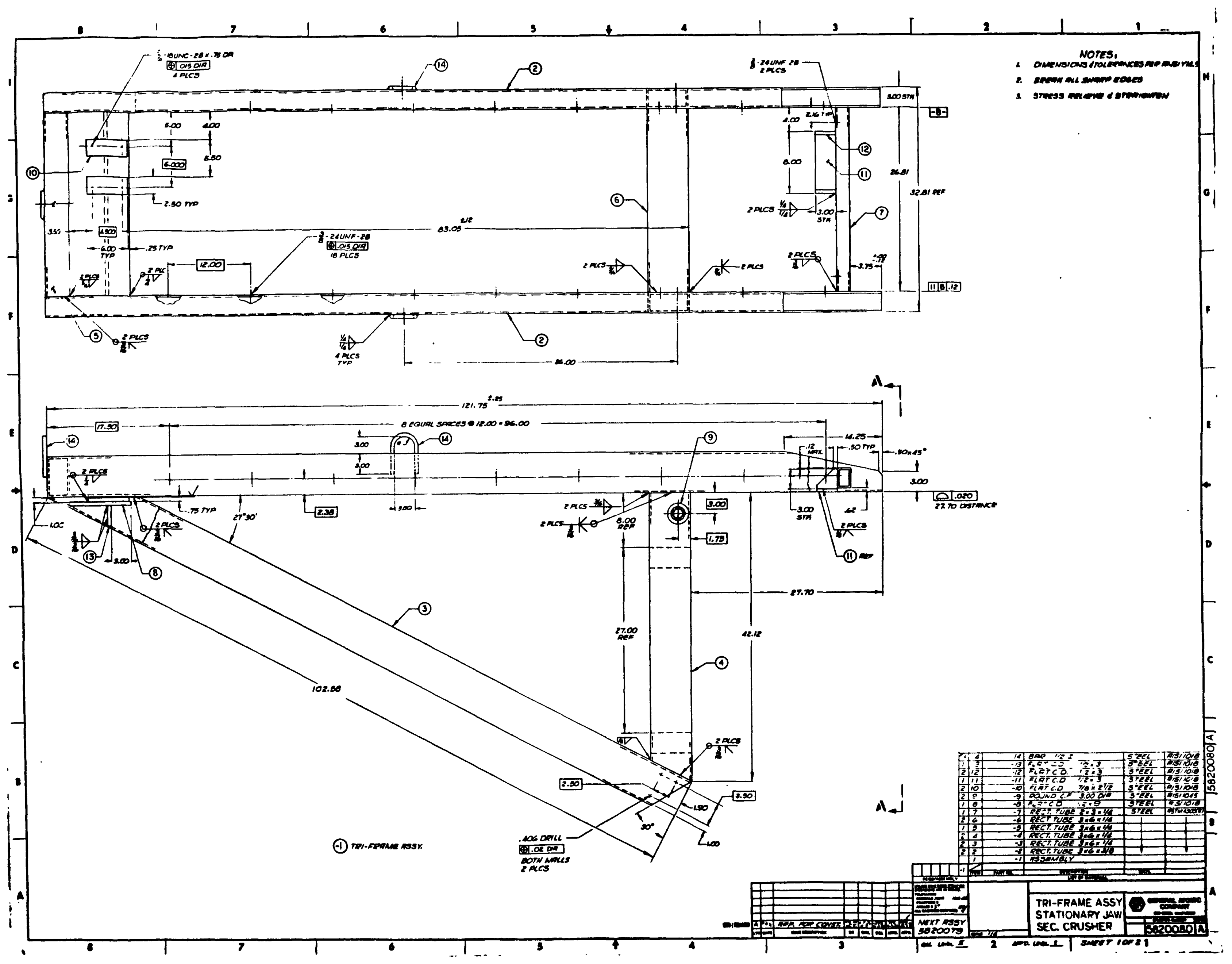




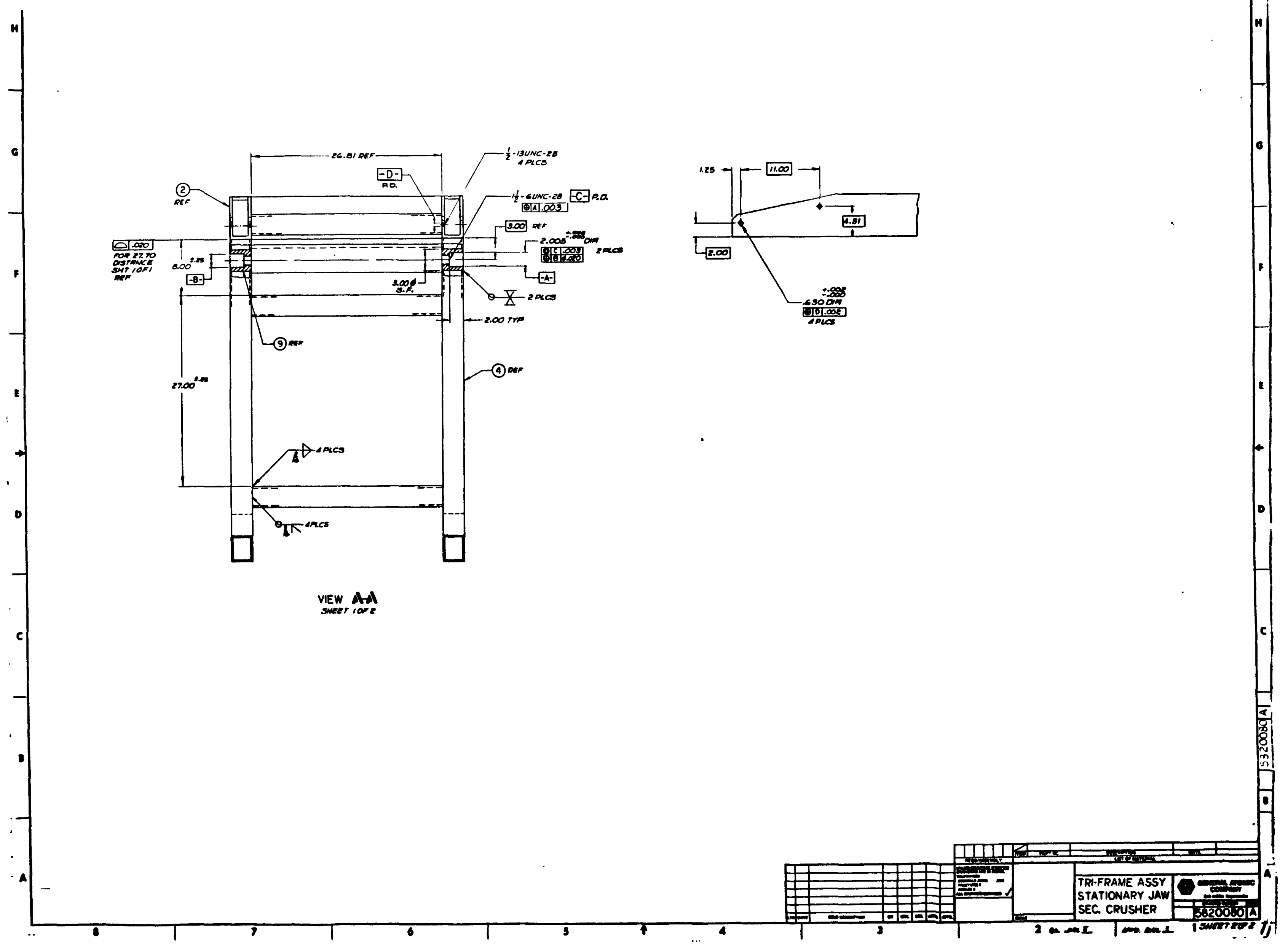



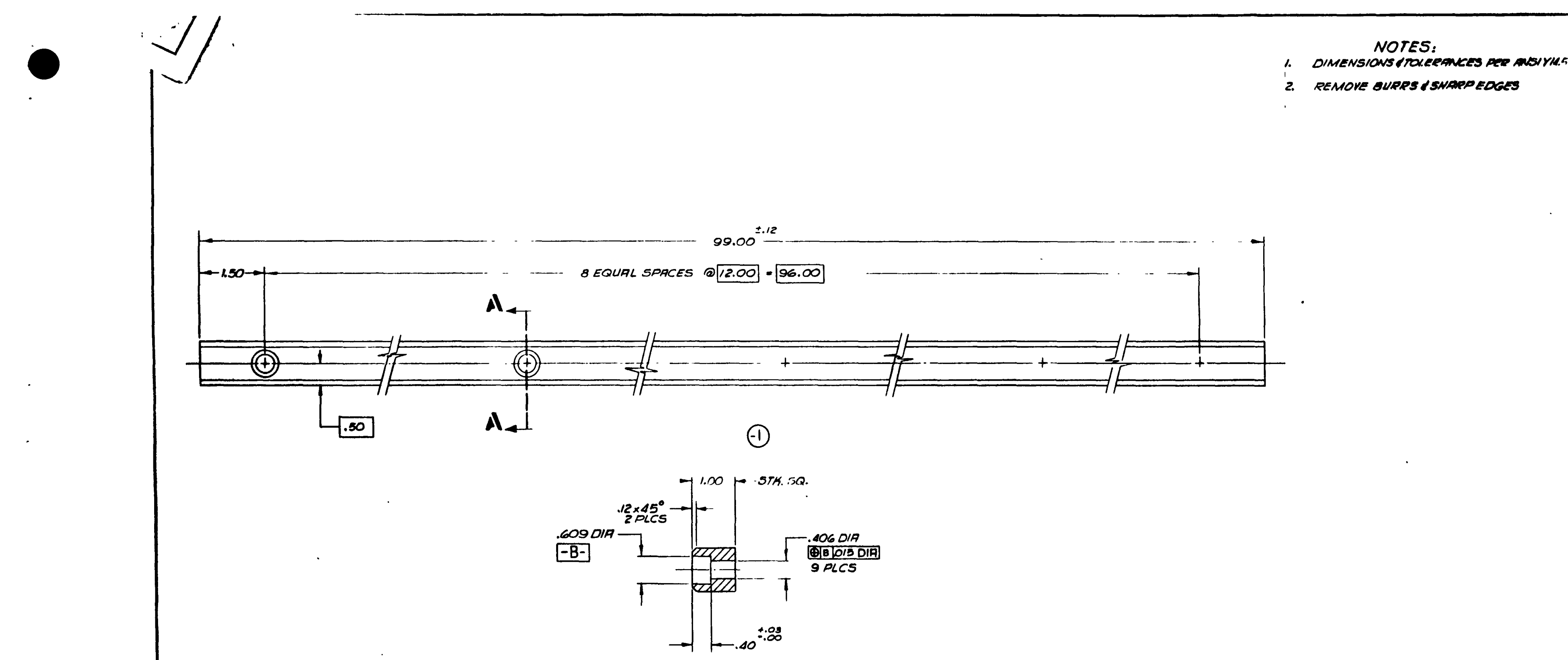

SECTION A-A

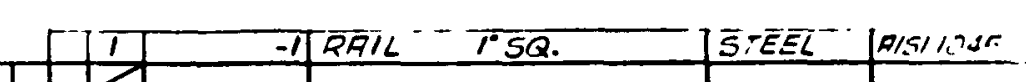

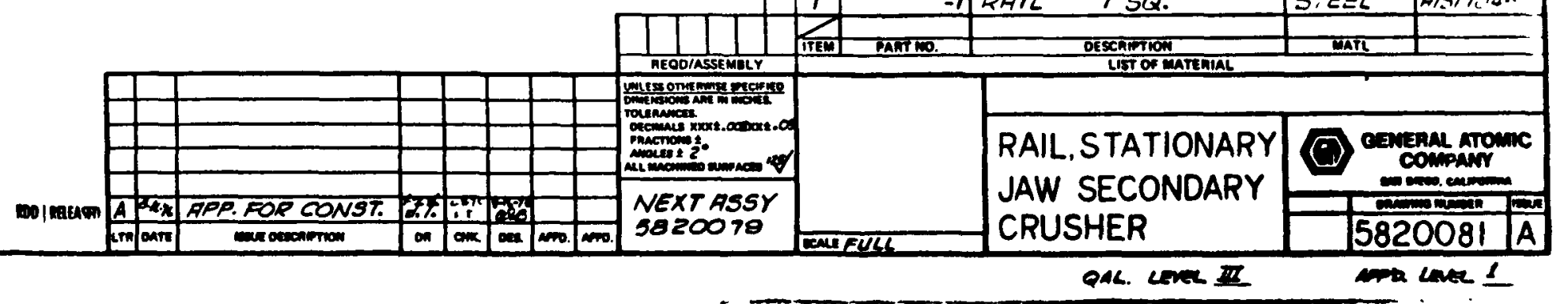




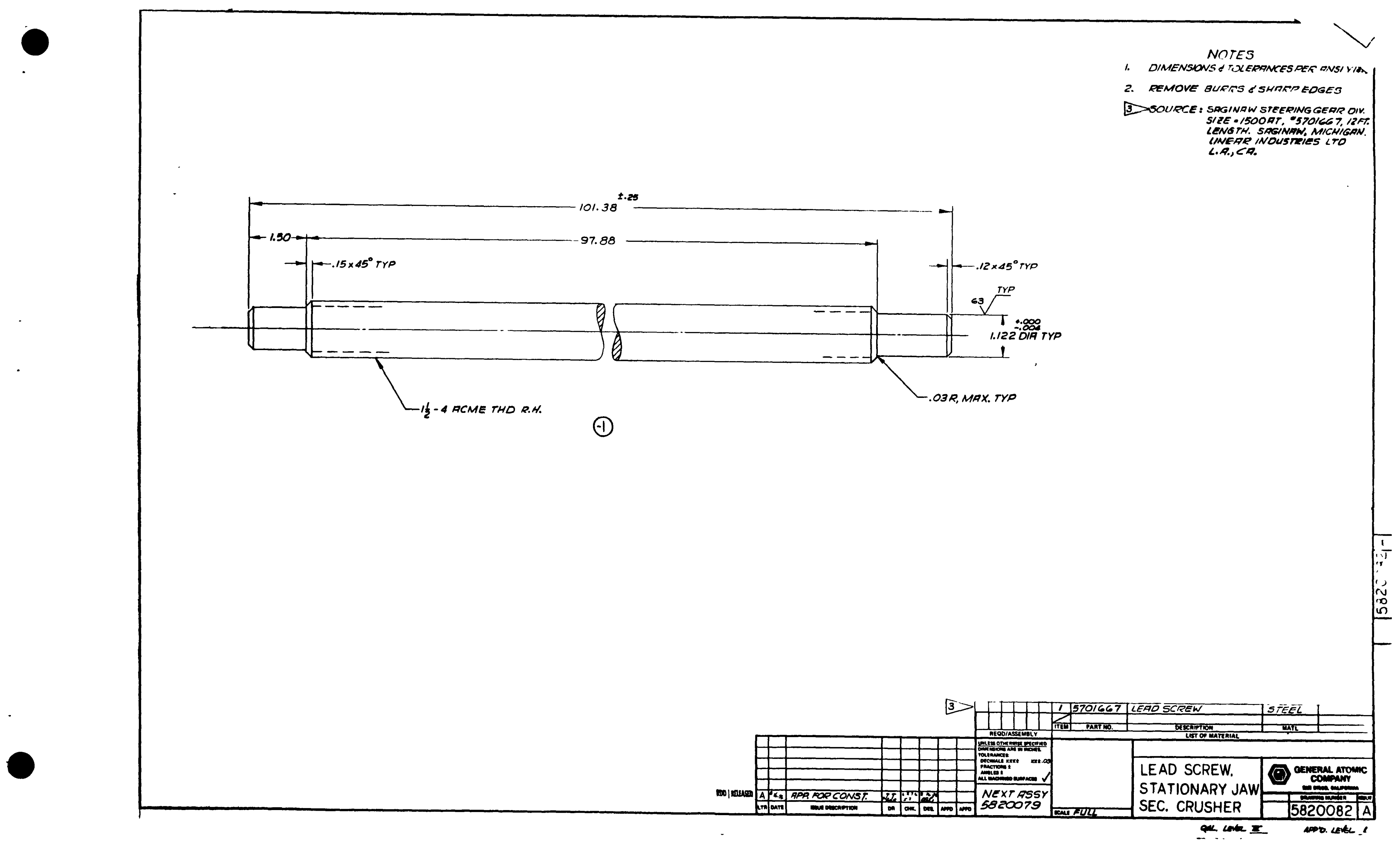




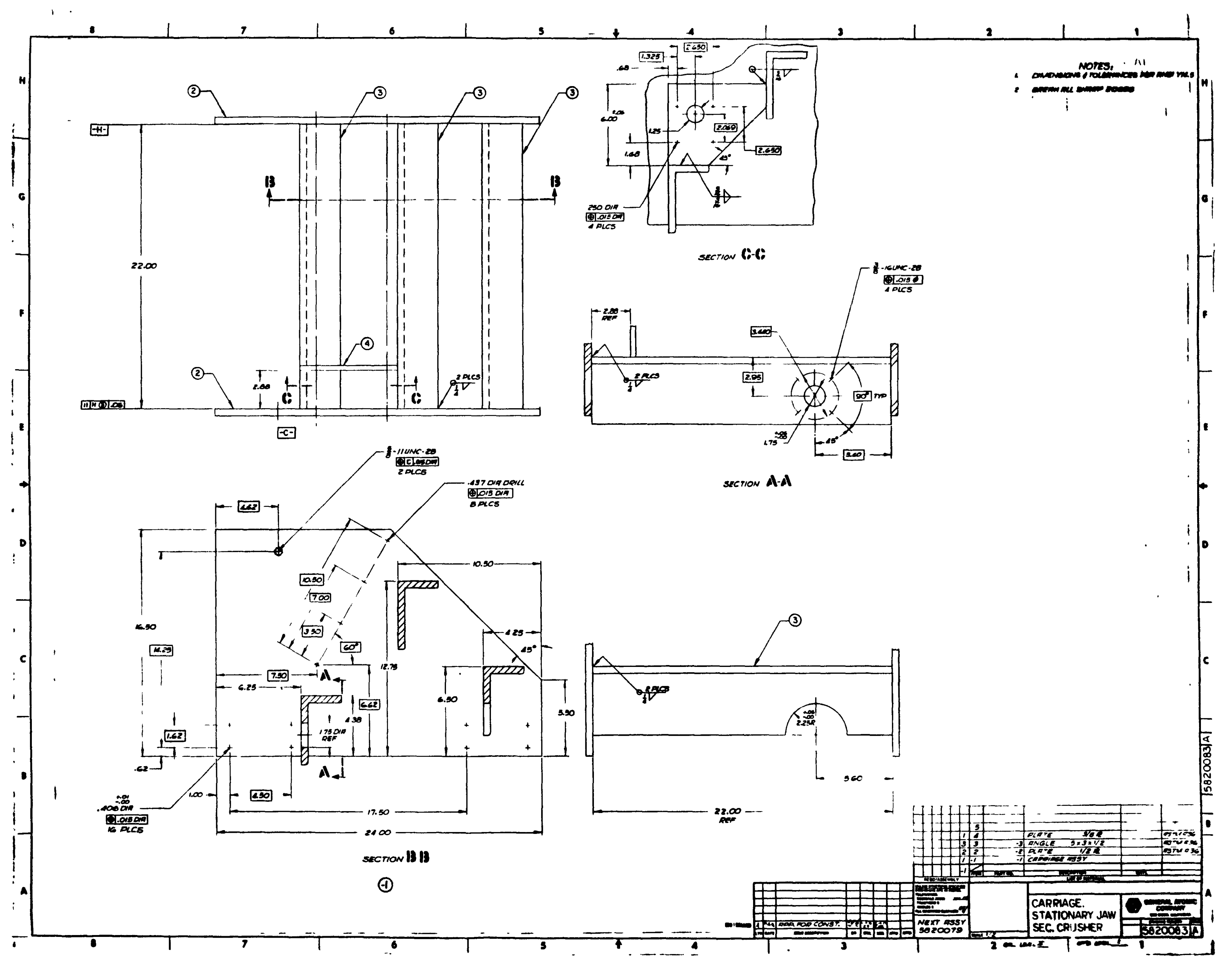




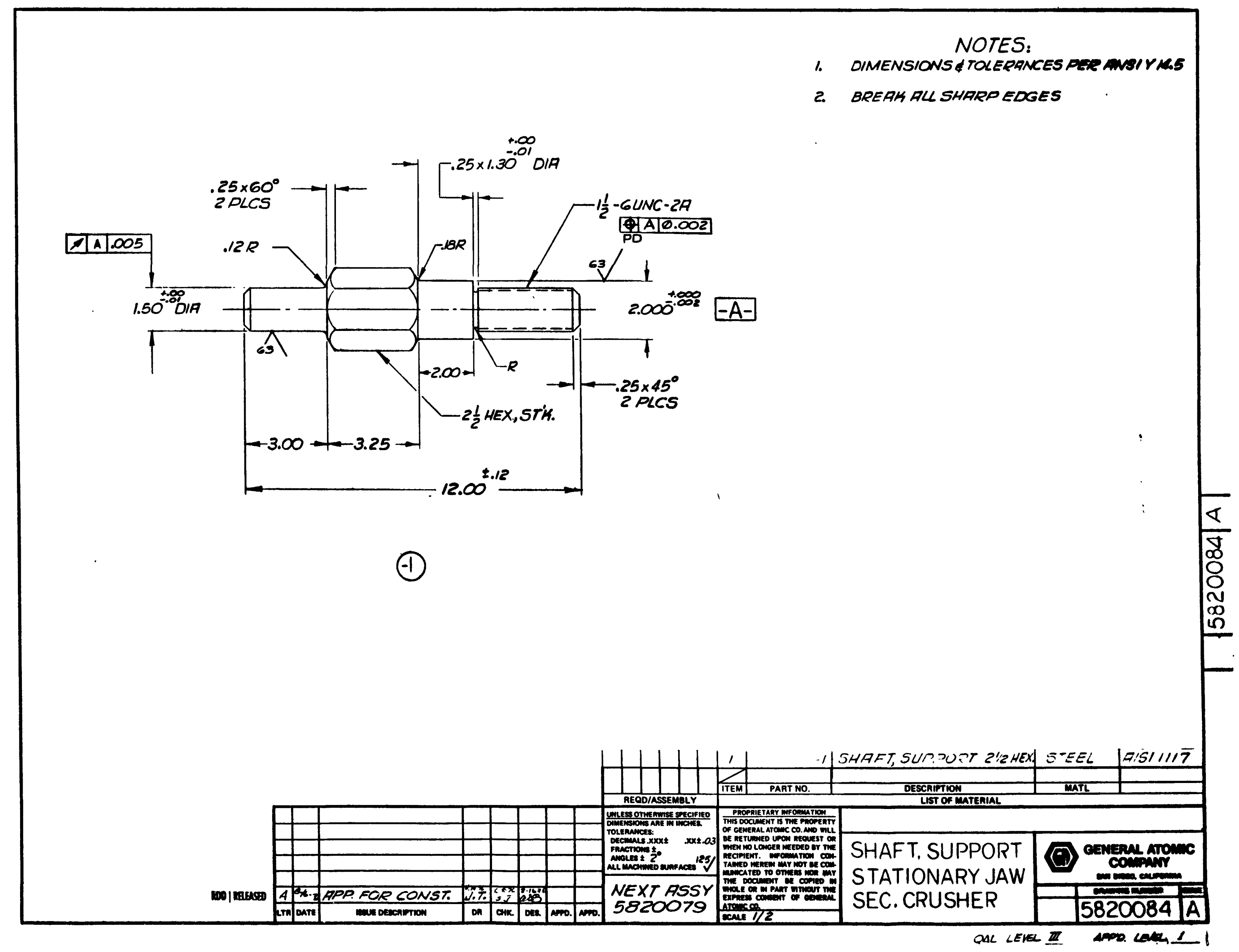




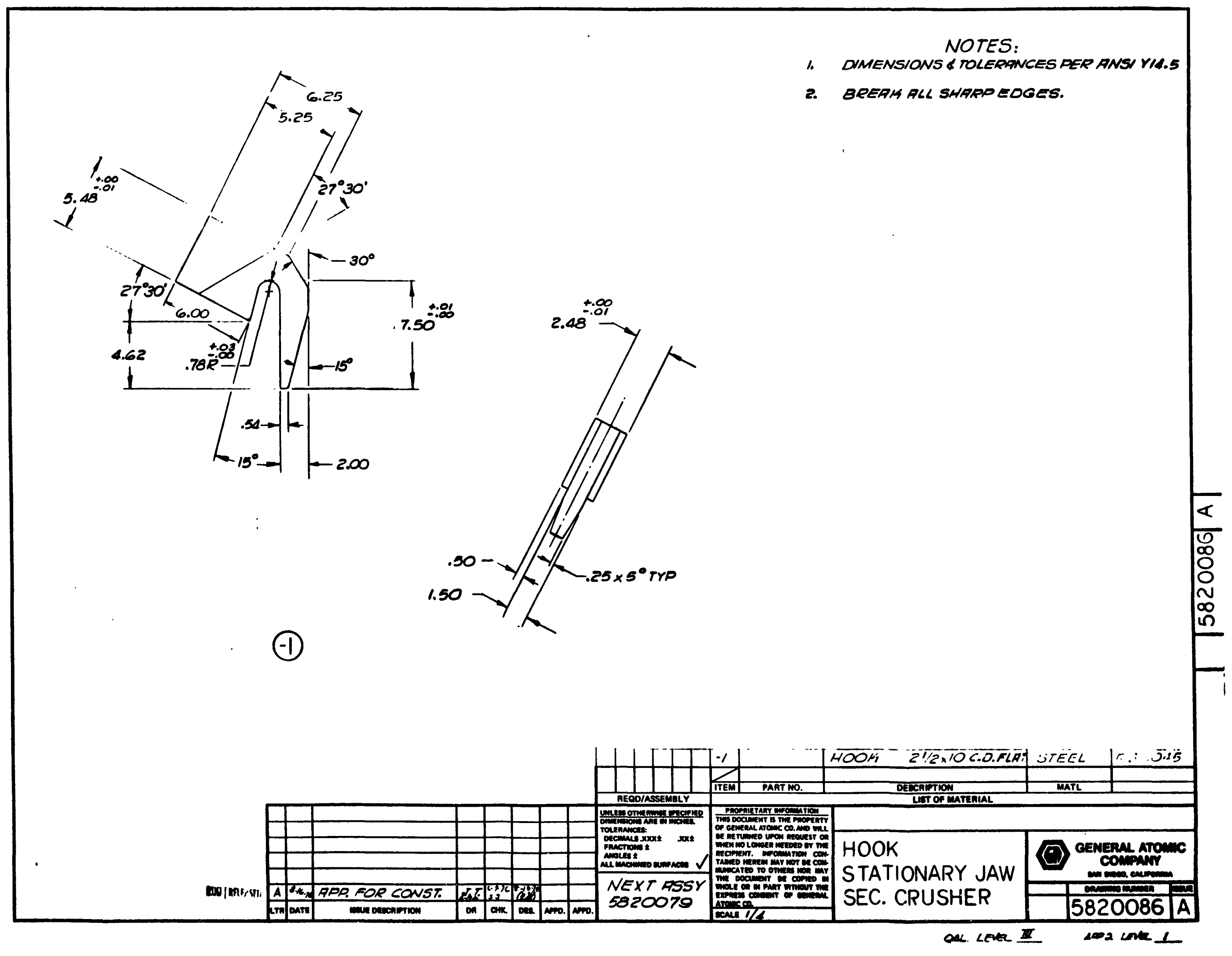




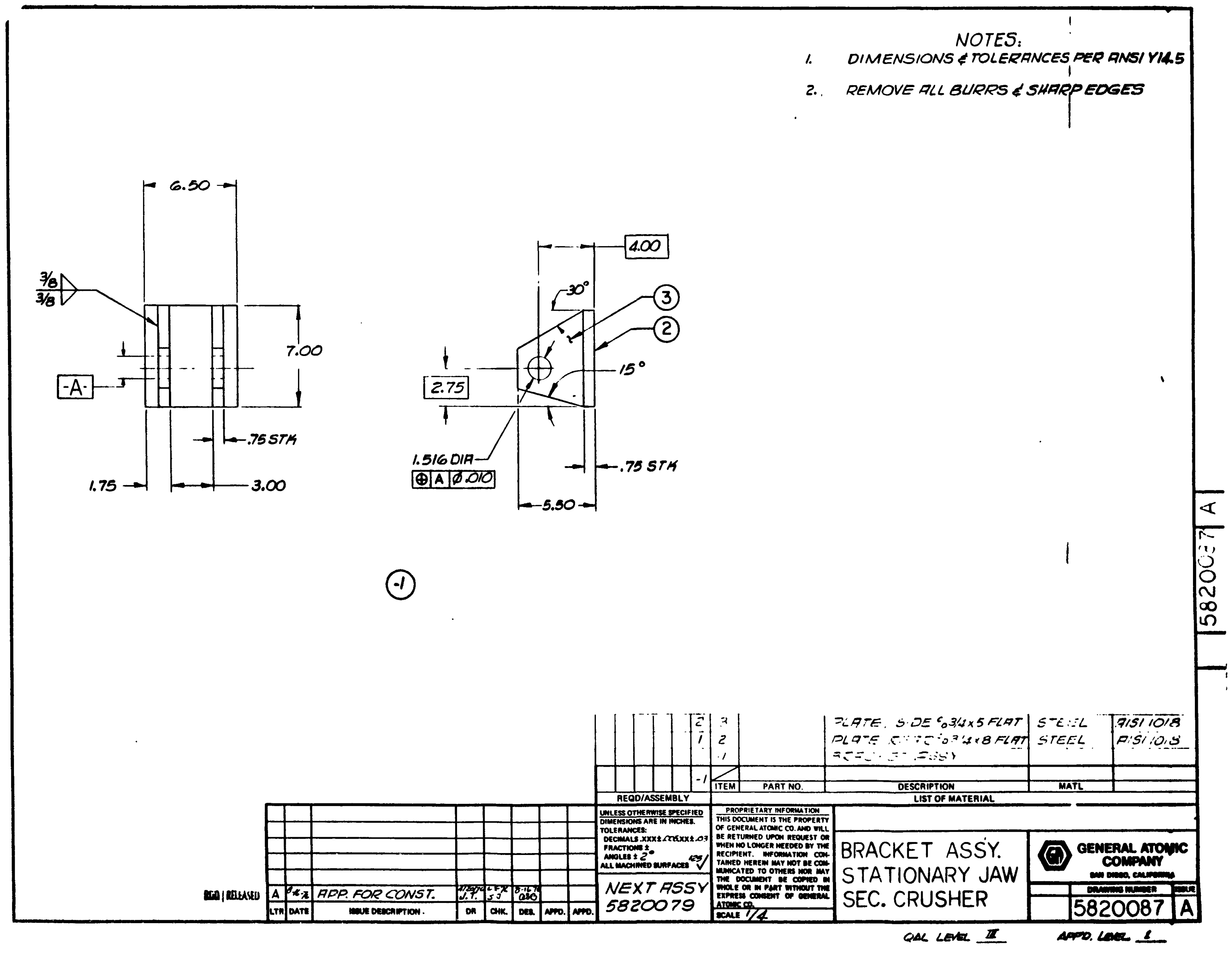




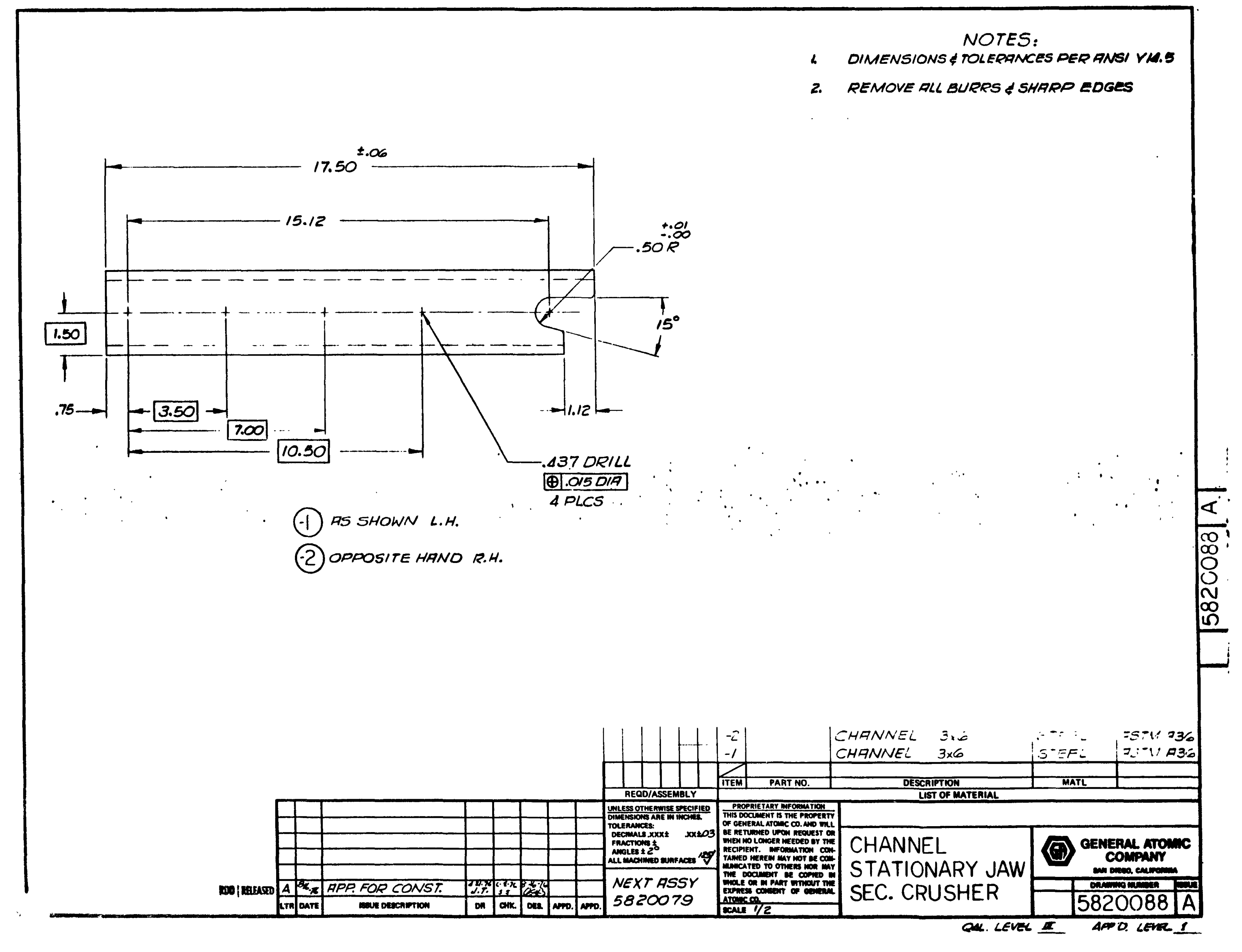




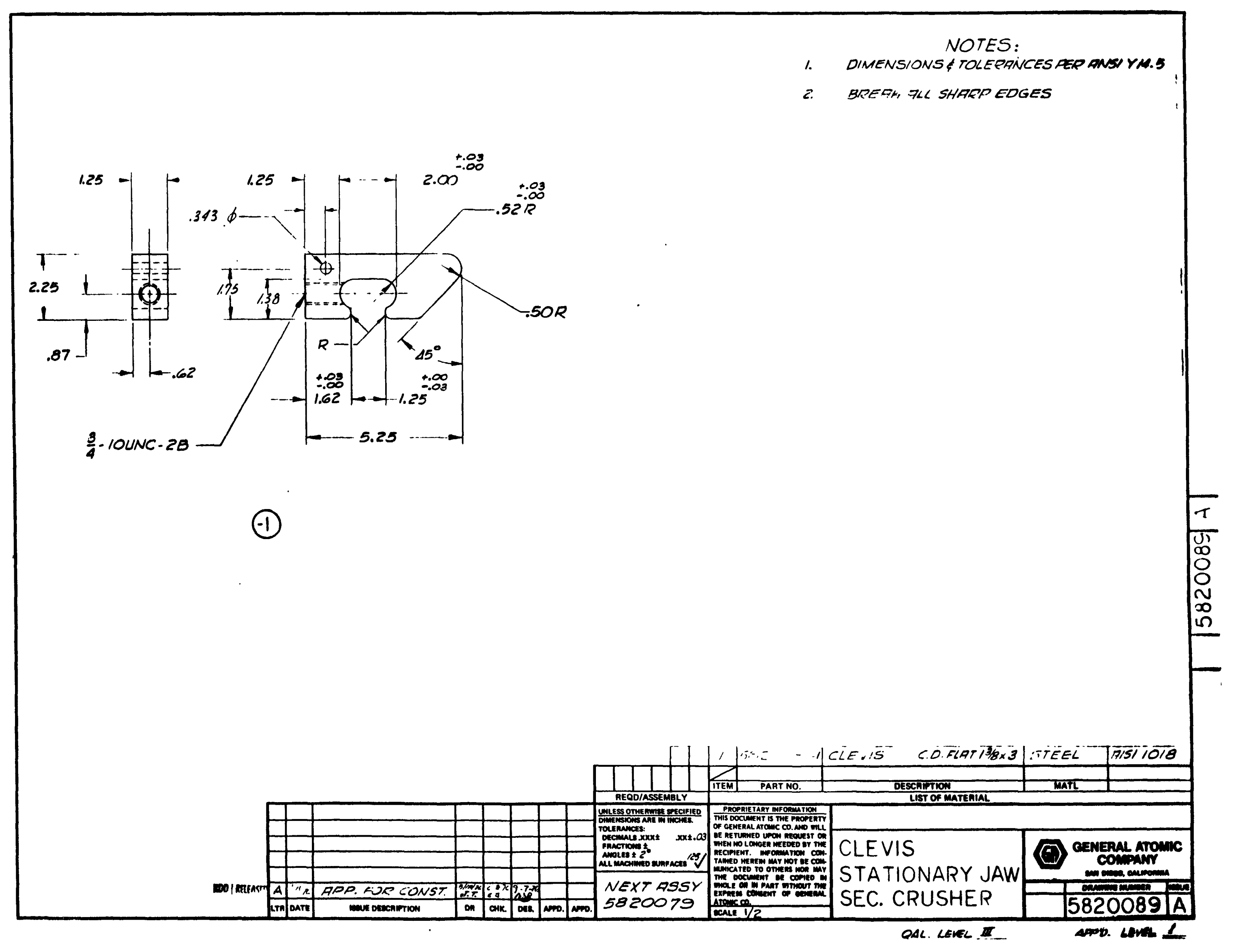


NOTES:

1. DIMENSIONS \& TOLERANCES PER ANSIYMS

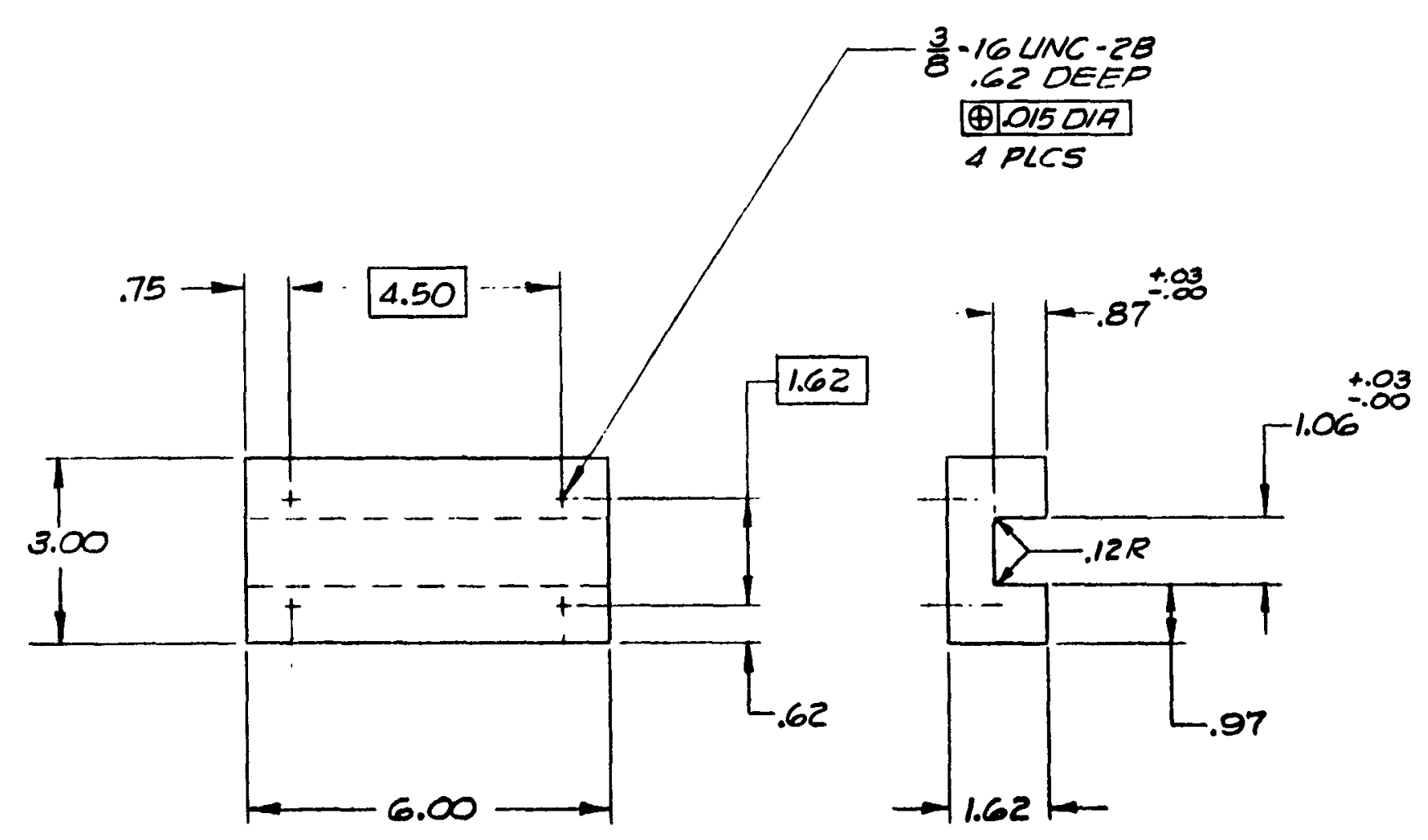

2. REMOVE ALL BURRS \& SHARP EDGES

(-1)

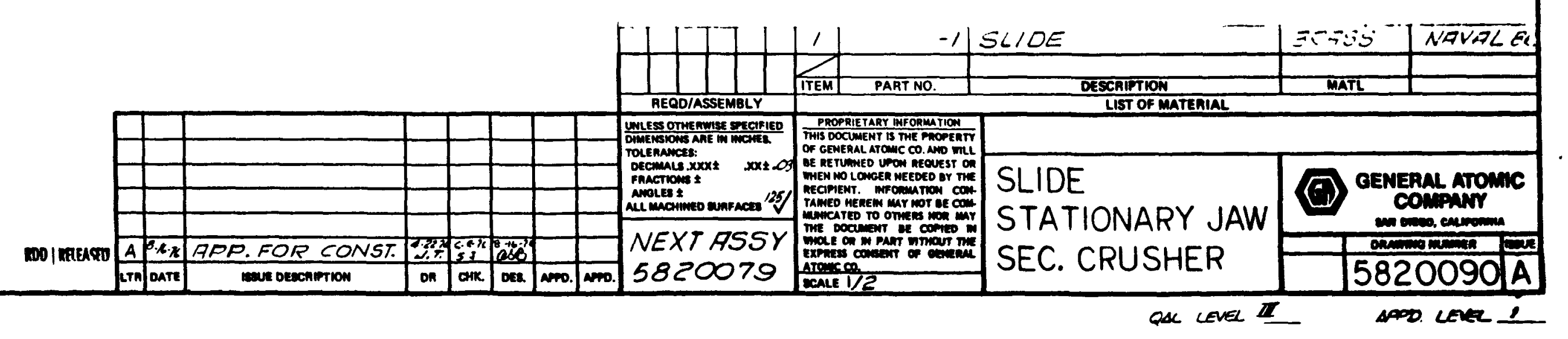




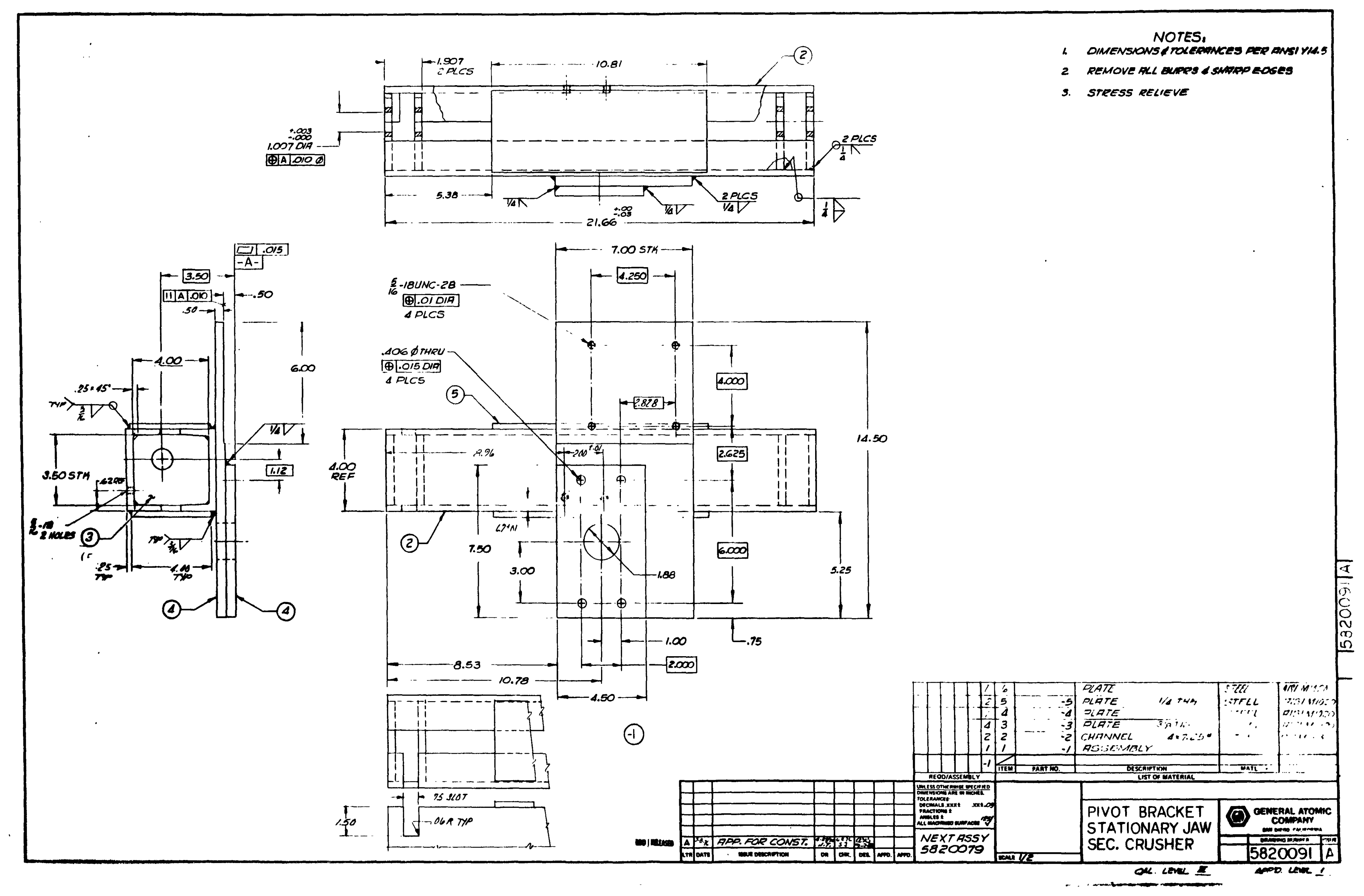




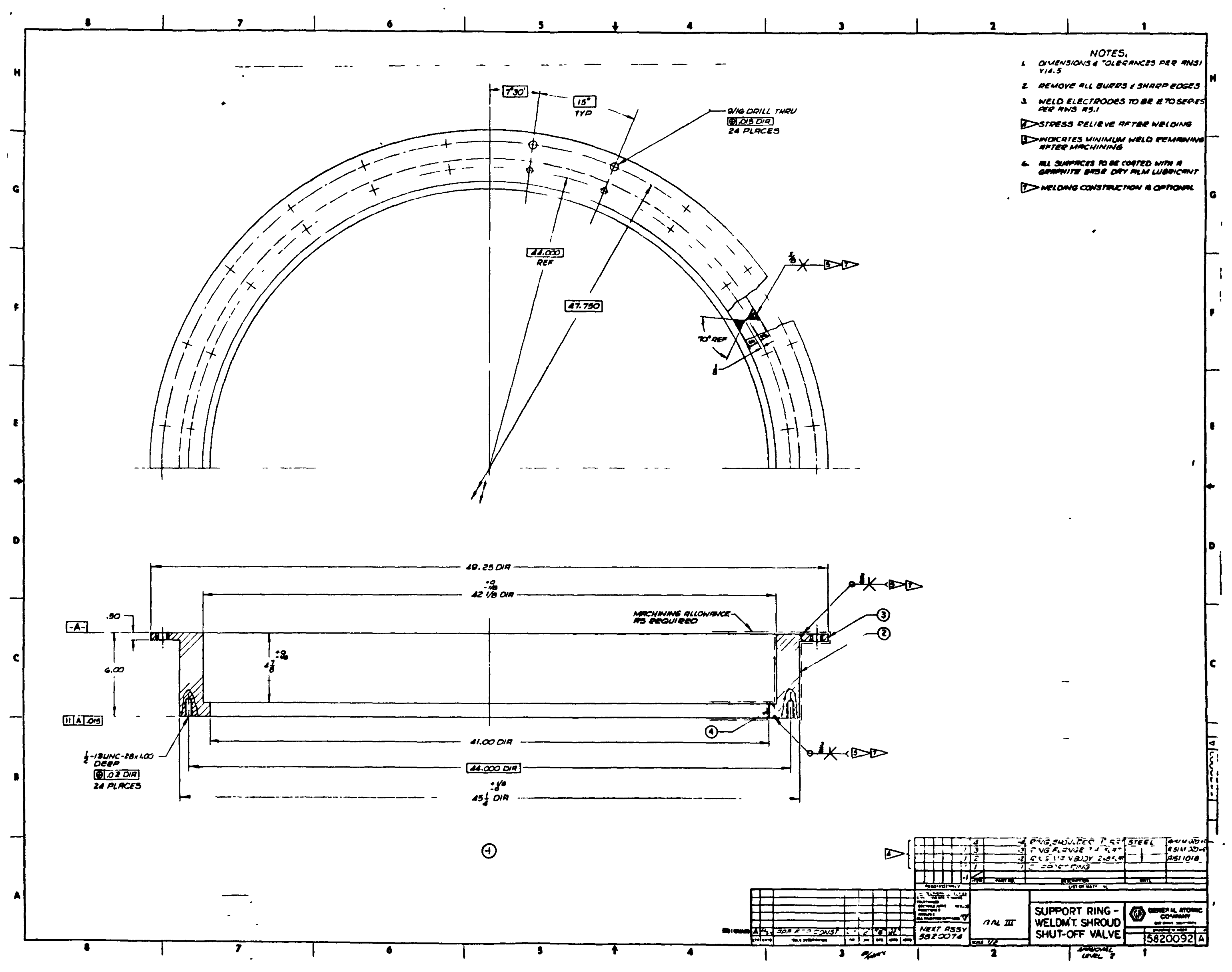




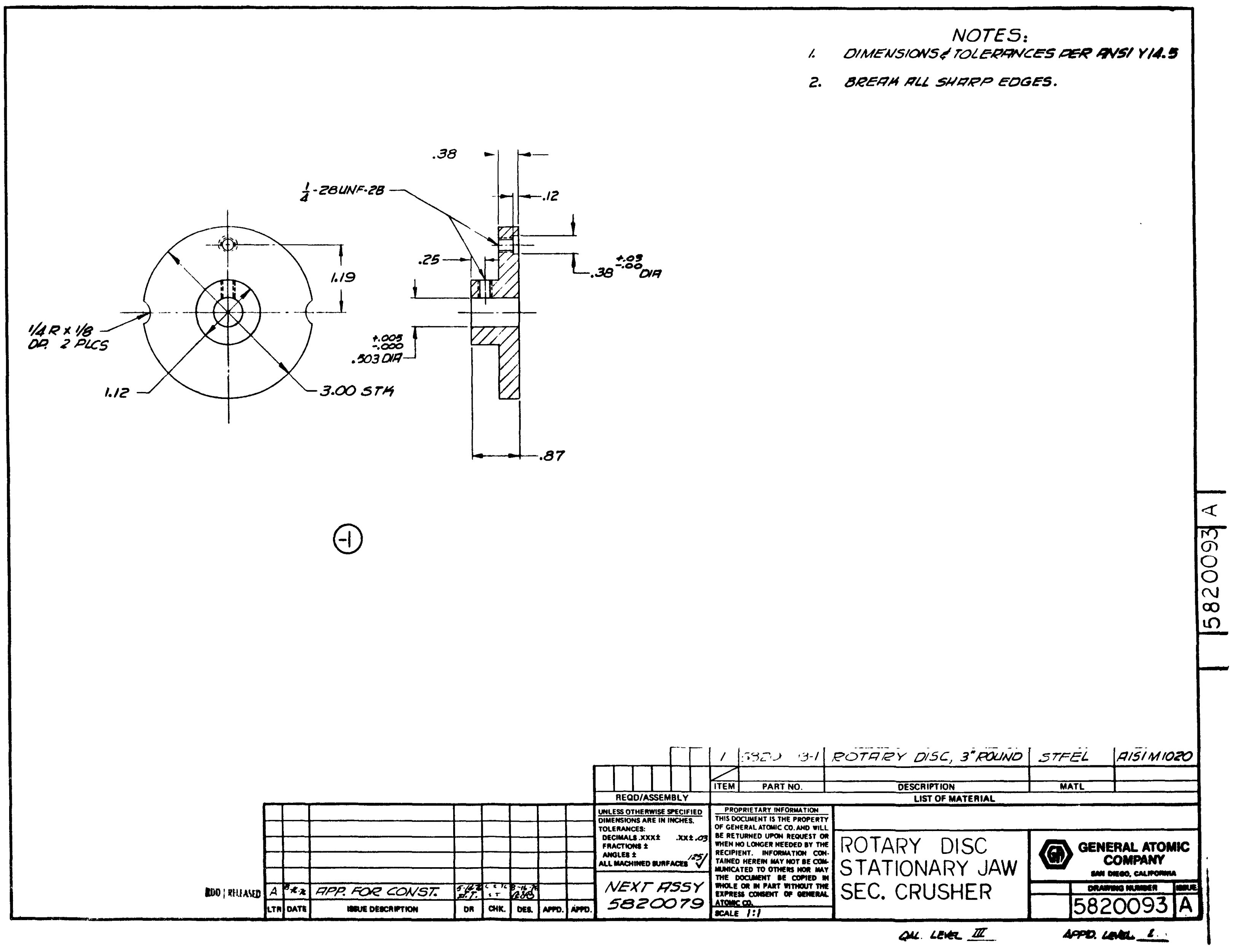


NOTES:

1. DIMENSIONS \& TOL ERANEES PERANOUMUS

2. BREAH ALL SHARPEDGES

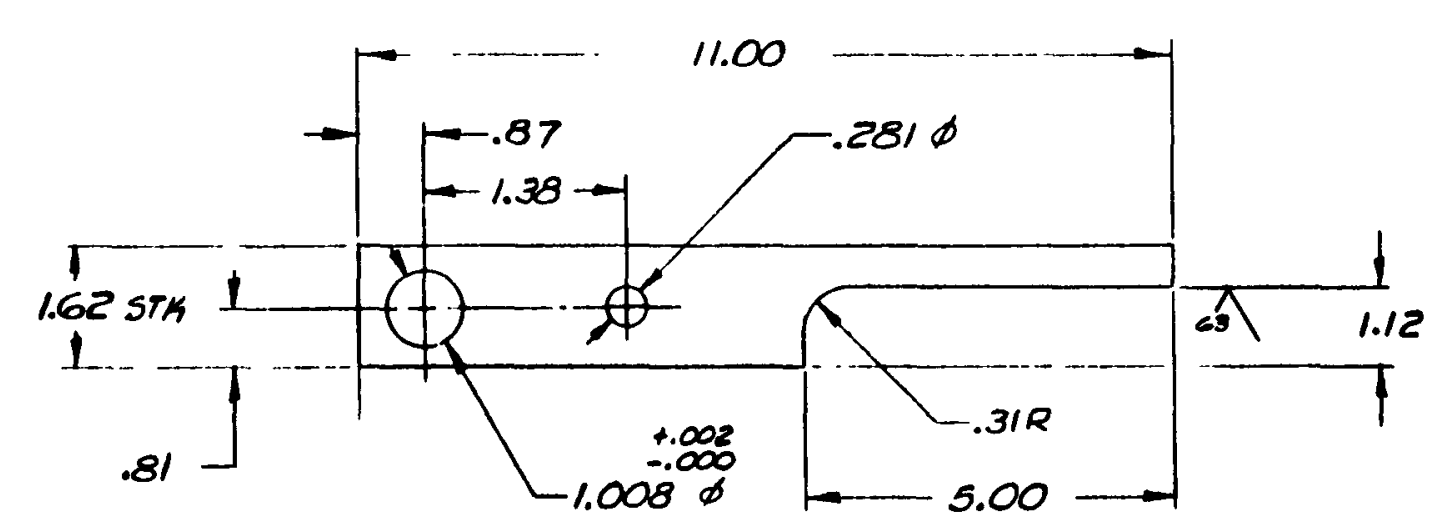

(1)

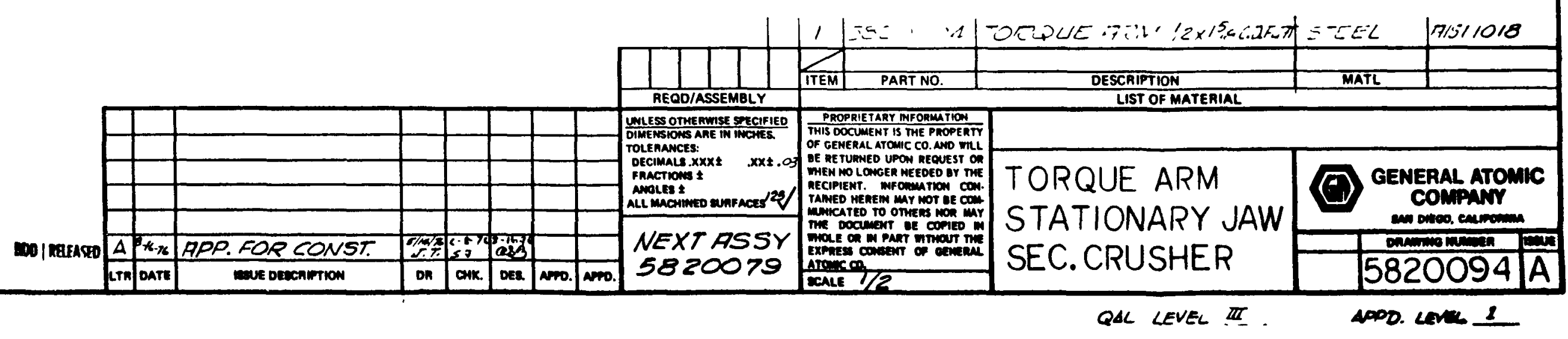




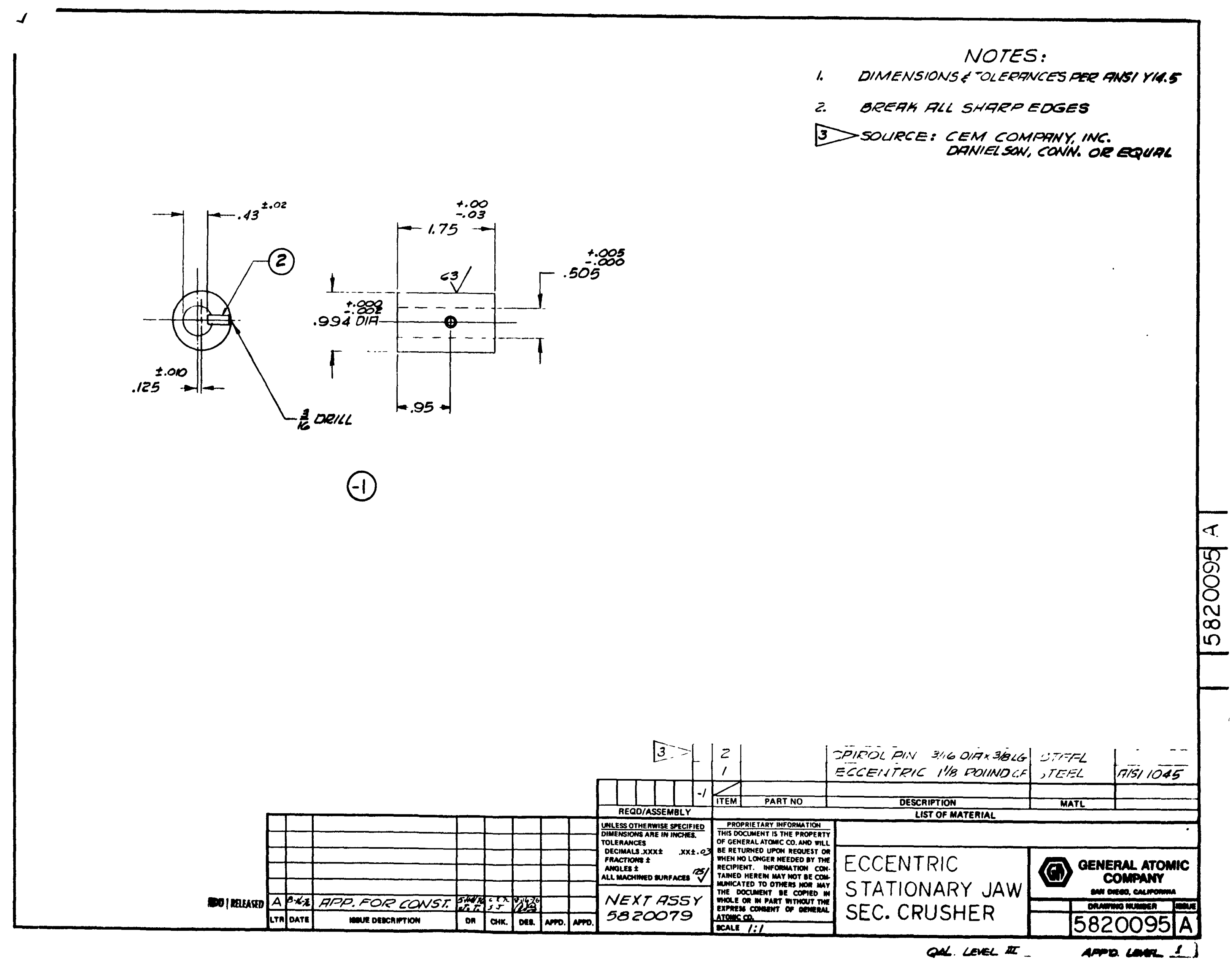



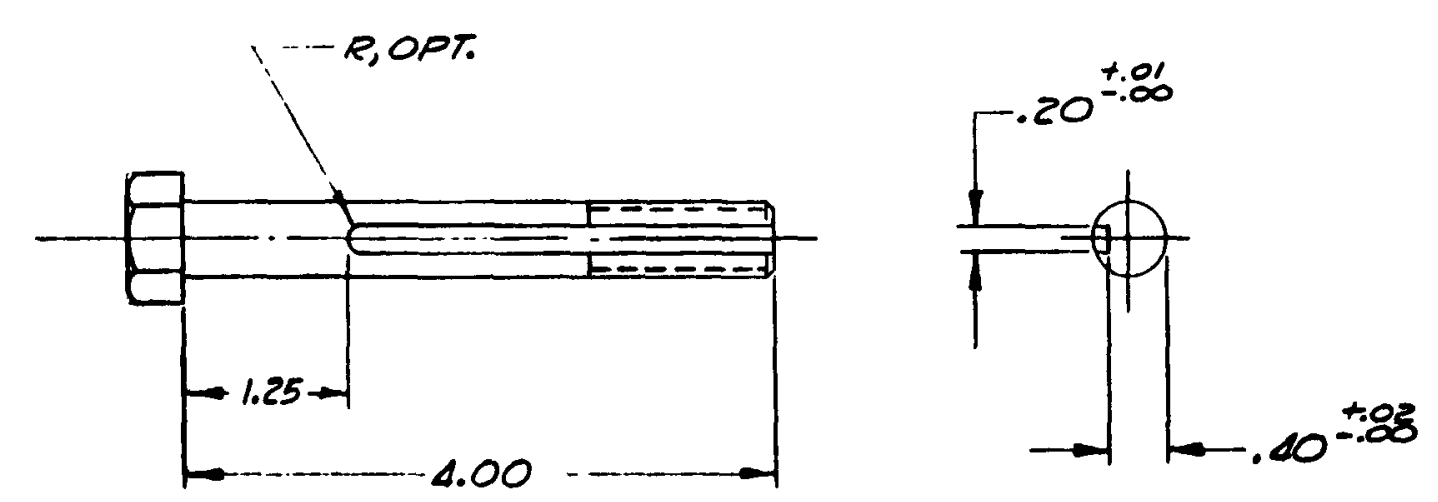

(1)

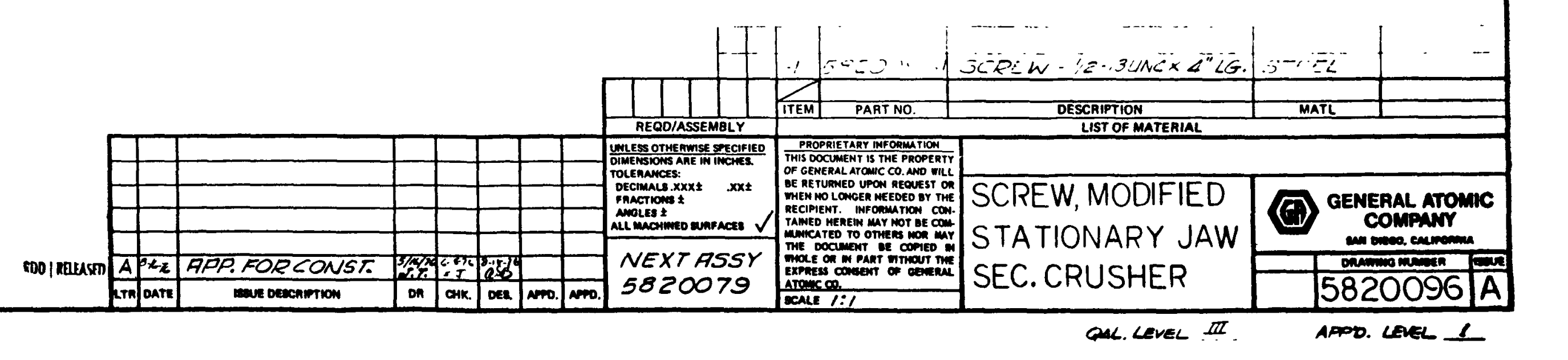




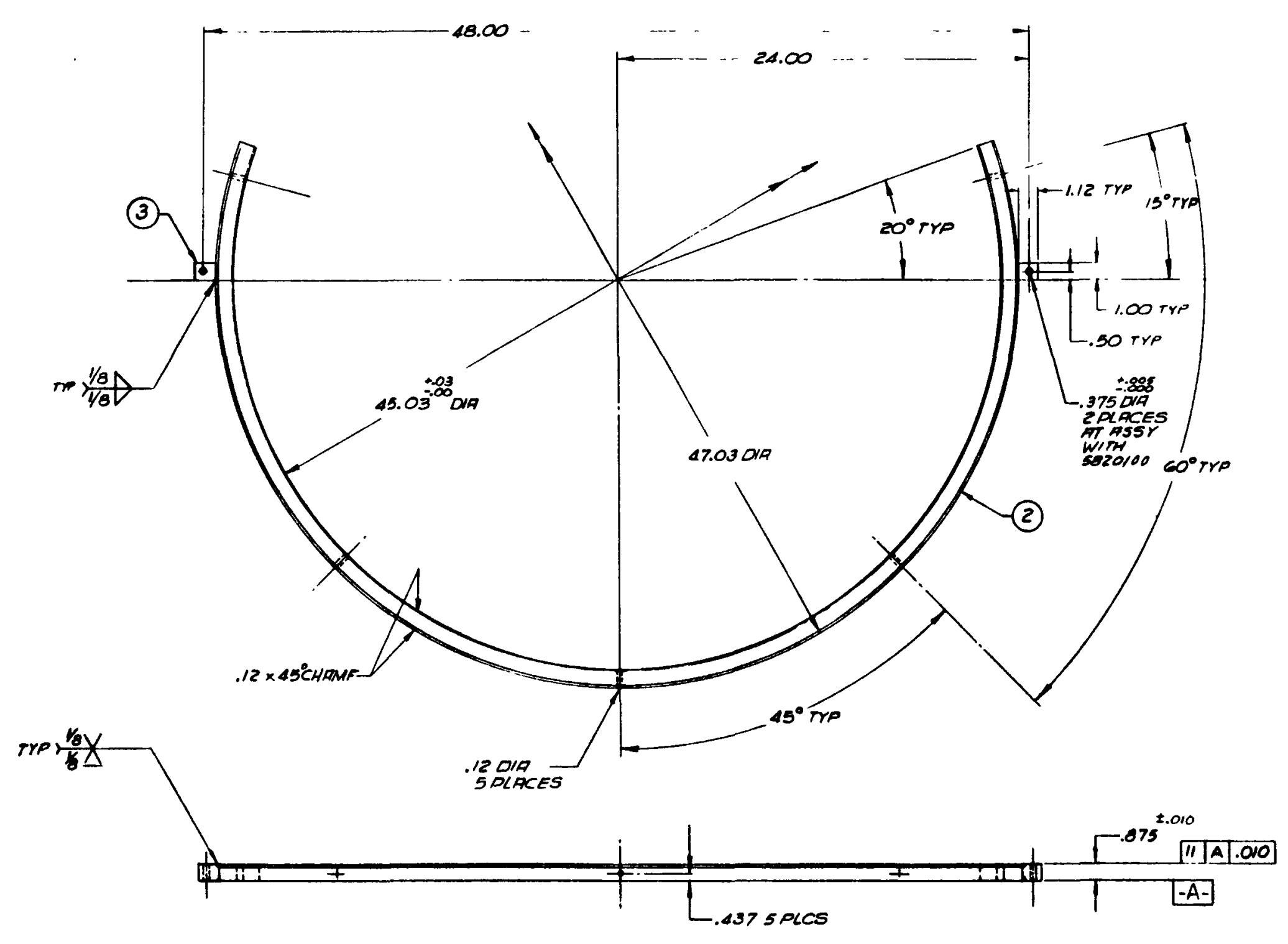

NOTES:

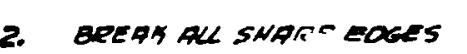

(1)

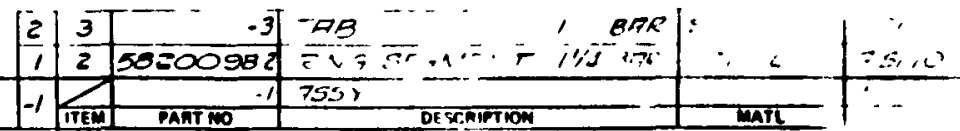




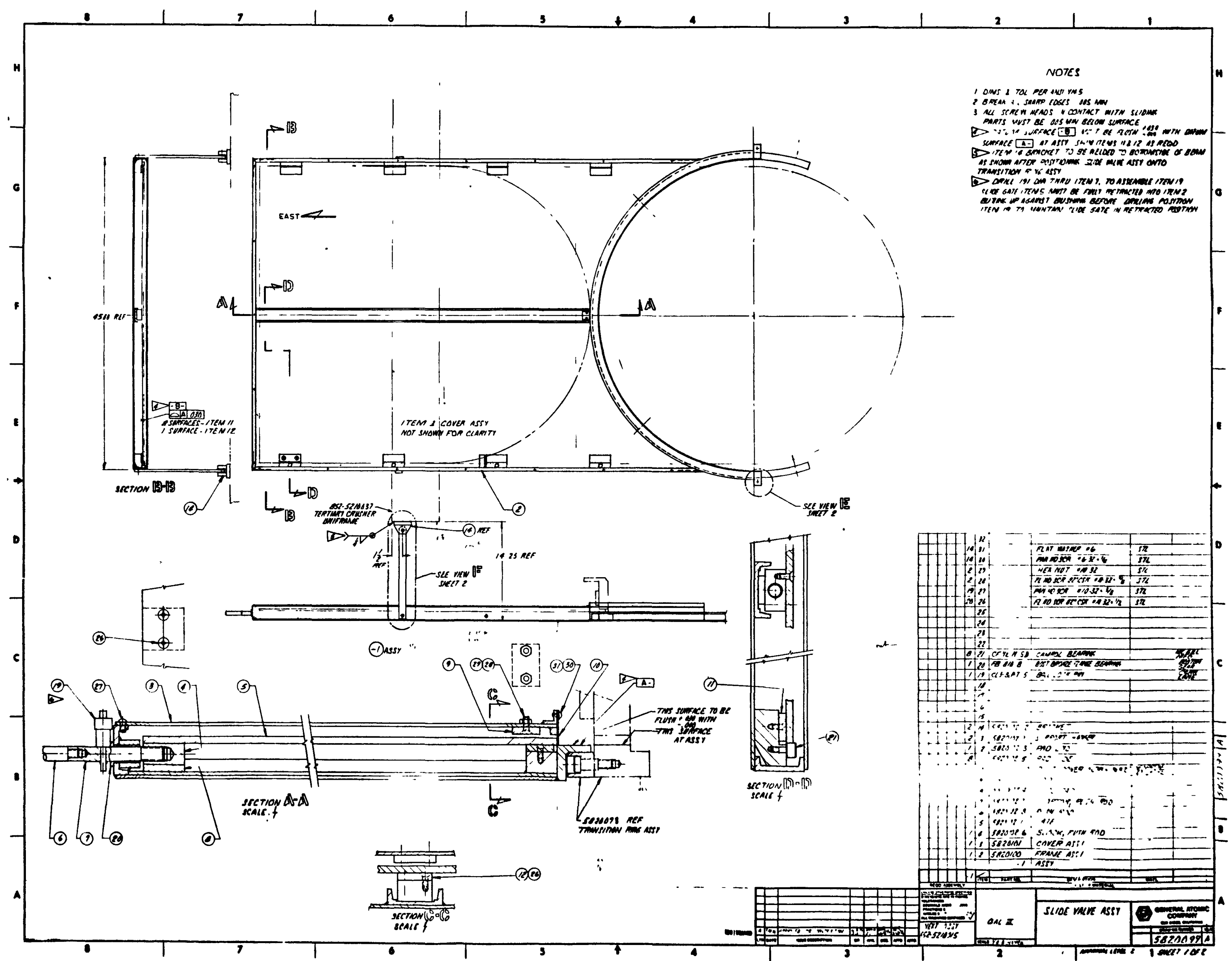




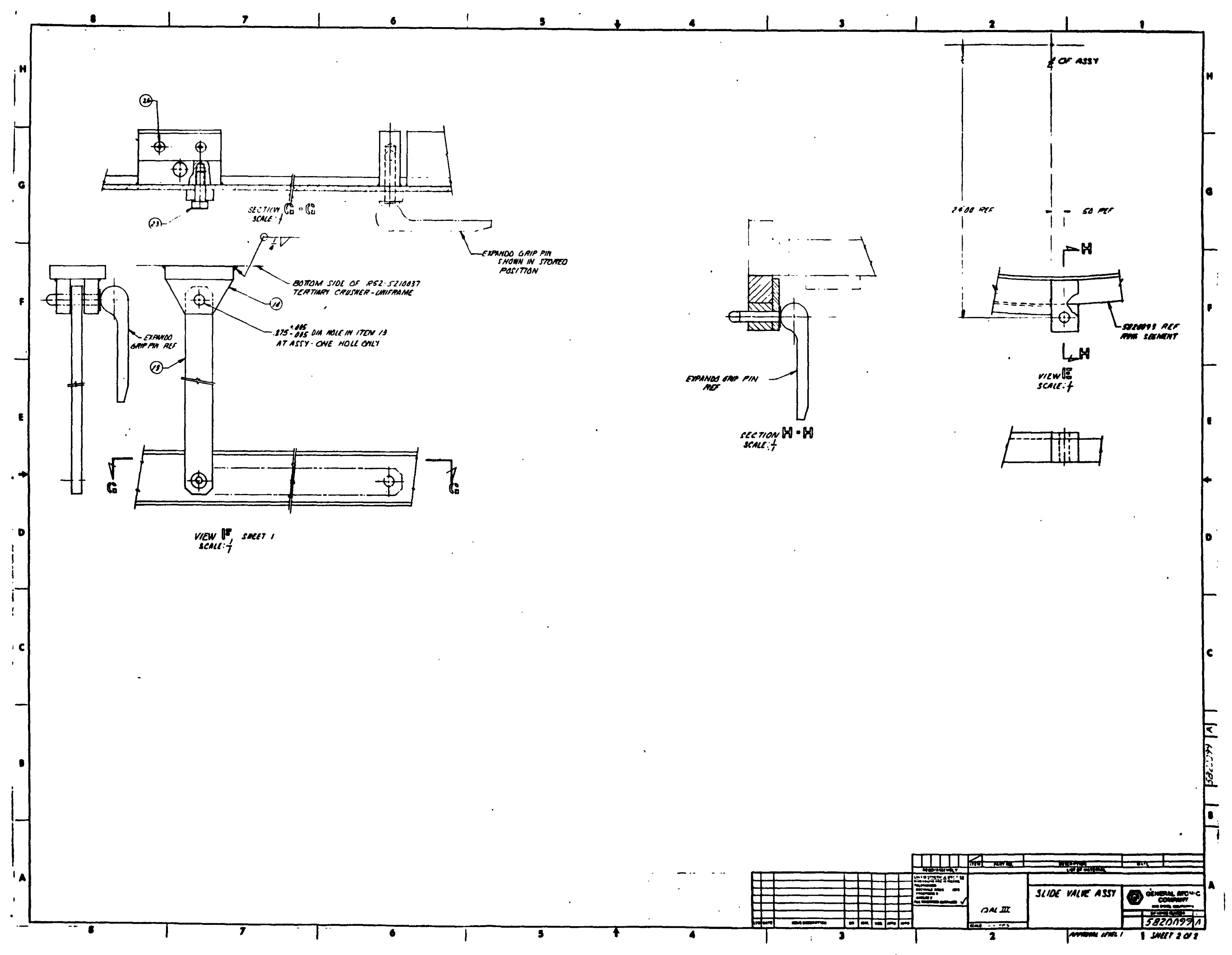




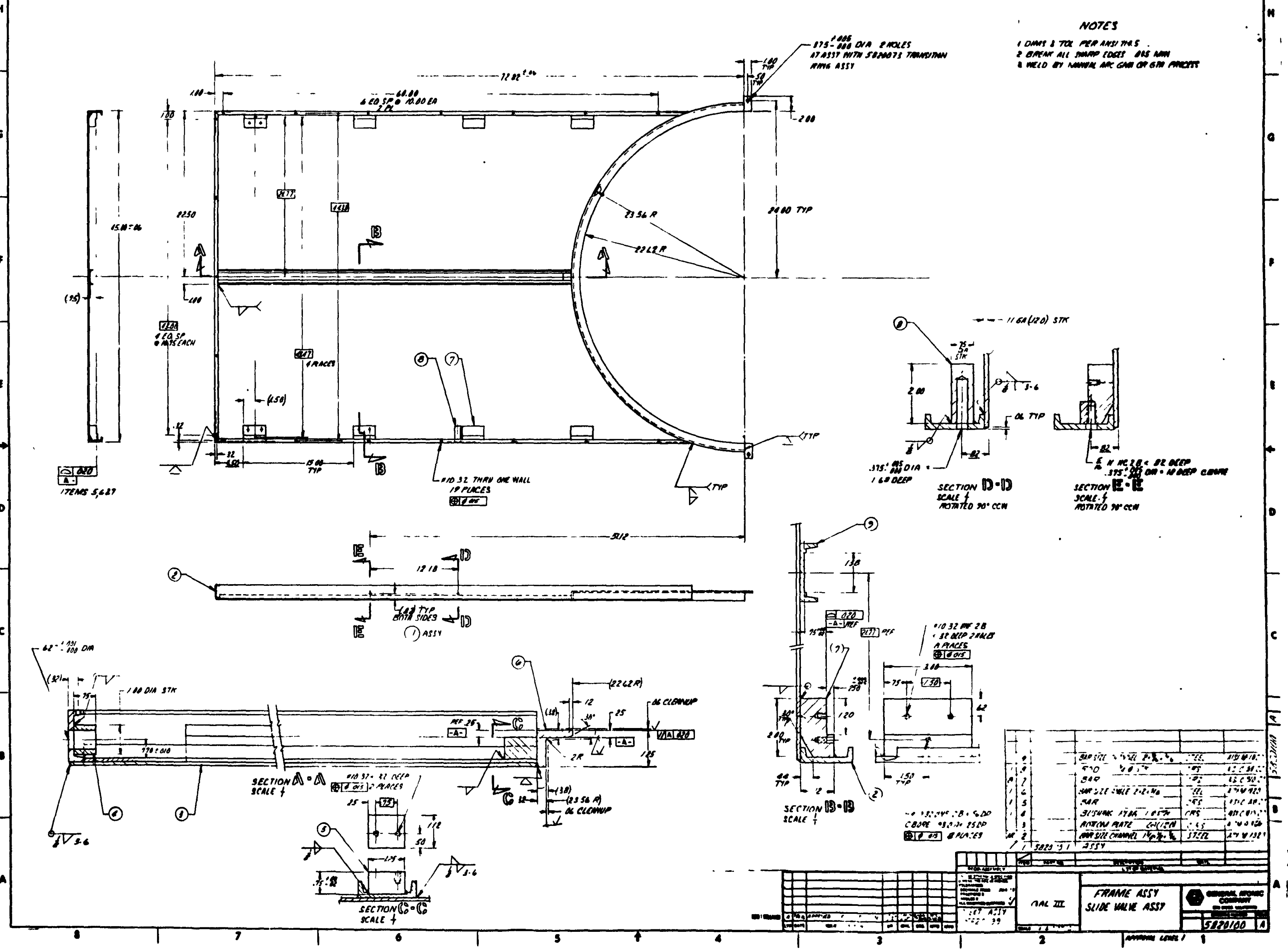




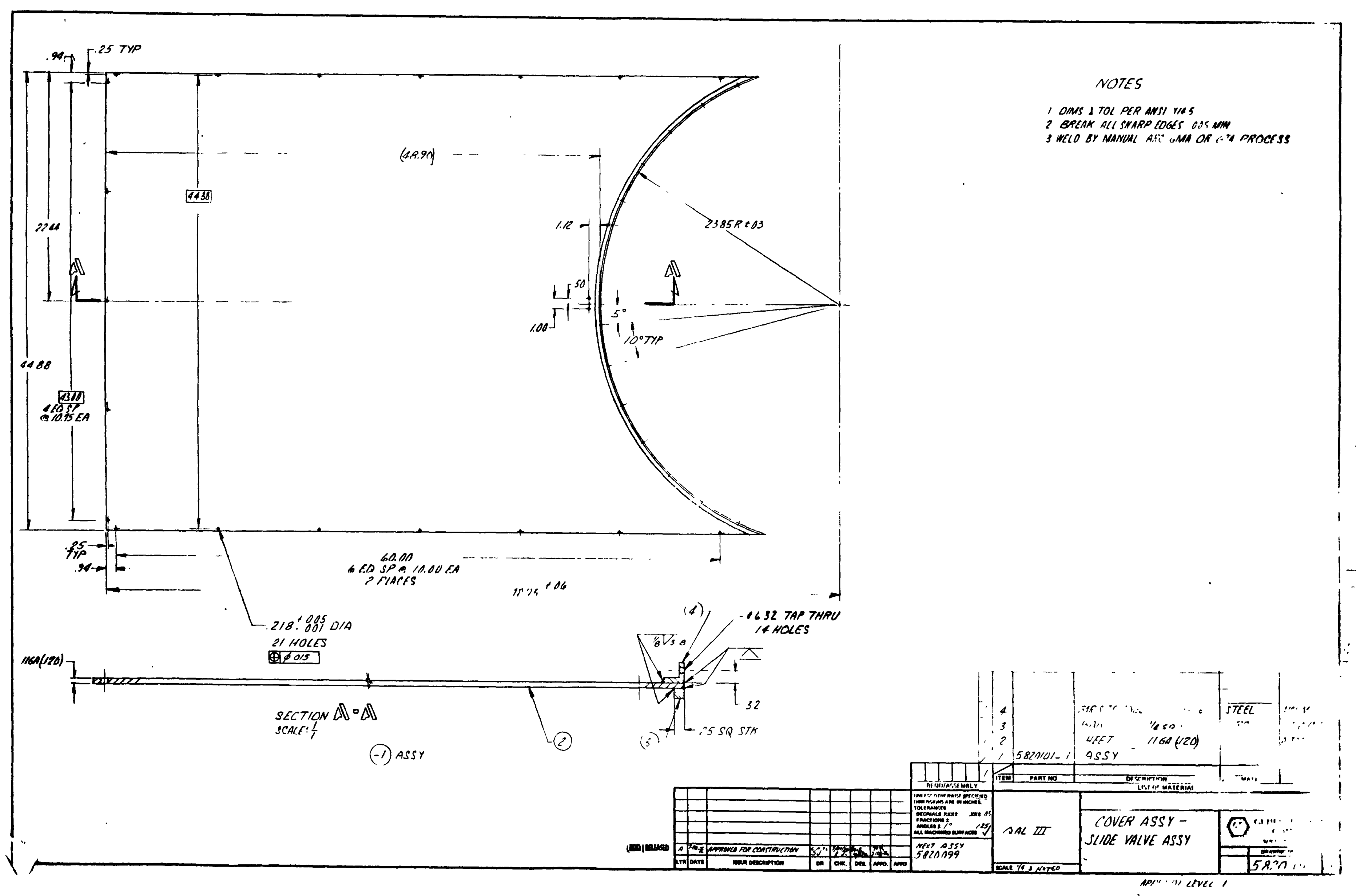




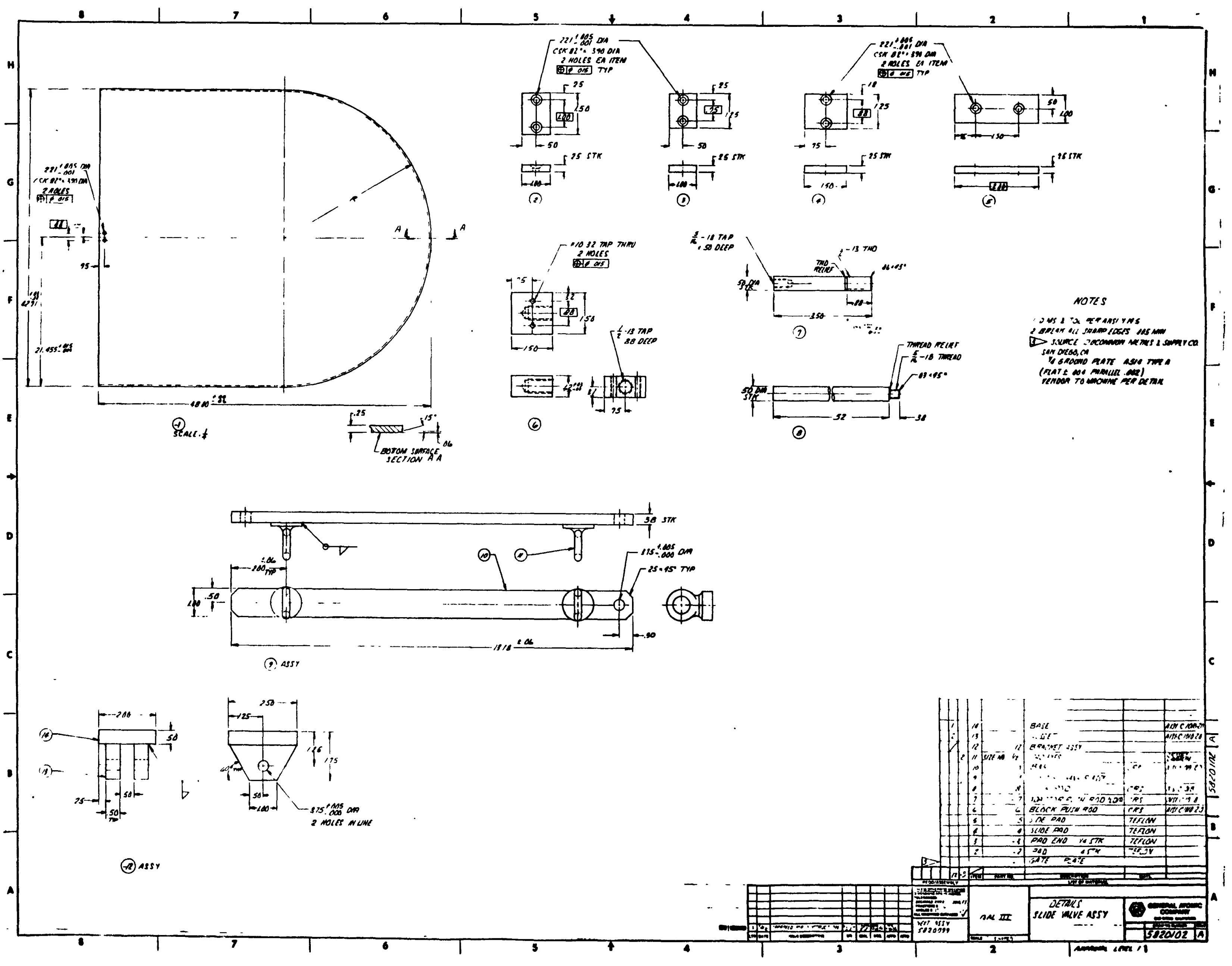




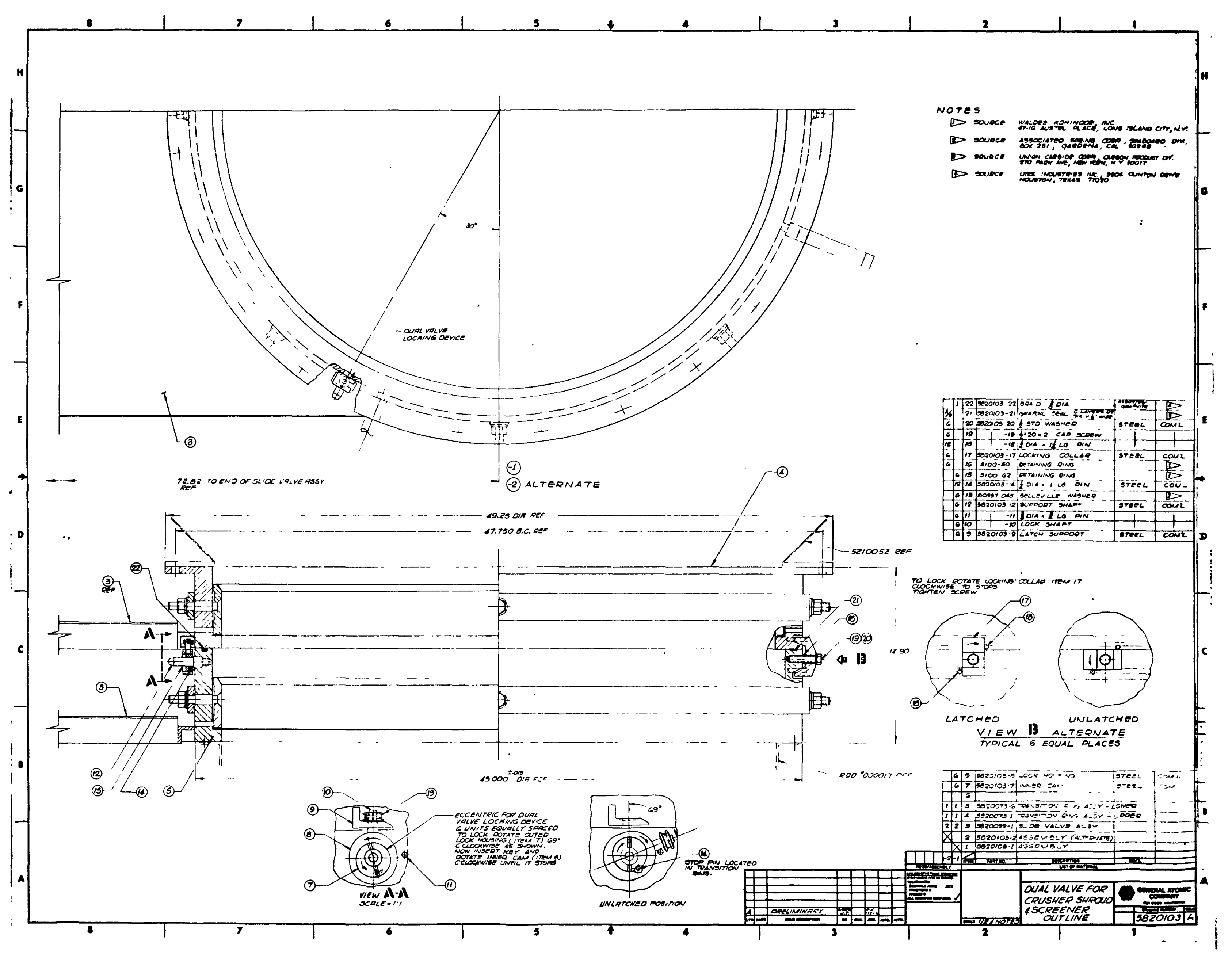




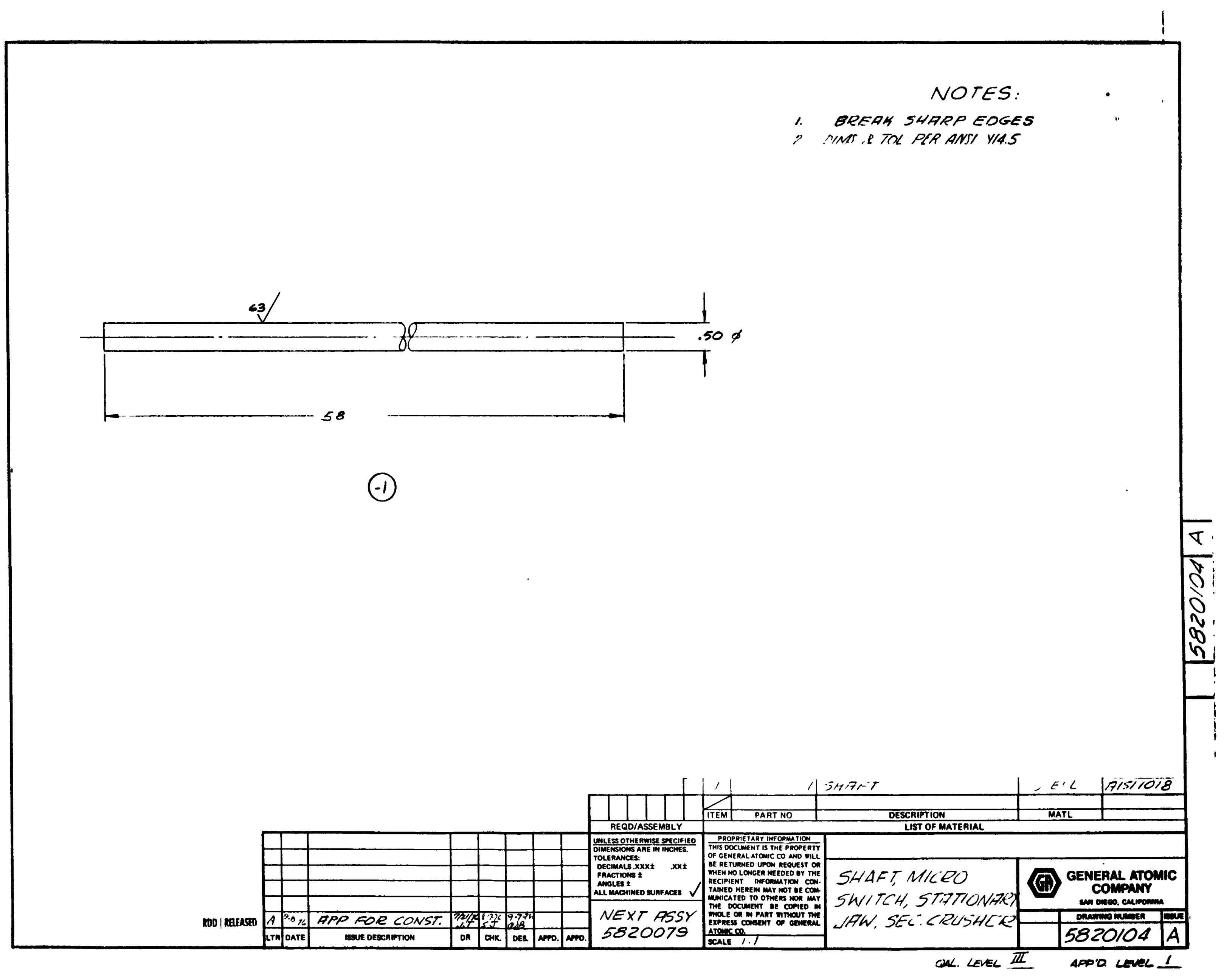




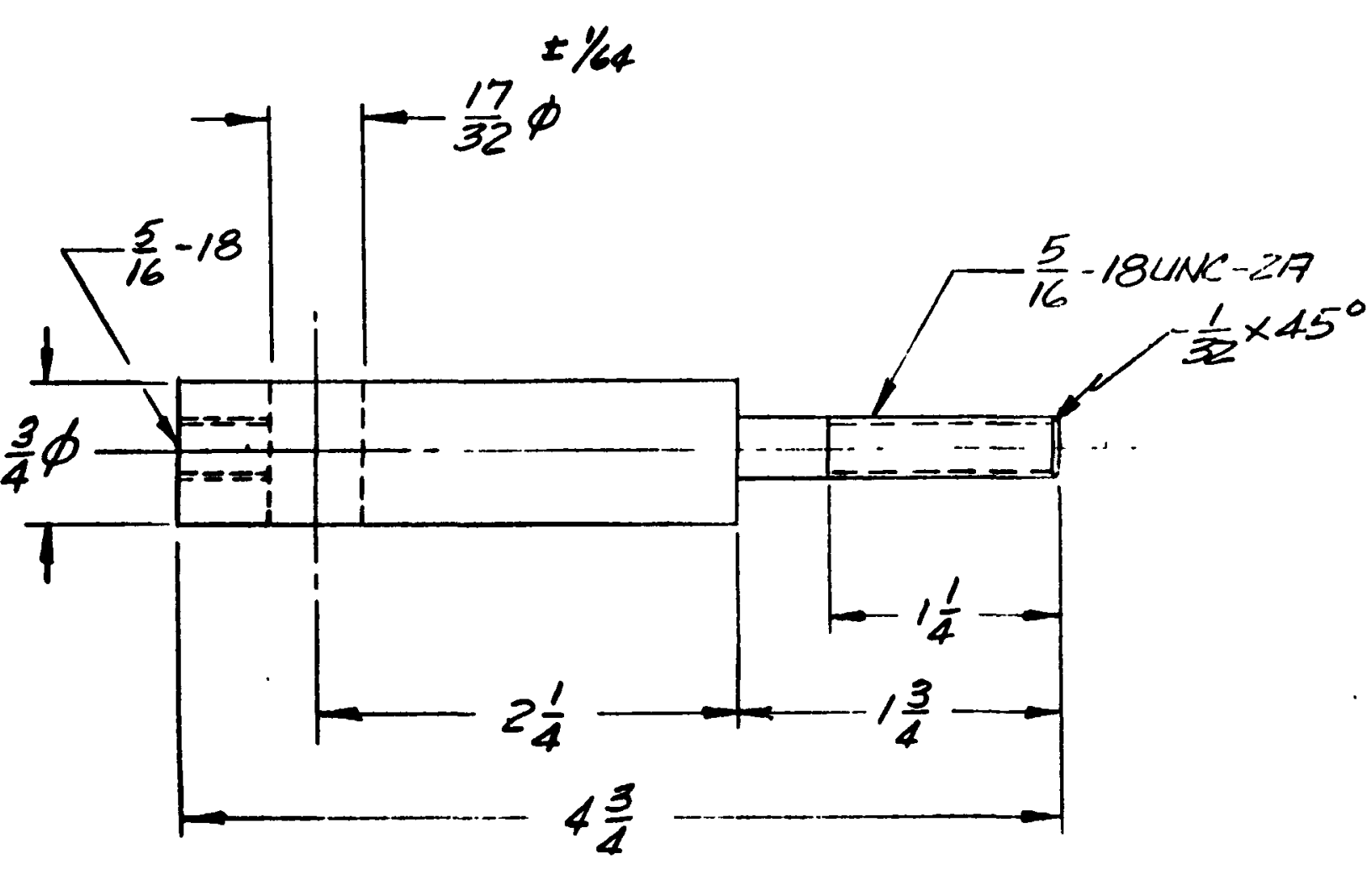

$$
\text { NOTES: }
$$

1. BREAK SHARP EDGES

2 DIMS \& TOL PER ANSI Y/4.S

\section{$(-1)$}

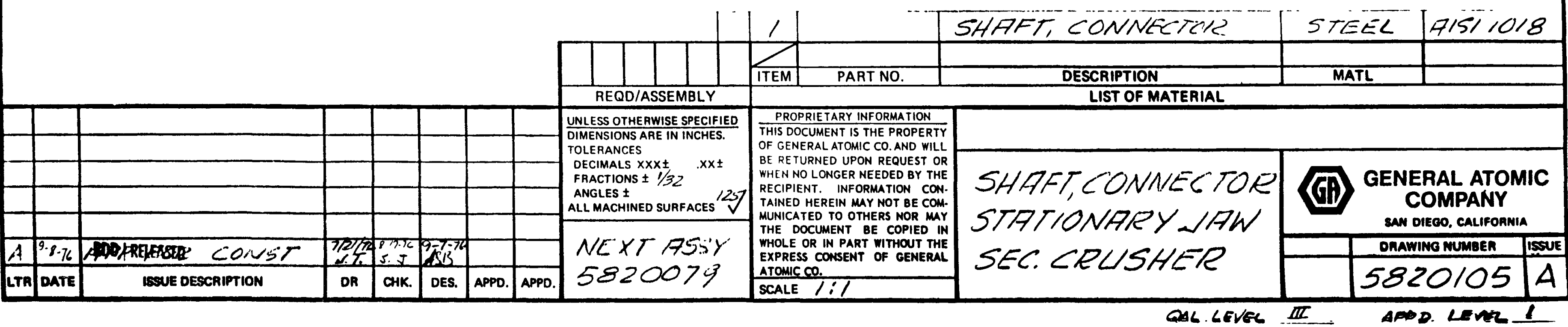




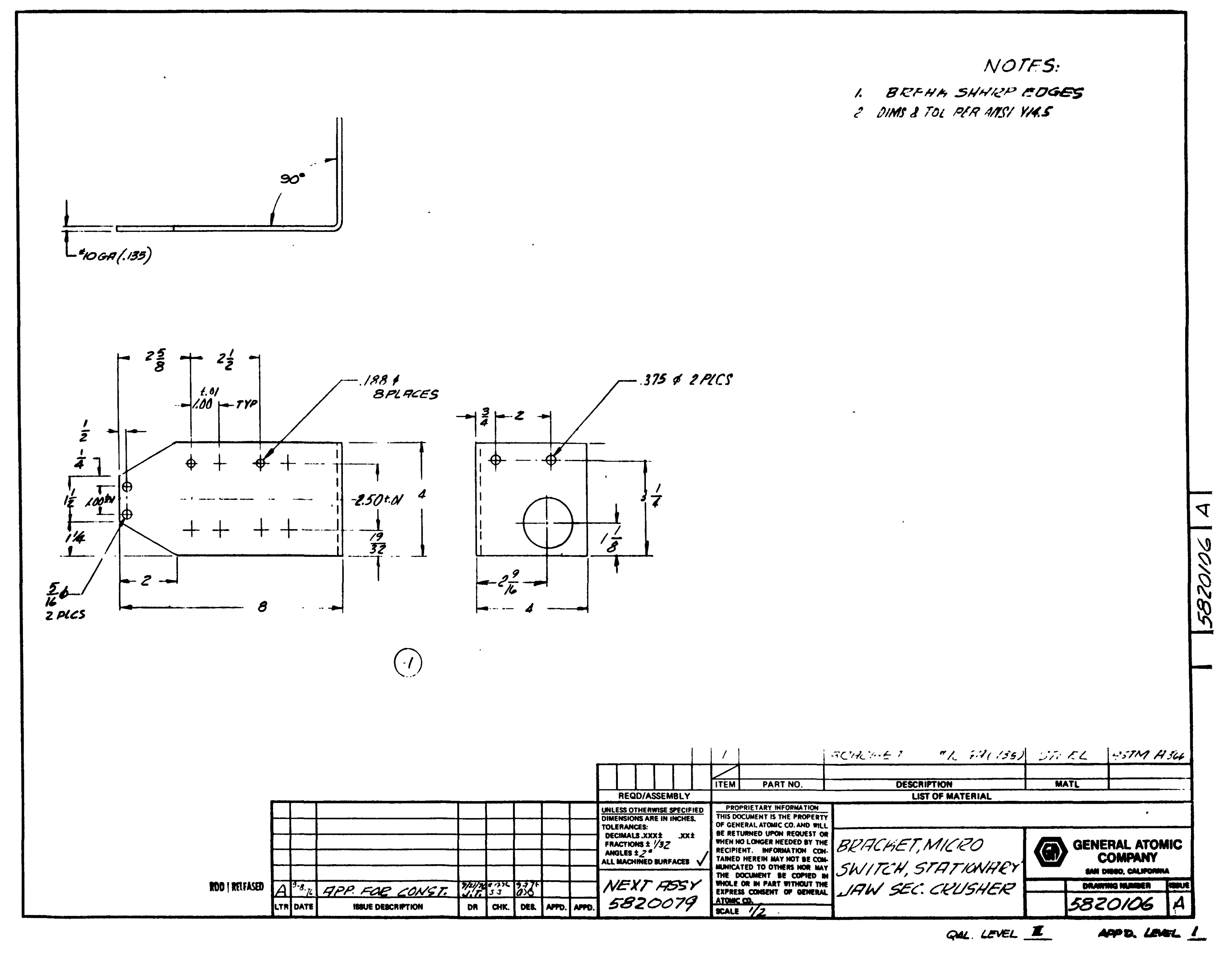




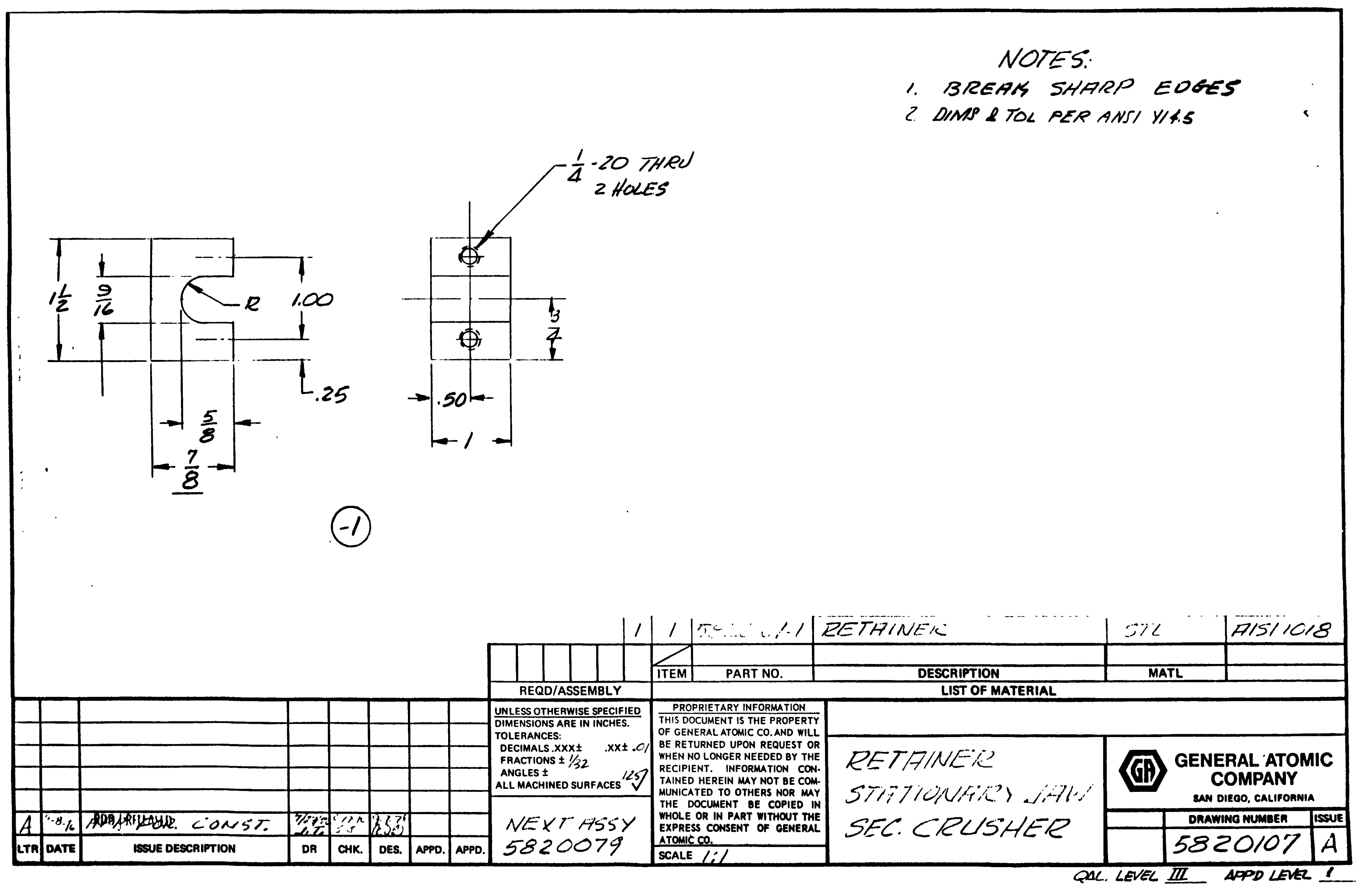




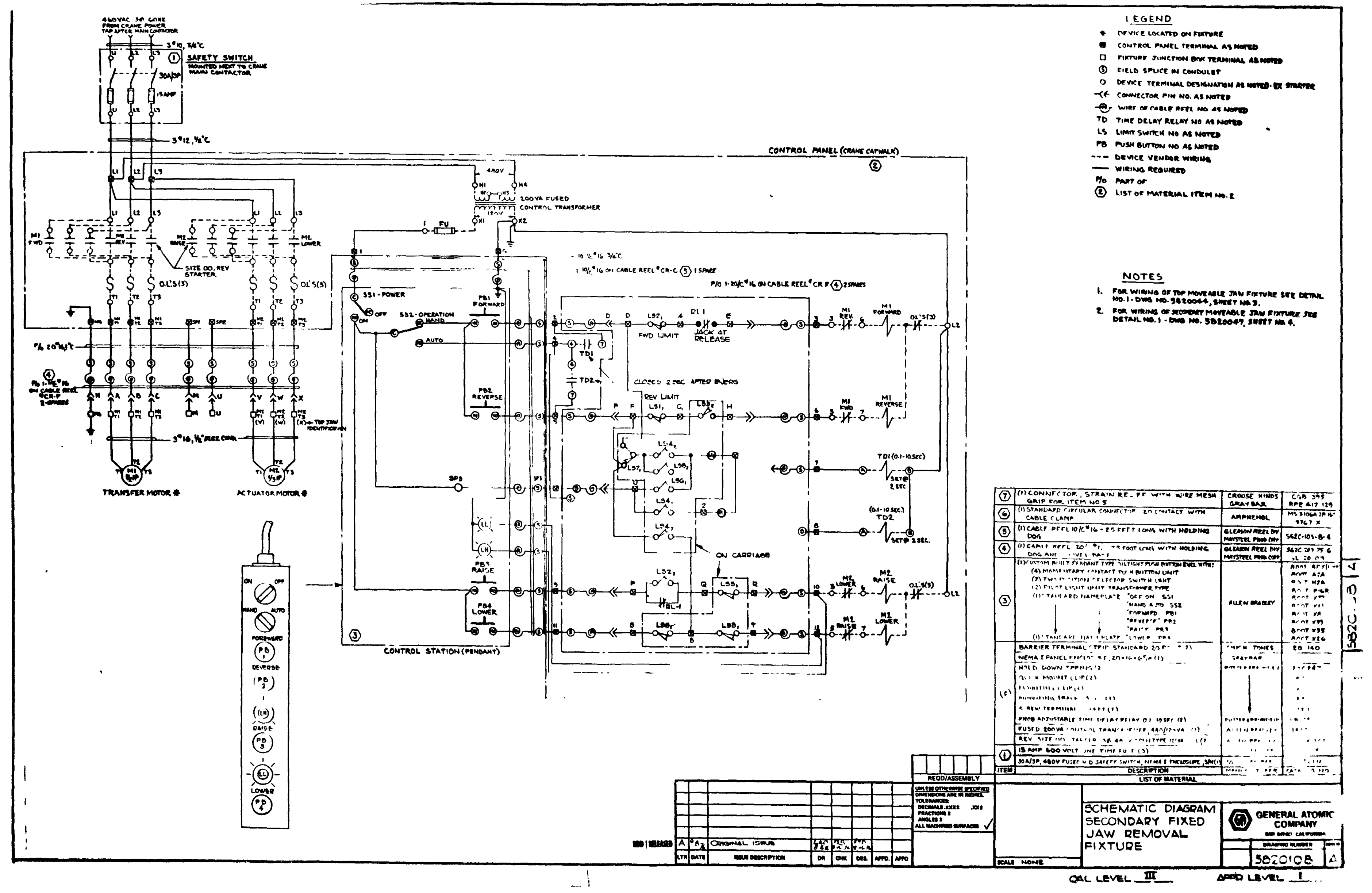


APPENDIX D

OPERATING PROCEDURE FOR HORIZONTAL REMOVAL FIXTURE FOR SECONDARY CRUSHER FIXED JAW

Temporary Installation of Horizontal Fixture on The UNIFRAME

*The horizontal fixture is lifted by means of three lugs on the top tube of the tri-frame. Interpose the Hydra-set between the crane and the fixture to provide a continuous reading of load. This will clearly indicate any fouling. Couple the Hydra-set with the fixture by means of a sling (Fig. D-1). Before lifting, couple the 20-pin plug suspended from the reel on the crane to the receptacle on the fixture tri-frame.

Raise the fixture slowly. The correct attitude for the top of the tri-frame for installation is an angle of approximately $5^{\circ}$. The sling arrangement shown in Fig. D-1 will provide the appropriate attitude.

Ralse the fixture until the hooks on the lower corner (nearest the crusher) are slightly above the level of the lower attachment points on the UNIFRAME.

Move horizontally until the lower hooks are immediately above their attachment points and then lower the fixture. Some manual guidance may be necessary in this operation. [Note: only the hooks should contact the UNIFRAME in this attitude (Fig. D-2)].

Move the crane trolley slowly in a westerly direction. This will tilt the tri-frame toward the horizontal. Two pins on the right angle corner of the tri-frame will contact the latch ramps on the UNIFRAME.

*These procedures preceded by an asterisk are manual operations. 


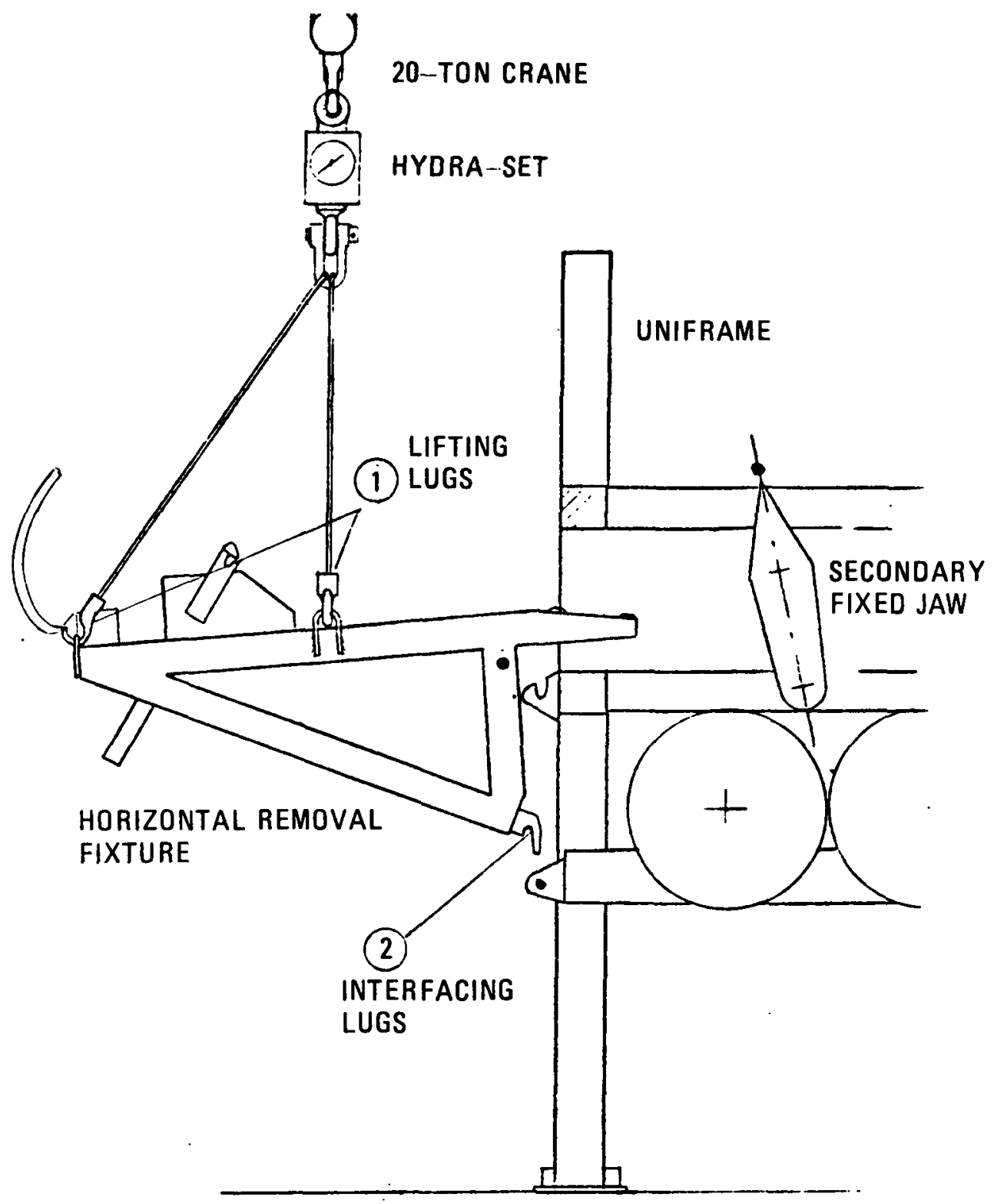

Fig. D-1. Horizontal removal fixture: semiremote installation onto UNIFRAME stage one 


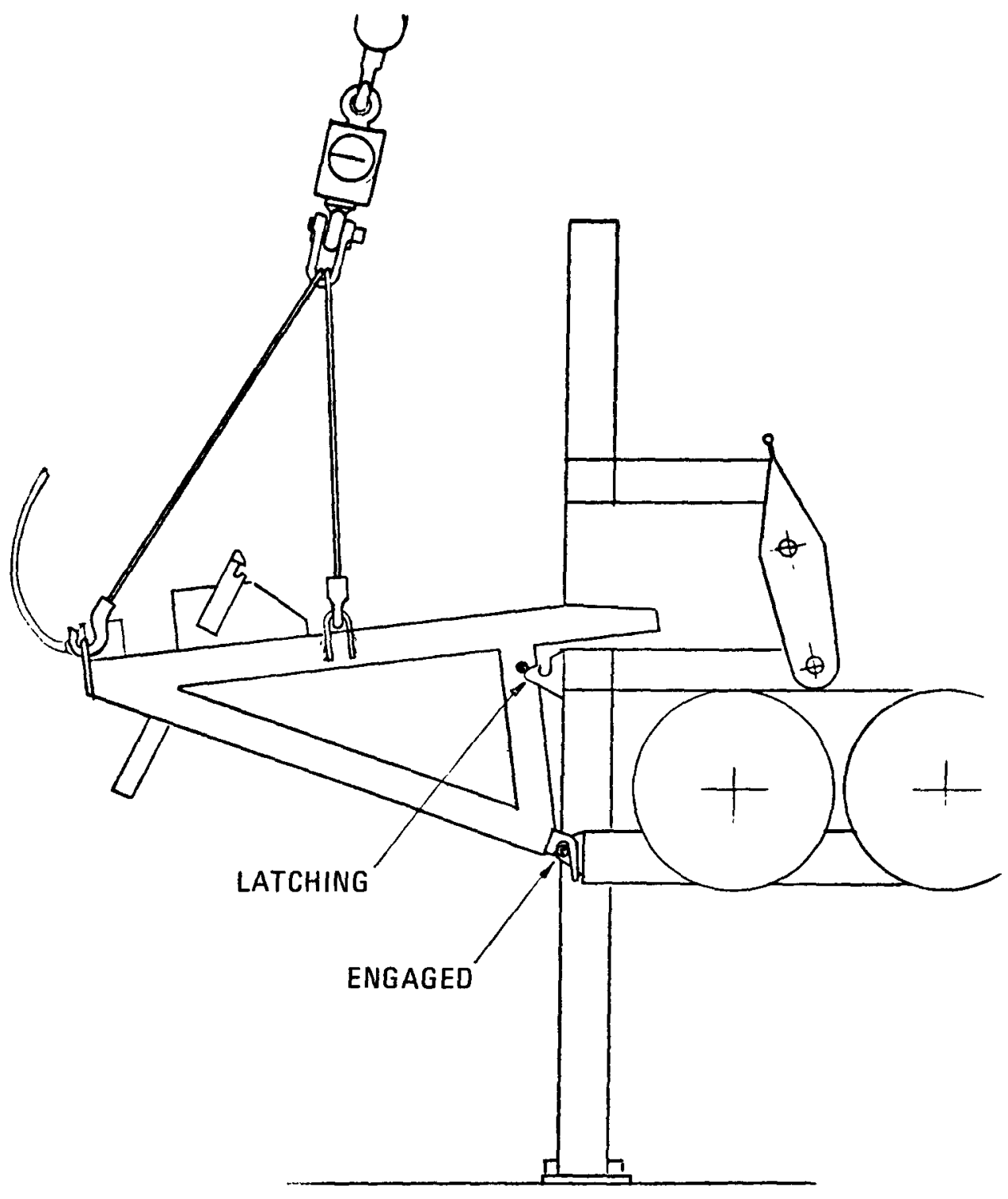

Fig. D-2. Horizontal removal fixture: semiremote installation onto UNIFRAME stage two 
Further motion westward with the crane trolley will latch the fixture into place (Fig. D-3).

Disconnect sling. Fixture is ready for use.

Semiremote Removal of Secondary Fixed Jaw

Push button PB1 (forward) and hold until motion of carriage stops.

Push button PB3 (raise) and hold until motion of fack stops (Fig. D-4).

Check (visually) that the hook on the fack has latched onto the bar on the top edge of the fixed jaw.

*Jack-in the top pins supporting the fixed Jaw. Slacken the lower pins at the base of the fixed faw.

Push button PB4 (lower). The fack will stop immediately after starting; to overcome this interlock, push PB1 briefly. Hold PB4 until the jaw has pivoted down onto the cradle on the carriage (Fig. D-5).

*Withdraw bottom pins holding Jaw in UNIFRAME.

To remove Jaw, push button PB2 (reverse) and hold until motion of the carriage stops.

Push button PB3 (raise) and hold till motion of jack stops. This releases the clamp action on the bar at top of faw (Fig. D-6).

To swing clamp clear of bar, push button PB2 (reverse - dual action) and release; do not hold. The jaw is now ready to lift off the fixture. 


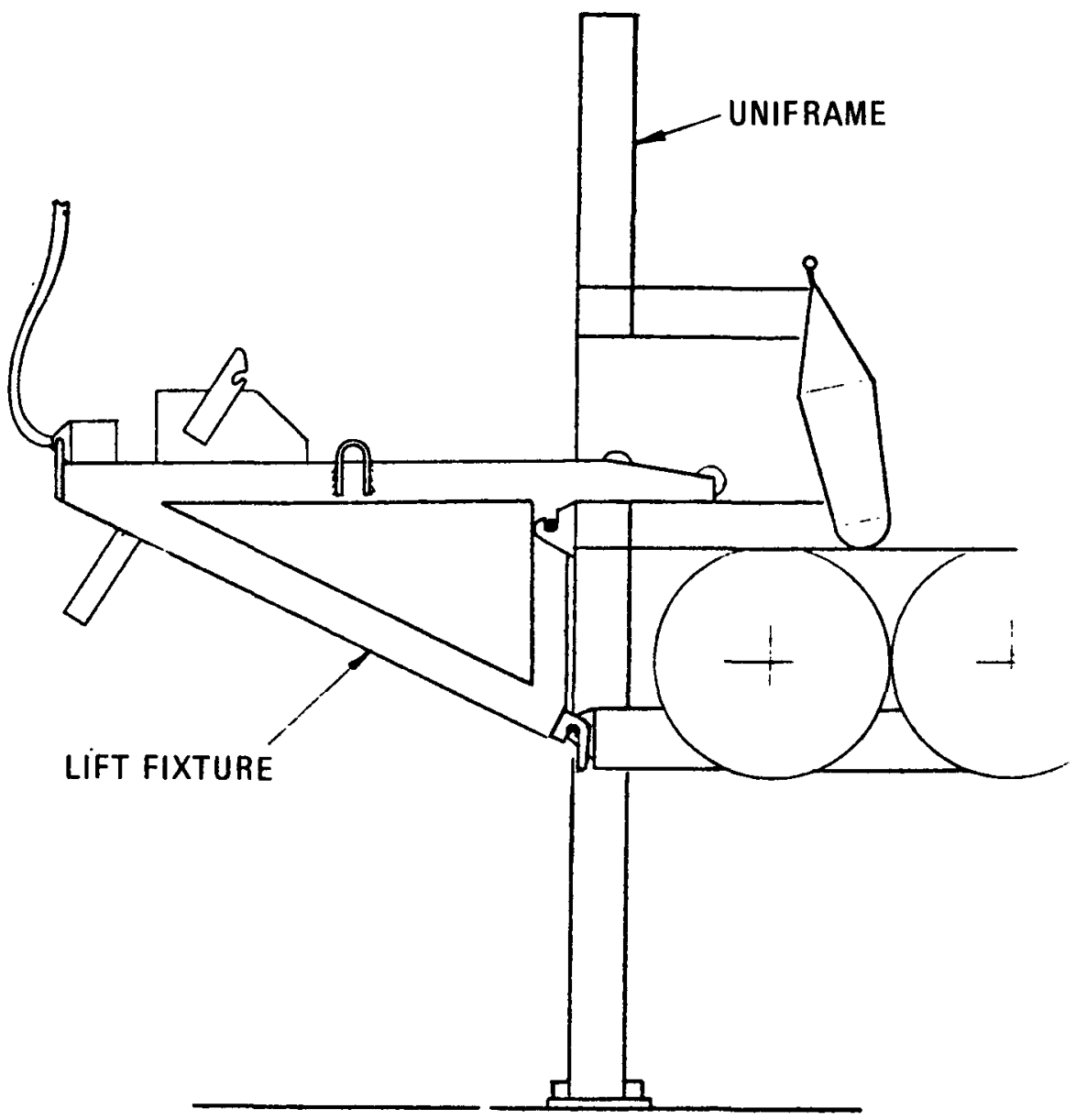

Fig. D-3. Installation of fixture onto UNIFRAME complete 


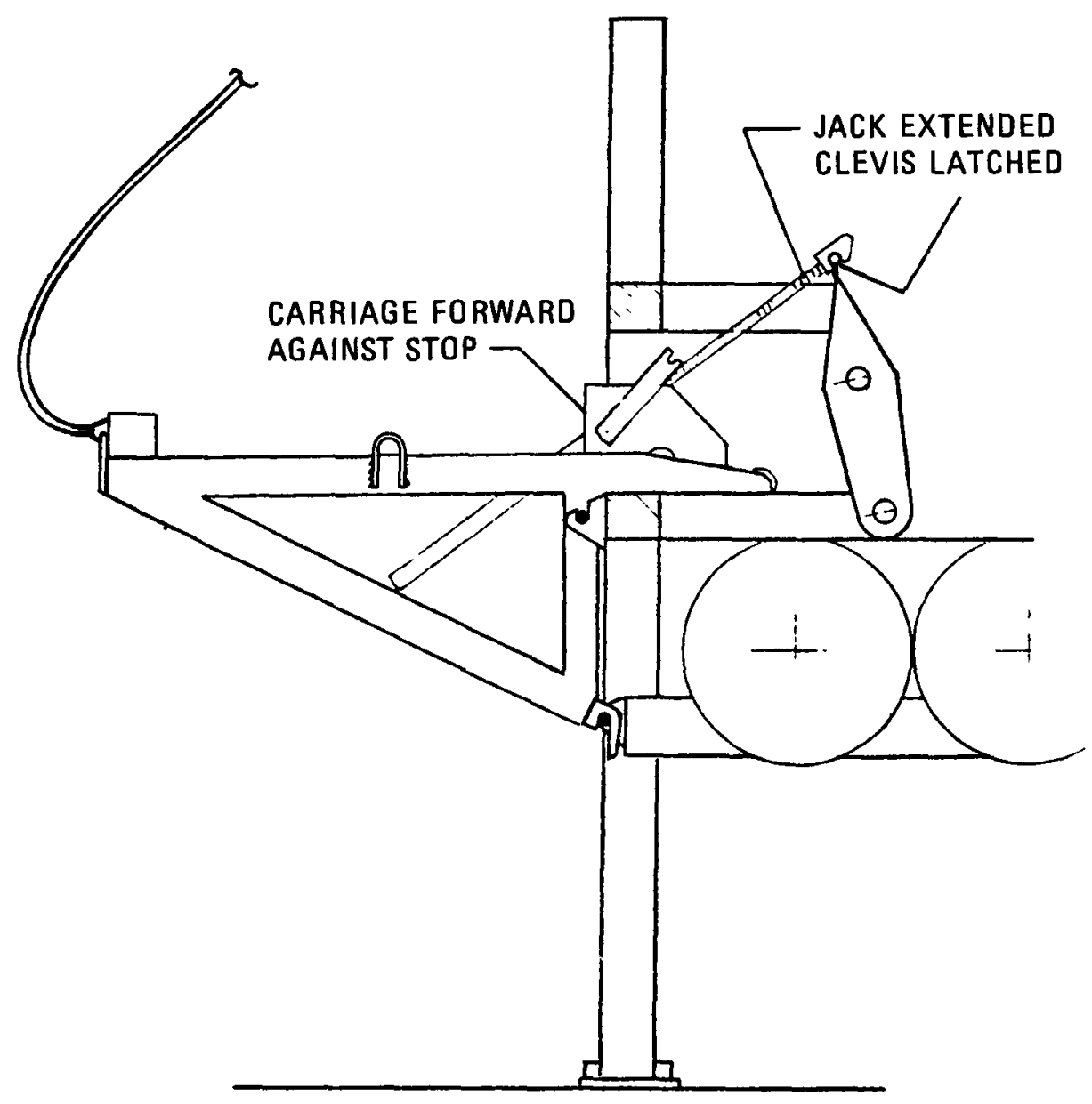

Fig. D-4. Engagement of the clevis with the jaw 


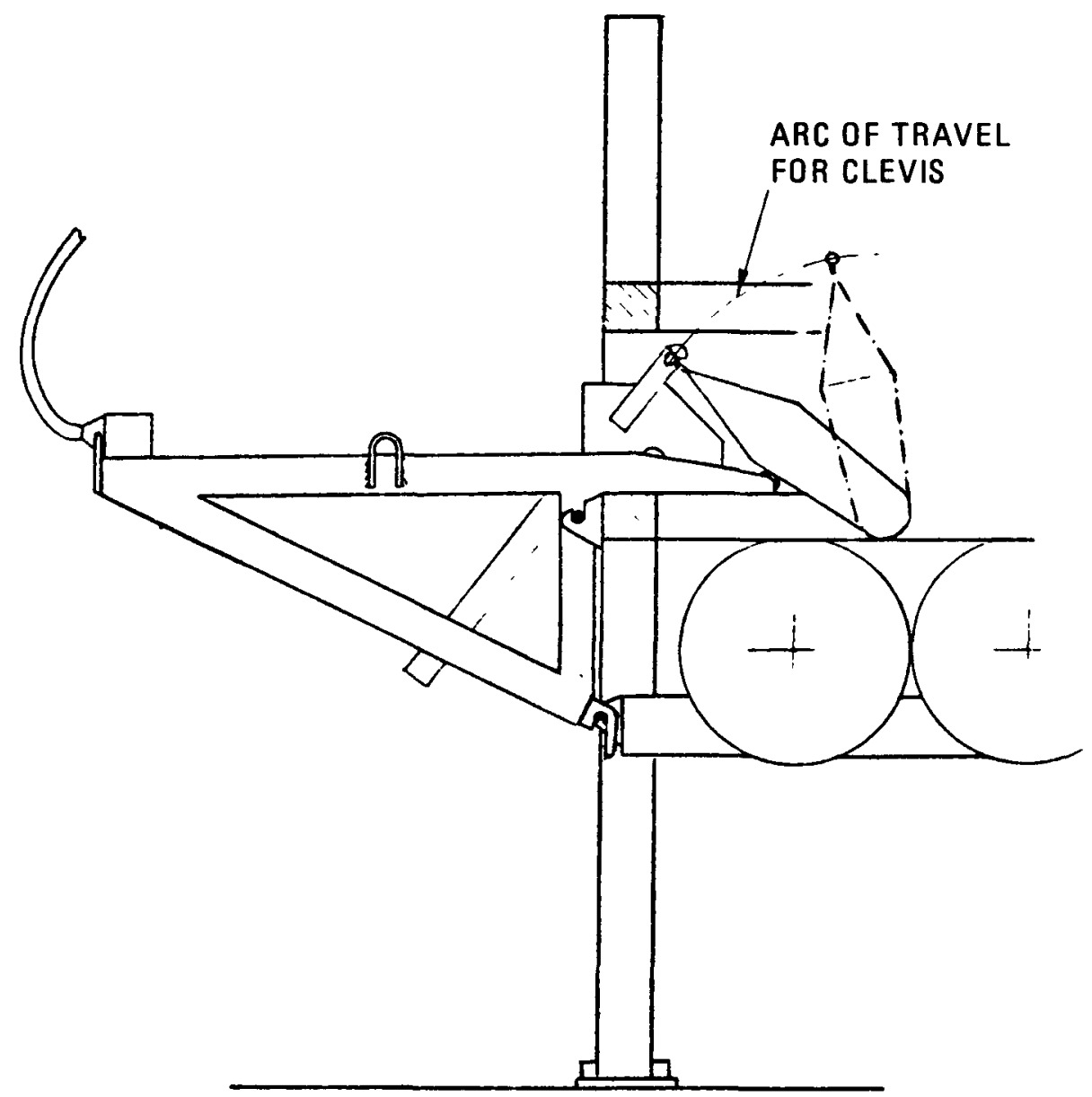

Fig. D-5. Jaw lowered into cradle and secured for withdrawal 


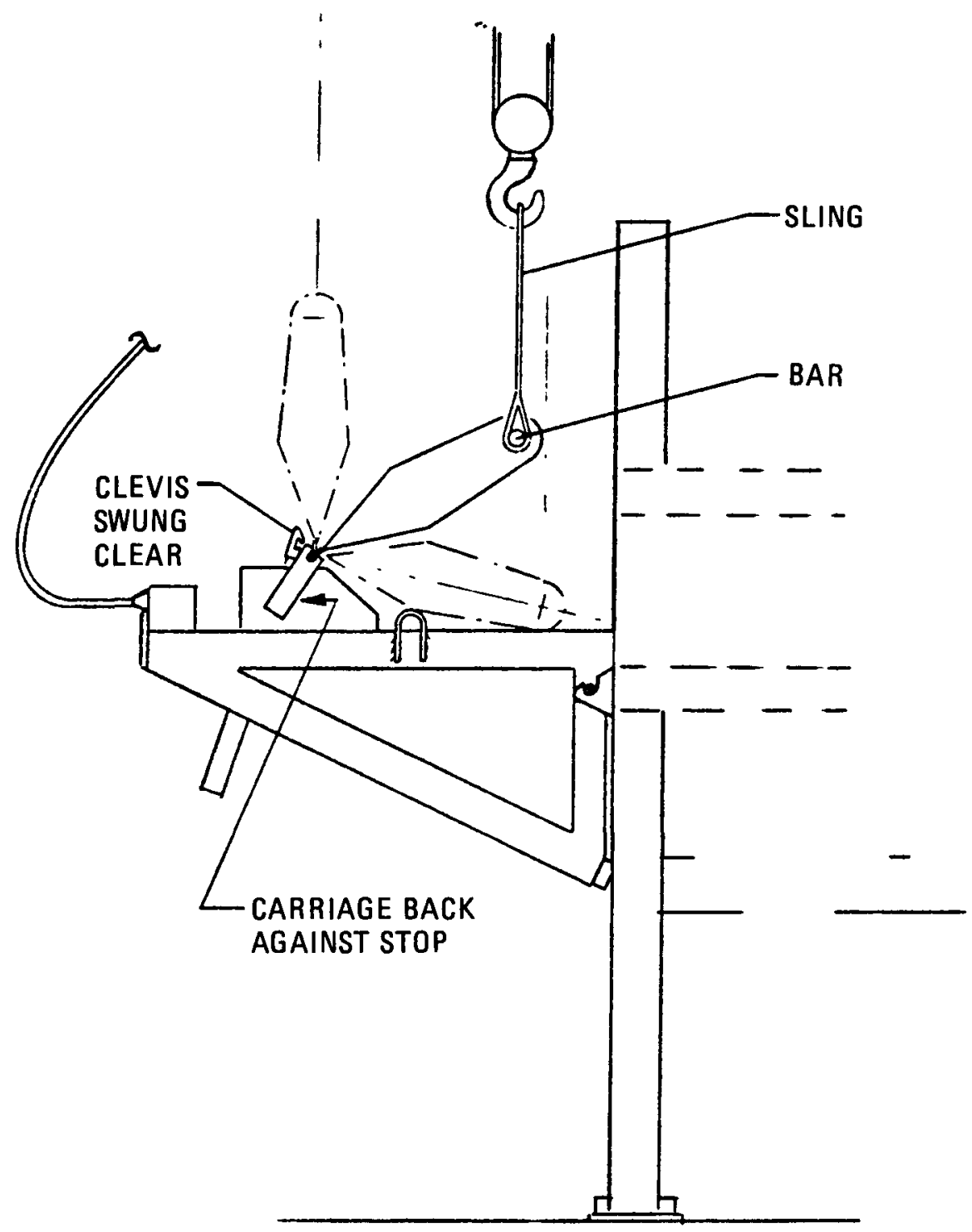

Fig. D-6. Removal of stationary jaw from fixture 
*Place lifting bar through lower fixing hole in faw and apply sling to bar (Fig. D-6).

Lift slowly allowing faw to pivot on the cradle in the carriage. When vertical, lift Jaw off the carriage and transport to work or decontamination area.

Push button PB1 (forward - dual action) to return clamp hook to operating position.

Push button PB4 (lower) to return Jack to lowest position.

Installation of Secondary Fixed Jaw in UNIFRAME

Install horizontal fixture on UNIFRAME (see above).

Push button PB2 (reverse) to ensure that carriage is at rearward limit of travel.

Push button PB3 (raise) to unlock clamp on carriage.

Push button PB2 (reverse - dual action). Swing clamp hook clear of cradle arms.

Pick up the secondary fixed jaw with the crane as shown in Fig. D-6.

Lower jaw upside down into cradle on the carriage so that grooves provided for location are positioned in the cradle arms. Some manual guidance may be necessary.

Move crane trolley very slowly westward while lowering the hook unt1l the base of the faw contacts the upper surface of the tri-frame.

Push button PB1 (forward - dual action) to swing hook into operation around the bar on the top of the jaw. 
Push button PB4 (1ower) to clamp jaw to cradle.

Push button PB1 (forward) and hold until faw is driven completely into the window of the UNIFRAME and has come to rest canted downward into the crusher (Fig. D-3).

*Replace the lower tapered pins but do not tighten completely.

Push button PB3 (raise) and hold until the faw is in its normal working position and motion has stopped (Fig. D-4).

*Jack-out upper support pins.

Push button PB4 (lower). The jack will move about $1 / 4$ in. downward and stop.

Push button PB2 (reverse - dual action) to pivot hook clear of jaw.

Push button PB2 momentarily to overcome interlock. Push button PB4 (lower) and hold until the fack is completely retracted.

Push button PB2 (reverse) and hold until the carriage has completed its reverse motion (Fig. D-3).

Remove fixture from UNIFRAME and return to storage.

$\underline{\text { Removal of Fixture from UNIFRAME }}$

Ensure that the carriage is fully retracted on the fixture.

*Reinstate sling on the lift eyes on the tri-frame and raise very slowly until the top locating pins clear the latches on the UNIFRAME.

Back the crane trolley eastward very slowly until the top of the triframe is at about $5^{\circ}$ to the horiozntal (Fig. D-2). 
Raise the crane very slowly until the lower hooks on the tri-frame fust clear the bars on the lower attachment points (Fig. D-1).

Disconnect 20-pin electrical connector.

*Transport fixture to storage and disconnect from Hydra-set.

Transport Hydra-set to storage and disconnect from crane. 
APPENDIX E

ELECTRICAL SEQUENCE FOR REMOVAL AND REPLACEMENT OF SECONDARY CRUSHER STATIONARY JAW 


\section{APPENDIX E}

ELECTRICAL SEQUENCE FOR REMOVAL AND REPLACEMENT OF SECONDARY CRUSHER STATIONARY JAW

At the start of this sequence, the fixture is assumed to be installed on the UNIFRAME with the carriage in the outer position. The carriage jack is in the fully down (locked) position. All controls are on the control pendant.

Removing Jaw From UNIFRAME

Step 1 Switch "hand/auto" to "hand" and turn power on.

Step 2 PB1 (carriage forward) energizes main jack motor M1 (forward) via limit switch LS2 (forward limit) and relay RL1 (jack at release).

Step 3 PB3 (raise jack) energizes carriage jack motor M2 (raise) via $\mathrm{LS}_{2}$ (forward limit) and LS5 (jack at raised limit). Hold button until LS5 opens (LS2 2 bypasses RL1 interrupt).

Step 4 Manual operation - wind top support pins into jaw.

Step 5 PB4 (lower) energizes M2 (lower) via LS3 (lower limit) and LS8. Hold (LS8 opens, jack stops); maintain hold.

Step 6 PB1 momentarily bypasses PB4 via LS7 $_{2}$ and LS8 via LS3. (The motor M1 will not be energized by PB1 because it is inhibited by LS2.)

Step 7 PB4 becomes effective again immediately. Jack moves from LS8 energized position. Jack will travel to its lower limit, LS3 opens, M2 is de-energized. Release PB4. The handling bar is now locked into the support arms by the lowered jack. 
Step 8 Manual operation - withdraw lower Jaw support pins.

Step 9 PB2 energizes M1 (reverse) via LS1 (rear Iimit) and LS3 ${ }_{2}$.

Step 10 The jaw is now fully clear of the UNIFRAME. Hold until RL1 opens.

Step 11 PB2 momentarily (reverse) energizes M3 via LS4 ${ }_{2}$. As M3 output shaft starts to revolve, disc cam actuates LS6 to maintain circuit until unlock position is gained when LS6 is deactuated. (M1 will not respond to PB2 because it is inhibited by LS1.) The faw is free to be lifted from the fixture.

Replacing Jaw in the UNIFRAME

Fixture status: interfaced with UNIFRAME, carriage fully back against stops, jack at lower release position, and clevis swung to unlatch position. This is the situation at which the previous operation ended.

Step 1 Manual operation - the traveling crane is attached to a bridle across the rear through the lower mounting holes in the faw. The jaw is hanging upside down. Locate the handling bar into the carriage cradle.

Step 2 PB1 momentarily energizes M3 via LS7 and $\mathrm{LS}_{2}{ }_{2}$ when M3 rotates. LS6 maintains M3 power until near "locked" position. LS7 is actuated and LS6 opens. (Motor M1 is inhibited by RL1.)

Step 3 PB4 energizes M2 via LS3 and LS8 until jaw is clamped and LS3 opens.

Step 4 PB1 energizes M1 (forward) via LS2 and RL1. Hold unti1 LS2 opens. (M3 is inhibited by LS7.)

Step 5 Manual operation - insert lower jaw support pins. 
Step 6 PB3 (raise) energizes M2 (raise) via LS2 2 and LS5. Hold until LS5 opens.

Step 7 Manual operation - insert upper jaw support pins.

Step 8 PB4 (lower) energizes M2 (lower) via LS8 and LS3. Hold until LS8 opens.

Step 9 PB2 momentarily energizes M3 via LS7 and $\mathrm{LSB}_{2}$. [M1 (reverse) is inhibited by $\mathrm{LS}_{2}{ }_{2}$ ] As $\mathrm{M} 3$ rotates, LS6 maintains power until latch is unlocked.

Step 10 PB2 momentarily energizes M2 (lower) via LS7 2 and LS3. Do not hold.

Step 11 As soon as jack clears LS8, PB4 may be used to complete retraction of jack via LS8 and LS3 until LS3 opens.

Step 12 PB2 energizes M1 (reverse) via LS1 and $\mathrm{LS}_{2}$. Carriage moves to rear of fixture. (M3 is inhibited by $\mathrm{LS}_{2}$ and $\mathrm{LS}_{2}{ }^{\circ}$ )

Step 13 When carriage is in rear of fixture, PB3 energizes M2 via RL1 and LS5. When RI1 opens, Jack will stop.

Step 14 PB2 energizes M3 via LS7 and LS4 $2^{\cdot}$ M3 rotates and LS6 maintains power until LS6 drops out in unlocked position.

Fixture is back to start of cycle.

$$
\text { E-3 }
$$

